\title{
Markers of endothelial function and progression of cerebral small vessel disease
}

Citation for published version (APA):

van Overbeek, E. (2018). Markers of endothelial function and progression of cerebral small vessel disease: A longitudinal MR Imaging study. [Doctoral Thesis, Maastricht University]. Proefschriftmaken.nI II Uitgeverij Boxpress. https://doi.org/10.26481/dis.20181102eo

Document status and date:

Published: 01/01/2018

DOI:

10.26481/dis.20181102eo

Document Version:

Publisher's PDF, also known as Version of record

\section{Please check the document version of this publication:}

- A submitted manuscript is the version of the article upon submission and before peer-review. There can be important differences between the submitted version and the official published version of record.

People interested in the research are advised to contact the author for the final version of the publication, or visit the DOI to the publisher's website.

- The final author version and the galley proof are versions of the publication after peer review.

- The final published version features the final layout of the paper including the volume, issue and page numbers.

Link to publication

\footnotetext{
General rights rights.

- You may freely distribute the URL identifying the publication in the public portal. please follow below link for the End User Agreement:

www.umlib.nl/taverne-license

Take down policy

If you believe that this document breaches copyright please contact us at:

repository@maastrichtuniversity.nl

providing details and we will investigate your claim.
}

Copyright and moral rights for the publications made accessible in the public portal are retained by the authors and/or other copyright owners and it is a condition of accessing publications that users recognise and abide by the legal requirements associated with these

- Users may download and print one copy of any publication from the public portal for the purpose of private study or research.

- You may not further distribute the material or use it for any profit-making activity or commercial gain

If the publication is distributed under the terms of Article $25 \mathrm{fa}$ of the Dutch Copyright Act, indicated by the "Taverne" license above, 


\section{MARKERS OF ENDOTHELIAL FUNCTION AND}

\section{PROGRESSION OF CEREBRAL SMALL VESSEL DISEASE}

A longitudinal MR Imaging study 
(C) E.C. van Overbeek, 's-Hertogenbosch 2018

ISBN 9789463800075

Cover design: Marian Vrielink

Printed by: ProefschriftMaken || www.proefschriftmaken.nl 


\section{MARKERS OF ENDOTHELIAL FUNCTION AND \\ PROGRESSION OF CEREBRAL SMALL VESSEL DISEASE}

A longitudinal MR Imaging study

\section{PROEFSCHRIFT}

ter verkrijging van de graad van doctor aan de Universiteit Maastricht

op gezag van de Rector Magnificus Prof. dr. Rianne M. Letschert, volgens het besluit van het College van Decanen,

in het openbaar te verdedigen

op vrijdag 2 november om 14:00 uur

door

Ellen Catharine van Overbeek 


\section{Promotor}

Prof. dr. R.J. van Oostenbrugge

\section{Co-promotor}

Dr. J.E.A. Staals

\section{Beoordelingscommissie}

Prof. dr. P.A.M. Hofman (voorzitter)

Prof. dr. ir. E.A.L. Biessen

Dr. H. Kerkhoff (Albert Schweitzer Ziekenhuis, Dordrecht)

Prof. dr. A.A. Kroon

Prof. dr. H.F. de Leeuw (Radboud UMC, Nijmegen) 


\section{Contents}

Abbreviations

Chapter 1 General introduction

Chapter 2 Markers of vascular inflammation and progression of MRI

features of cerebral small vessel disease in lacunar stroke patients

Chapter 3 Plasma tPA-activity and progression of cerebral white matter hyperintensities in lacunar stroke patients

Chapter 4 Vitamin B12 and progression of white matter lesions. A 2-year 53 follow-up study in first-ever lacunar stroke patients

Chapter 5 Decreased kidney function is associated with progression of 67 cerebral microbleeds in lacunar stroke patients

Chapter 6 High MRI burden of cerebral small vessel disease is associated with higher long-term mortality in lacunar stroke patients

General discussion

Nederlandse samenvatting

Valorisatie

Dankwoord

Curriculum vitae

List of publications 



\section{Abbreviations}

ABPM

BBB

CMBs

(hs) CRP

CSF

CSVD

eGFR

HR

MAP

PAI-1

PP

PVS

t-PA

WMH ambulatory blood pressure monitoring

blood-brain barrier

cerebral microbleeds, brain microbleeds

(high sensitive) C-reactive protein

cerebral spinal fluid

cerebral small vessel disease

estimated glomerular filtration rate

hazard ratio

mean arterial (blood) pressure

plasminogen activator inhibitor type 1

pulse (blood) pressure

perivascular spaces

tissue plasminogen activator

white matter hyperintensities 

Chapter 1

General introduction 



\section{Cerebral small vessel disease}

The term cerebral small vessel disease (cSVD) is generally used to describe the consequences of pathology of the small vessels in the brain (1). Disease of the small brain vessels is related to damage to the surrounding brain parenchyma leading to several radiological manifestations and/or clinical symptoms $(1,2)$. Although the terminology cSVD implies a single disease identity, it refers to several different diseases that may affect the small vessels (1). These include arteriolosclerosis or risk factor related small vessel disease, cerebral amyloid angiopathy, hereditary causes such as CADASIL or Fabry disease, and inflammatory or immune mediated vasculitis (1). In this thesis we mainly focus on arteriolosclerosis or risk factor related small vessel disease.

\section{MRI manifestations}

When MRI was not yet integrated in routine clinical practice, the clinical lacunar stroke syndrome and/or CT findings of small lacunar infarcts and leukoaraiosis, defined patients with cSVD. Nowadays neuroimaging with MRI principally defines the concept of cSVD and a clinical lacunar stroke or acute lacunar infarct are not obligatory (3). cSVD is now mainly recognised by "silent" features visible on brain MRI.

The main manifestations of cSVD on brain MRI are small subcortical infarcts, lacunes, white matter hyperintensities (WMH), enlarged perivascular spaces (PVS) and cerebral microbleeds (CMBs) (2,3). Although lacunes, WMH, PVS and CMBs have often been referred to as being "silent" because these manifestations do not cause acute symptoms, they are related to clinical, more insidious, symptoms as will be described later.

\section{Small subcortical infarct}

The term small subcortical infarct is used for MRI evidence of a recent, small infarction (diameter of less than $20 \mathrm{~mm}$ in the axial plane) in the territory of one perforating small artery and when the location of the lesion is compatible with the clinical symptoms (3). The small subcortical infarct appears bright on diffusionweighted-images (DWI), which indicates restrictive diffusion in the acute and subacute phase, and/or hyperintense on T2-weighted and fluid-attenuated inversion recovery (FLAIR) MR images (3). This term replaces the old "acute lacunar infarct".

\section{Lacunes}

Lacunes are small ( $3 \mathrm{~mm}-15 \mathrm{~mm}$ in diameter), round or ovoid, fluid-filled cavities (signal intensity similar to the cerebral spinal fluid (CSF) on all MRI sequences) with 
typically a hyperintense rim on T2-weighted and FLAIR images (4). These lesions are thought to be a previous acute (often asymptomatic) small subcortical infarct or haemorrhage in the territory of one perforating artery (3).

\section{WMH}

White matter changes of presumed vascular origin are bilateral hyperintensities on T2-weighted and FLAIR images in the white matter, without cavitation (3). WMH may be located in the periventricular white matter as well as the deep white matter. The severity of the white matter changes can be visually assessed by using the Fazekas score or can be automatically calculated using computer software for volumetric measurements $(3,5)$.

\section{PVS}

PVS follow the course of a vessel within the brain and therefore appear linear when imaged parallel to the course of the vessel and round or ovoid when imaged perpendicular to the vessel (4). The PVS are fluid-filled spaces and therefore have signal intensity similar to the CSF on all MRI sequences (4). They are small (mostly $<3 \mathrm{~mm}$ ) and usually do not have a hyperintense rim. They appear at the level of the basal ganglia and in the centrum semiovale.

\section{CMBs}

$\mathrm{CMBs}$ are micro-haemorrhages within the brain parenchyma and are visible on gradient echo (susceptibility weighted) MR images due to small hemosiderin depositions (3). The CMBs are often divided in two groups based on location. CMBs located in the deep cerebral regions of the brain (basal ganglia, thalamus and internal or external capsule) are linked to lipohyalinotic vessel wall changes and risk factor associated cerebral small vessel disease and CMBs with a lobar distribution are linked to cerebral amyloid angiopathy (6). CMBs may also appear infratentorial.

\section{Other features}

In addition to the manifestations on MRI as described above, brain atrophy and haemorrhagic stroke are also considered to be radiological features of cSVD.

\section{Total SVD score}

Recently a scale was developed to combine the main features of cSVD on MRI in a total SVD score (7-10). This score rates the presence of lacunes, extensive WMH, moderate to severe PVS and CMBs and appoints one point to each of these manifestations leading to a total score of 0 to 4 . The total SVD score provides a more 
complete estimate of the full impact of SVD on the brain than individual MRI manifestations. Furthermore, it is a simple visual MRI score and therefore a useful tool for both research and clinical use.

\section{Clinical implications}

\section{Acute clinical symptoms}

Clinical consequences of cSVD can present acute or may develop more gradually over time. The most studied and probably most common acute presentation is the lacunar stroke syndrome due to a small subcortical infarct. Lacunar stroke presents with deficits compatible with an occlusion of one of the small perforating arteries that provide blood to the brain's deep structures. Lacunar stroke due to cSVD accounts for approximately $25 \%$ of all acute ischemic stroke presentations (11). Typical clinical lacunar syndromes are pure motor hemiparesis, pure sensory stroke, sensorimotor stroke, ataxia hemiparesis and dysarthria-clumsy hand syndrome $(12,13)$. In addition to these syndromes, small subcortical infarcts localized in the brainstem and thalamus cause specific syndromes related to the anatomic structures involved in these brain areas $(14,15)$.

\section{Chronic / delayed clinical symptoms}

Clinical consequences of cSVD that may develop over time include cognitive disorders, motor disturbances and psychiatric consequences $(1,10,16-20)$. Cognitive impairment after an acute lacunar stroke appears to be common (21). Additional manifestations of cSVD on MRI are likely to increase the impact of lacunar stroke on cognition. The individual MRI manifestations of CSVD as well as the combination of several MRI manifestations with and without a small subcortical infarct are associated with declined cognitive function in community-based, memory clinicbased and lacunar stroke populations (1, 10, 16-18). WMH, lacunes and CMBs are also associated to motor and gait disturbances and a number of psychiatric syndromes, of which depression is best studied $(1,19,20,22-25)$.

\section{Mortality}

Short term mortality or "30-day case fatality" is lower in lacunar stroke compared to large vessel and cardio-embolic stroke $(26,27)$. In the past, lacunar stroke was considered a "benign" stroke. However, studies comparing long-term mortality between patients with different ischemic stroke etiologies, revealed that long-term mortality in lacunar stroke patients is not significantly different from that of large vessel or cardio-embolic stroke $(26,27)$. 
Several studies found that the individual MRI markers of cSVD relate to higher longterm mortality (28-30). Probably, mortality depends on cSVD related co-morbidities such as gait disturbances and cognitive disorders. Also, cardiovascular co-morbidity and increased stroke risk have been related to MRI markers of cSVD and lead to increased mortality (31). Therefore it seems unlikely that there is a direct causal relation between individual MRI markers and mortality. Assuming that it is the underlying disease in its full extent that adds to the increased morbidity, a total SVD score might reflect the association between cSVD and mortality more realistically.

\section{Pathology}

As mentioned before, cSVD may refer to different diseases and underlying pathologies such as cerebral amyloid angiopathy, hereditary causes such as CADASIL or Fabry disease, and inflammatory or immune mediated vasculitis (1). In this thesis however we will focus on arteriolosclerosis also referred to as risk factor related small vessel disease. Post mortem studies showed changes in the wall of smaller arterioles, referred to as arteriolosclerosis, lipohyalinosis or fibrinoid necrosis $(1,13)$. Pathologically there is loss of smooth muscle cells from the tunica media and deposits of fibro-hyaline material. These processes narrow the lumen of the vessel and thicken the vessel wall. Also microatheroma in the small distal arterioles is described in pathological studies, narrowing or occluding the small vessels (1). Hypothetical, lumen restriction may lead to a chronic hypoperfusion resulting in damage to the white matter. In case there is an acute occlusion of a small vessel acute tissue ischemia in the territory of the vessel may occur, resulting in a small subcortical infarction (1). However, the precise mechanism how these pathological changes occur, and how they lead to parenchymal damage within the brain is still unknown.

\section{Presumed pathogenic mechanisms of disease in cerebral small vessel disease Endothelial activation}

Endothelial dysfunction seems to play an important role in the development of cSVD $(2,32)$. The activated endothelium has multiple functions including regulation of vascular tone, inflammation, fibrinolysis and coagulation and blood vessel remodelling and repair (32). Furthermore, the endothelium is part of the blood-brain barrier (BBB). Endothelial dysfunction may refer to disturbance and failing or chronic overactivation of any or all of these functions. Recent concepts on small vessel disease, consider the disease to be a systemic disorder that affects various organs and areas of the body $(1,32)$. Nonetheless the brain can be the main target or at least present the main source of the most important clinical and radiological manifestations of small vessel disease. 
Many studies have tried to show an association between circulating blood markers of endothelial activation and manifestations of cerebral small vessel disease $(32,33)$. Among these markers are molecules that are direct products of endothelial cells, as well as molecules that reflect endothelial damage or repair. For example, tissue plasminogen activator (tPA) and plasminogen activator inhibitor type 1 (PAI-1) antigen are components of the fibrinolytic system and are considered to be haemostasis-related markers of endothelial function (33-36). High levels of plasma tPA-activity and low levels of PAI-1 were associated cross-sectional with extensive $\mathrm{WMH}$ in lacunar stroke patients (37).

Another group of circulating markers that is linked to cSVD and endothelial activation and/or dysfunction consists of markers that indicate vascular inflammation. Activated endothelial cells express adhesion molecules enabling interactions with leukocytes $(33,38)$. Circulating soluble forms of the adhesion molecules are E-selectin, $\mathrm{P}$ selectin, VCAM-1 and ICAM-1 (39). Also neopterin, as a marker of T-cell mediated macrophage activation, is linked to cSVD. Neopterin promotes the expression of adhesion molecules on endothelial cells (40). Results from previous cross-sectional studies on the association between lacunar stroke or radiologic features of cSVD and these blood markers of vascular inflammation report conflicting results $(33,41-49)$.

\section{BBB leakage}

The brain's vascular endothelium is part of the BBB and is characterized by extensive tight junctions and restricted transport, forming a true barrier between the blood and the brain (32). Damage or increased permeability of the BBB may lead to damage within the so-called "neurovascular unit". The neurovascular unit is the functional unit where vessels and brain interact. It is constituted by the endothelium and basal lamina, neurons and their axons, astrocyte end-feet, pericytes, microglia and extracellular matrix (32). It is thought that BBB disruption may lead to leakage into and damage of the vessel wall, in the end leading to rupture or narrowing of the vessel with subsequent (micro)haemorrhage and/or ischemic changes in the surrounding tissue. Another mechanism that may lead to manifestations of cSVD is the leakage of plasma components to the surrounding brain tissue causing local damage.

\section{Vitamin B12}

Previous findings that showed that lower vitamin B12 levels were more frequent in lacunar stroke patients and moreover were associated with periventricular $\mathrm{WMH}$, 
triggered a hypothesis that vitamin B12 could affect the endothelium and the BBB, and could play a role in the etiology of CSVD (50). Effects of vitamin B12 are mostly attributed to its role in lowering homocysteine levels (51-54). Hyperhomocysteinemia is related to both endothelial dysfunction and WMH (51-54). Nevertheless vitamin B12 also seems to effect the white matter beyond the homocysteine lowering effect $(53,55)$. A study in vitamin B12 deficient rats showed increased TNF-alpha levels in the central nervous system and these higher levels were linked to an increase of the BBB permeability in other studies (55-57). Also in humans the cerebrospinal fluid / serum albumin ratio, which is considered to reflect the permeability of the BBB, was decreased in patients treated with vitamin B12-B6-folate combination (58).

\section{Hemodynamics}

As mentioned above cSVD is often thought of as part of a multi-system endothelial disorder. cSVD is associated with small vessel pathology of the retina and also the kidneys (59). Chronic kidney disease or kidney failure are considered to be small vessel disease within the kidney (59). Processes that induce endothelial activation and vascular inflammation are likely to be systemic which might explain the link between small vessel disease within the brain and other organs. Anatomic and hemodynamic similarities could also explain the co-occurrence of cerebral and renal small vessel disease. The glomerular afferent arterioles of the juxtamedullary nephrons of the kidneys and the small perforating arteries of the brain are both low resistance vessels that arise from larger high-pressure arteries and are exposed to high blood volume $(59,60)$. These small vessels maintain high vascular tone and are susceptible for microvascular damage, especially in increasing age, when fluctuations of blood pressure within the cardiac cycle increases $(60,61)$. Shared risk factors, most importantly blood pressure and its fluctuations, may therefore explain the association between renal SVD and CSVD.

\section{Common vascular risk factors}

Older age and hypertension are strongly associated with the occurrence of cSVD and its manifestations on brain $\operatorname{MRI}(1,7,11)$. This is why the most common type of SVD is termed "risk factor associated cSVD".

\section{Genetics}

Monogenetic disorders, such as CADASIL and Fabry disease, can cause cSVD. In risk factor related or sporadic cSVD also several genetic factors are identified. There is an increased genetic relative risk of stroke in first-degree relatives of patients with a first-ever lacunar stroke (62). In these patients, a family history of stroke was also related to the presence of lacunes (63). In several studies WMH were shown to be 
highly heritable $(64,65)$. Genetic studies on sporadic cSVD reveal associations between candidate genes and occurrence of various features of sporadic cerebral SVD, such as WMH and lacunes, however strong associations with clinical implications, have not yet been found (66).

\section{Progression and longitudinal effects of cSVD}

Research into etiological mechanisms of SVD has mainly been focussed on crosssectional associations. Most studies used the presence of a single MRI manifestations as marker of cSVD and studied the relation with possible etiological factors. Longitudinal studies on progression of cSVD on MRI are limited. Although observational cross-sectional studies are a good way to study characteristics among population subsets, it only reflects a single point in time. A longitudinal study design will learn more on cause-and-effect relationships. Studying progression of MRI manifestations of cSVD in relation to markers of endothelial function and SVD in other organs will provide valuable information on etiological mechanisms in the development and progression of cSVD.

Former studies on longitudinal effects of cSVD in terms of long-term mortality were focussed on individual MRI manifestations of cSVD. Combining the different features probably provides a more complete estimate of the full impact of SVD on the brain than individual MRI manifestations. Such a "total SVD" view was developed only recently.

\section{General aim of this thesis}

The general aim of this thesis was to study the relation between several etiological factors and progression of SVD in a longitudinal observational study design. We studied markers of haemostasis, endothelial activation, vascular inflammation and kidney function in relation to progression of the different MRI manifestations of cSVD. A secondary aim was to assess the association between the total MRI burden of cSVD and long-term mortality.

\section{Study population and methods}

The study population in this thesis is a cohort of first-ever lacunar stroke patients who were collected at the Maastricht University Medical Center (Maastricht, the Netherlands) and the Orbis Medical Center (Sittard, the Netherlands) between May 2003 and January 2008. We defined lacunar stroke as an acute stroke syndrome with a compatible lacunar lesion on MR imaging. If no MR lesion was visible, we used established clinical criteria for lacunar stroke (12). To increase the likelihood that the 
lacunar syndrome had resulted from cSVD, patients with potential cardiac embolic source of stroke (mostly atrial fibrillation) or with severe carotid stenosis (> $70 \%$ ) were excluded.

Clinical follow-up brain MRI was offered 2-year after baseline MRI. Baseline and follow-up MR images were acquired with a 1.5 Tesla (T) or 3T MRI scanner (Philips, Eindhoven, the Netherlands). Standard axial T2-weighted fast spin echo, fluid attenuated inversion recovery (FLAIR) and T2-weighted gradient recalled echo (GRE, Philips FFE) images were obtained. Lacunes, WMH, PVS and CMBs were rated at baseline and follow-up. This data was used to calculate a total small vessel disease score at baseline and to evaluate progression of the individual manifestations of cSVD on MRI at follow-up.

At baseline vascular risk factors including 24-hour ambulatory blood pressure measurements were collected. Also at baseline blood samples were collected to perform routine blood tests and to determine plasma levels of vitamin B12 and specific markers of haemostasis, endothelial activation and vascular inflammation. These markers were already studied in cross-sectional studies and these results were published before $(37,41,50)$.

On September 1, 2015 we recorded survival status and we registered date of death if the patient had died.

\section{Research questions}

\section{Are markers of vascular inflammation associated with the progression of MRI manifestations of cSVD? (Chapter 2)}

Previous, mainly cross-sectional, studies determined the association between inflammation blood markers and several manifestations of cSVD on brain MR, with inconsistent results $(33,41-49)$. It is however unknown whether these markers are related to progression of cSVD. In chapter 2 , we study the association between blood markers of vascular inflammation, in particular neopterin, VCAM-1, ICAM-1, Eselectin and P-selectin, and the progression of MRI manifestations of SVD over 2 years of follow-up in first-ever lacunar stroke patients.

\section{Are plasma levels of tPA-activity and PAI-1 associated with the progression of WMH? (Chapter 3)}

tPA-activity and PAI-1 levels are considered to be haemostasis-related markers of endothelial activation. An earlier cross-sectional study found these to be related to presence of $\mathrm{WMH}$ (37). It is unknown however, whether these markers are related to progression of cSVD. In chapter 3, we study whether tPA-activity and PAI-1 levels are 
associated with WMH progression over 2 years of follow-up in first-ever lacunar stroke patients.

\section{Is plasma vitamin B12 associated to progression of WMH? (Chapter 4)}

In a cross-sectional study periventricular WMH were related to low plasma levels of vitamin B12 and this led to the hypothesis that vitamin B12 plays a role in the etiology of SVD (50). Whether low vitamin B12 levels are also related to progression of WMH is still unknown. In chapter 4, we studied baseline vitamin B12 levels and its association with progression of WMH over 2 years of follow-up in first-ever lacunar stroke patients.

\section{Is kidney function associated to progression of CMBs? (Chapter 5)}

It is hypothesized that impaired kidney function and CMBs represent microvascular damage in different organs $(59,60)$. The brain and kidneys are both susceptible for microvascular damage, probably due to their hemodynamic similarities $(60,61)$. Several cross-sectional studies found impaired kidney function to be associated with the presence of $\mathrm{CMBs}$ (67-72). Thus far, there are no longitudinal data on the relation between decreased kidney function and progression of CMBs. In chapter 5, we study the association between kidney function and progression of CMBs over 2 years of follow-up in first-ever lacunar stroke patients.

\section{Is total burden of cerebral small vessel disease on MRI related to long-term mortality? (Chapter 6)}

Several studies found that the individual MRI manifestations of cSVD relate to longterm mortality. Recently a total small vessel disease score (SVD) was developed which is an ordinal score of the total burden of CSVD on brain MRI $(7,9)$. The total SVD score provides a more complete estimate of the full impact of SVD on the brain than individual MRI markers. In chapter 6 , we study the association between the total SVD score and long-term mortality in first-ever lacunar stroke patients during a mean follow-up duration of almost 10 years. 


\section{References}

1. Pantoni L. Cerebral small vessel disease: from pathogenesis and clinical characteristics to therapeutic challenges. Lancet Neurol. 2010 Jul;9(7):689-701. PubMed PMID: 20610345.

2. Wardlaw JM, Smith C, Dichgans M. Mechanisms of sporadic cerebral small vessel disease: insights from neuroimaging. Lancet Neurol. 2013 May;12(5):483-97. PubMed PMID: 23602162. Pubmed Central PMCID: 3836247.

3. Wardlaw JM, Smith EE, Biessels GJ, Cordonnier C, Fazekas F, Frayne R, et al. Neuroimaging standards for research into small vessel disease and its contribution to ageing and neurodegeneration. Lancet Neurol. 2013 Aug;12(8):822-38. PubMed PMID: 23867200. Pubmed Central PMCID: 3714437.

4. Doubal FN, MacLullich AM, Ferguson KJ, Dennis MS, Wardlaw JM. Enlarged perivascular spaces on MRI are a feature of cerebral small vessel disease. Stroke; a journal of cerebral circulation. 2010 Mar;41(3):450-4. PubMed PMID: 20056930.

5. Fazekas F, Kleinert R, Offenbacher H, Schmidt R, Kleinert G, Payer F, et al. Pathologic correlates of incidental MRI white matter signal hyperintensities. Neurology. 1993 Sep;43(9):1683-9. PubMed PMID: 8414012.

6. Yates PA, Villemagne VL, Ellis KA, Desmond PM, Masters CL, Rowe CC. Cerebral microbleeds: a review of clinical, genetic, and neuroimaging associations. Frontiers in neurology. 2014 Jan 6;4:205. PubMed PMID: 24432010. Pubmed Central PMCID: 3881231.

7. Klarenbeek P, van Oostenbrugge RJ, Rouhl RP, Knottnerus IL, Staals J. Ambulatory blood pressure in patients with lacunar stroke: association with total MRI burden of cerebral small vessel disease. Stroke; a journal of cerebral circulation. 2013 Nov;44(11):2995-9. PubMed PMID: 23982717.

8. Huijts M, Duits A, van Oostenbrugge RJ, Kroon AA, de Leeuw PW, Staals J. Accumulation of MRI Markers of Cerebral Small Vessel Disease is Associated with Decreased Cognitive Function. A Study in First-Ever Lacunar Stroke and Hypertensive Patients. Front Aging Neurosci. 2013;5:72. PubMed PMID: 24223555. Pubmed Central PMCID: 3818574.

9. Staals J, Makin SD, Doubal FN, Dennis MS, Wardlaw JM. Stroke subtype, vascular risk factors, and total MRI brain small-vessel disease burden. Neurology. 2014 Sep 30;83(14):1228-34. PubMed PMID: 25165388. Pubmed Central PMCID: 4180484.

10. Staals J, Booth T, Morris Z, Bastin ME, Gow AJ, Corley J, et al. Total MRI load of cerebral small vessel disease and cognitive ability in older people. Neurobiology of aging. 2015 Oct;36(10):2806-11. PubMed PMID: 26189091.

11. Benavente OR, White CL, Pearce L, Pergola P, Roldan A, Benavente MF, et al. The Secondary Prevention of Small Subcortical Strokes (SPS3) study. International journal of stroke : official journal of the International Stroke Society. 2011 Apr;6(2):164-75. PubMed PMID: 21371282. Pubmed Central PMCID: 4214141.

12. Bamford J, Sandercock P, Jones L, Warlow C. The natural history of lacunar infarction: the Oxfordshire Community Stroke Project. Stroke; a journal of cerebral circulation. 1987 MayJun;18(3):545-51. PubMed PMID: 3590244.

13. Fisher CM. Lacunes: Small, Deep Cerebral Infarcts. Neurology. 1965 Aug;15:774-84. PubMed PMID: 14315302.

14. Bogousslavsky J, Regli F, Uske A. Thalamic infarcts: clinical syndromes, etiology, and prognosis. Neurology. 1988 Jun;38(6):837-48. PubMed PMID: 3368064.

15. Bogousslavsky J, Maeder P, Regli F, Meuli R. Pure midbrain infarction: clinical syndromes, MRI, and etiologic patterns. Neurology. 1994 Nov;44(11):2032-40. PubMed PMID: 7969955.

16. Huijts M, Duits A, Staals J, Kroon AA, de Leeuw PW, van Oostenbrugge RJ. Basal ganglia enlarged perivascular spaces are linked to cognitive function in patients with cerebral small vessel disease. Current neurovascular research. 2014 May;11(2):136-41. PubMed PMID: 24606607. 
17. van der Flier WM, van Straaten EC, Barkhof F, Verdelho A, Madureira S, Pantoni L, et al. Small vessel disease and general cognitive function in nondisabled elderly: the LADIS study. Stroke; a journal of cerebral circulation. 2005 Oct;36(10):2116-20. PubMed PMID: 16141425.

18. Poels MM, Ikram MA, van der Lugt A, Hofman A, Niessen WJ, Krestin GP, et al. Cerebral microbleeds are associated with worse cognitive function: the Rotterdam Scan Study. Neurology. 2012 Jan 31;78(5):326-33. PubMed PMID: 22262748.

19. Smith EE, O'Donnell M, Dagenais G, Lear SA, Wielgosz A, Sharma M, et al. Early cerebral small vessel disease and brain volume, cognition, and gait. Ann Neurol. 2015 Feb;77(2):251-61. PubMed PMID: 25428654. Pubmed Central PMCID: 4338762.

20. Inzitari D, Simoni M, Pracucci G, Poggesi A, Basile AM, Chabriat $\mathrm{H}$, et al. Risk of rapid global functional decline in elderly patients with severe cerebral age-related white matter changes: the LADIS study. Archives of internal medicine. 2007 Jan 8;167(1):81-8. PubMed PMID: 17210882.

21. Norrving B. Long-term prognosis after lacunar infarction. Lancet Neurol. 2003 Apr;2(4):23845. PubMed PMID: 12849212.

22. Tang WK, Chen YK, Lu JY, Chu WC, Mok VC, Ungvari GS, et al. Cerebral microbleeds and depression in lacunar stroke. Stroke; a journal of cerebral circulation. 2011 Sep;42(9):2443-6. PubMed PMID: 21757672.

23. de Laat KF, van den Berg HA, van Norden AG, Gons RA, Olde Rikkert MG, de Leeuw FE. Microbleeds are independently related to gait disturbances in elderly individuals with cerebral small vessel disease. Stroke; a journal of cerebral circulation. 2011 Feb;42(2):494-7. PubMed PMID: 21164137.

24. de Laat KF, van Norden AG, Gons RA, van Oudheusden L, van Uden IW, Bloem BR, et al. Gait in elderly with cerebral small vessel disease. Stroke; a journal of cerebral circulation. 2010 Aug;41(8):1652-8. PubMed PMID: 20576951.

25. Steffens DC, Krishnan KR, Crump C, Burke GL. Cerebrovascular disease and evolution of depressive symptoms in the cardiovascular health study. Stroke; a journal of cerebral circulation. 2002 Jun;33(6):1636-44. PubMed PMID: 12053004.

26. Staals J, van Raak L, Hilton A, Lodder J. Differences in long-term survival in two lacunar stroke types: a 15-year follow-up study in 782 cerebral infarct patients. Cerebrovascular diseases. 2008;25(1-2):26-31. PubMed PMID: 18033955.

27. Sacco S, Marini C, Totaro R, Russo T, Cerone D, Carolei A. A population-based study of the incidence and prognosis of lacunar stroke. Neurology. 2006 May 9;66(9):1335-8. PubMed PMID: 16682663.

28. Bokura H, Kobayashi S, Yamaguchi S, lijima K, Nagai A, Toyoda G, et al. Silent brain infarction and subcortical white matter lesions increase the risk of stroke and mortality: a prospective cohort study. Journal of stroke and cerebrovascular diseases : the official journal of National Stroke Association. 2006 Mar-Apr;15(2):57-63. PubMed PMID: 17904049.

29. Henneman WJ, Sluimer JD, Cordonnier C, Baak MM, Scheltens P, Barkhof F, et al. MRI biomarkers of vascular damage and atrophy predicting mortality in a memory clinic population. Stroke; a journal of cerebral circulation. 2009 Feb;40(2):492-8. PubMed PMID: 19109551.

30. Akoudad S, Ikram MA, Koudstaal PJ, Hofman A, van der Lugt A, Vernooij MW. Cerebral microbleeds and the risk of mortality in the general population. Eur J Epidemiol. 2013 Oct;28(10):815-21. PubMed PMID: 24072508.

31. Vermeer SE, Longstreth WT, Jr., Koudstaal PJ. Silent brain infarcts: a systematic review. Lancet Neurol. 2007 Jul;6(7):611-9. PubMed PMID: 17582361.

32. Poggesi A, Pasi M, Pescini F, Pantoni L, Inzitari D. Circulating biologic markers of endothelial dysfunction in cerebral small vessel disease: a review. Journal of cerebral blood flow and metabolism : official journal of the International Society of Cerebral Blood Flow and Metabolism. 2015 Jun 10. PubMed PMID: 26058695. Pubmed Central PMCID: 4758546. 
33. Wiseman S, Marlborough F, Doubal F, Webb DJ, Wardlaw J. Blood Markers of Coagulation, Fibrinolysis, Endothelial Dysfunction and Inflammation in Lacunar Stroke versus Non-Lacunar Stroke and Non-Stroke: Systematic Review and Meta-Analysis. Cerebrovascular diseases. 2014;37(1):64-75. PubMed PMID: 24401164.

34. Barac A, Campia U, Panza JA. Methods for evaluating endothelial function in humans. Hypertension. 2007 Apr;49(4):748-60. PubMed PMID: 17309954.

35. Lowe GD, Danesh J, Lewington S, Walker M, Lennon L, Thomson A, et al. Tissue plasminogen activator antigen and coronary heart disease. Prospective study and meta-analysis. European heart journal. 2004 Feb;25(3):252-9. PubMed PMID: 14972427.

36. Wannamethee SG, Sattar N, Rumley A, Whincup PH, Lennon L, Lowe GD. Tissue plasminogen activator, von Willebrand factor, and risk of type 2 diabetes in older men. Diabetes care. 2008 May;31(5):995-1000. PubMed PMID: 18235054.

37. Knottnerus IL, Govers-Riemslag JW, Hamulyak K, Rouhl RP, Staals J, Spronk HM, et al. Endothelial activation in lacunar stroke subtypes. Stroke; a journal of cerebral circulation. 2010 Aug;41(8):1617-22. PubMed PMID: 20595673.

38. Knottnerus IL, Ten Cate H, Lodder J, Kessels F, van Oostenbrugge RJ. Endothelial dysfunction in lacunar stroke: a systematic review. Cerebrovascular diseases. 2009;27(5):519-26. PubMed PMID: 19372654.

39. Tervaert JW, Kallenberg CG. Cell adhesion molecules in vasculitis. Current opinion in rheumatology. 1997 Jan;9(1):16-25. PubMed PMID: 9110129.

40. Cirillo P, Pacileo M, S DER, Calabro P, Gargiulo A, Angri V, et al. Neopterin induces proatherothrombotic phenotype in human coronary endothelial cells. Journal of thrombosis and haemostasis : JTH. 2006 Oct;4(10):2248-55. PubMed PMID: 16842491.

41. Rouhl RP, Damoiseaux JG, Lodder J, Theunissen RO, Knottnerus IL, Staals J, et al. Vascular inflammation in cerebral small vessel disease. Neurobiology of aging. 2012 Aug;33(8):1800-6. PubMed PMID: 21601314.

42. Hassan A, Hunt BJ, O'Sullivan M, Parmar K, Bamford JM, Briley D, et al. Markers of endothelial dysfunction in lacunar infarction and ischaemic leukoaraiosis. Brain : a journal of neurology. 2003 Feb;126(Pt 2):424-32. PubMed PMID: 12538408.

43. Markus HS, Hunt B, Palmer K, Enzinger C, Schmidt H, Schmidt R. Markers of endothelial and hemostatic activation and progression of cerebral white matter hyperintensities: longitudinal results of the Austrian Stroke Prevention Study. Stroke; a journal of cerebral circulation. 2005 Jul;36(7):1410-4. PubMed PMID: 15905468.

44. Cherian P, Hankey GJ, Eikelboom JW, Thom J, Baker RI, McQuillan A, et al. Endothelial and platelet activation in acute ischemic stroke and its etiological subtypes. Stroke; a journal of cerebral circulation. 2003 Sep;34(9):2132-7. PubMed PMID: 12907813.

45. Lavallee PC, Labreuche J, Faille D, Huisse MG, Nicaise-Roland P, Dehoux M, et al. Circulating markers of endothelial dysfunction and platelet activation in patients with severe symptomatic cerebral small vessel disease. Cerebrovascular diseases. 2013;36(2):131-8. PubMed PMID: 24029712.

46. Umemura T, Kawamura T, Umegaki H, Mashita S, Kanai A, Sakakibara T, et al. Endothelial and inflammatory markers in relation to progression of ischaemic cerebral small-vessel disease and cognitive impairment: a 6-year longitudinal study in patients with type 2 diabetes mellitus. Journal of neurology, neurosurgery, and psychiatry. 2011 Nov;82(11):1186-94. PubMed PMID: 21478205.

47. Tsai NW, Chang WN, Shaw CF, Jan CR, Chang HW, Huang CR, et al. Levels and value of platelet activation markers in different subtypes of acute non-cardio-embolic ischemic stroke. Thrombosis research. 2009 Jun;124(2):213-8. PubMed PMID: 19233449.

48. Kozuka K, Kohriyama T, Nomura E, Ikeda J, Kajikawa H, Nakamura S. Endothelial markers and adhesion molecules in acute ischemic stroke--sequential change and differences in stroke subtype. Atherosclerosis. 2002 Mar;161(1):161-8. PubMed PMID: 11882328. 
49. Ilhan D, Ozbabalik D, Gulcan E, Ozdemir O, Gulbacs Z. Evaluation of platelet activation, coagulation, and fibrinolytic activation in patients with symptomatic lacunar stroke. The neurologist. 2010 May;16(3):188-91. PubMed PMID: 20445428.

50. Pieters B, Staals J, Knottnerus I, Rouhl R, Menheere P, Kessels A, et al. Periventricular white matter lucencies relate to low vitamin B12 levels in patients with small vessel stroke. Stroke; a journal of cerebral circulation. 2009 May;40(5):1623-6. PubMed PMID: 19286604.

51. Hassan A, Hunt BJ, O'Sullivan M, Bell R, D'Souza R, Jeffery S, et al. Homocysteine is a risk factor for cerebral small vessel disease, acting via endothelial dysfunction. Brain : a journal of neurology. 2004 Jan;127(Pt 1):212-9. PubMed PMID: 14607791.

52. Spence JD, Stampfer MJ. Understanding the complexity of homocysteine lowering with vitamins: the potential role of subgroup analyses. JAMA. 2011 Dec 21;306(23):2610-1. PubMed PMID: 22187282.

53. Scalabrino G. Cobalamin (vitamin $\mathrm{B}(12)$ ) in subacute combined degeneration and beyond: traditional interpretations and novel theories. Experimental neurology. 2005 Apr;192(2):46379. PubMed PMID: 15755562.

54. Vermeer SE, van Dijk EJ, Koudstaal PJ, Oudkerk M, Hofman A, Clarke R, et al. Homocysteine, silent brain infarcts, and white matter lesions: The Rotterdam Scan Study. Ann Neurol. 2002 Mar;51(3):285-9. PubMed PMID: 11891822.

55. Scalabrino G. The multi-faceted basis of vitamin B12 (cobalamin) neurotrophism in adult central nervous system: Lessons learned from its deficiency. Progress in neurobiology. 2009 Jul;88(3):203-20. PubMed PMID: 19394404.

56. Gianazza E, Veber D, Eberini I, Buccellato FR, Mutti E, Sironi L, et al. Cobalamin (vitamin B12)deficiency-induced changes in the proteome of rat cerebrospinal fluid. The Biochemical journal. 2003 Aug 15;374(Pt 1):239-46. PubMed PMID: 12769818. Pubmed Central PMCID: 1223583.

57. Mayhan WG. Cellular mechanisms by which tumor necrosis factor-alpha produces disruption of the blood-brain barrier. Brain research. 2002 Feb 15;927(2):144-52. PubMed PMID: 11821008.

58. Lehmann M, Regland B, Blennow K, Gottfries CG. Vitamin B12-B6-folate treatment improves blood-brain barrier function in patients with hyperhomocysteinaemia and mild cognitive impairment. Dementia and geriatric cognitive disorders. 2003;16(3):145-50. PubMed PMID: 12826740.

59. Thompson CS, Hakim AM. Living beyond our physiological means: small vessel disease of the brain is an expression of a systemic failure in arteriolar function: a unifying hypothesis. Stroke; a journal of cerebral circulation. 2009 May;40(5):e322-30. PubMed PMID: 19228835.

60. Ito S, Nagasawa T, Abe M, Mori T. Strain vessel hypothesis: a viewpoint for linkage of albuminuria and cerebro-cardiovascular risk. Hypertension research : official journal of the Japanese Society of Hypertension. 2009 Feb;32(2):115-21. PubMed PMID: 19262469.

61. O'Rourke MF, Safar ME. Relationship between aortic stiffening and microvascular disease in brain and kidney: cause and logic of therapy. Hypertension. 2005 Jul;46(1):200-4. PubMed PMID: 15911742.

62. Knottnerus IL, Gielen M, Lodder J, Rouhl RP, Staals J, Vlietinck R, et al. Family history of stroke is an independent risk factor for lacunar stroke subtype with asymptomatic lacunar infarcts at younger ages. Stroke; a journal of cerebral circulation. 2011 May;42(5):1196-200. PubMed PMID: 21441152.

63. Knottnerus IL, Gielen M, Lodder J, Rouhl RP, Staals J, Vlietinck R, et al. Estimating the magnitude of genetic factors by calculating the genetic relative risk of stroke in first-ever lacunar stroke patients. PloS one. 2011;6(6):e21439. PubMed PMID: 21747905. Pubmed Central PMCID: 3126831.

64. Freudenberger P, Schmidt R, Schmidt H. Genetics of age-related white matter lesions from linkage to genome wide association studies. Journal of the neurological sciences. $2012 \mathrm{Nov}$ 15;322(1-2):82-6. PubMed PMID: 22795385. Pubmed Central PMCID: 3484396. 
65. Dichgans M. Genetics of ischaemic stroke. Lancet Neurol. 2007 Feb;6(2):149-61. PubMed PMID: 17239802.

66. Choi JC. Genetics of cerebral small vessel disease. Journal of stroke. 2015 Jan;17(1):7-16. PubMed PMID: 25692103. Pubmed Central PMCID: 4325630.

67. Cho AH, Lee SB, Han SJ, Shon YM, Yang DW, Kim BS. Impaired kidney function and cerebral microbleeds in patients with acute ischemic stroke. Neurology. 2009 Nov 17;73(20):1645-8. PubMed PMID: 19917986.

68. Akoudad S, Sedaghat S, Hofman A, Koudstaal PJ, van der Lugt A, Ikram MA, et al. Kidney function and cerebral small vessel disease in the general population. International journal of stroke : official journal of the International Stroke Society. 2015 Mar 5. PubMed PMID: 25753173.

69. Toyoda G, Bokura H, Mitaki S, Onoda K, Oguro H, Nagai A, et al. Association of mild kidney dysfunction with silent brain lesions in neurologically normal subjects. Cerebrovascular diseases extra. 2015 Jan-Apr;5(1):22-7. PubMed PMID: 25873927. Pubmed Central PMCID: 4376920.

70. Shima H, Ishimura E, Naganuma T, Yamazaki T, Kobayashi I, Shidara K, et al. Cerebral microbleeds in predialysis patients with chronic kidney disease. Nephrology, dialysis, transplantation : official publication of the European Dialysis and Transplant Association European Renal Association. 2010 May;25(5):1554-9. PubMed PMID: 20037183.

71. Watanabe A. Cerebral microbleeds and intracerebral hemorrhages in patients on maintenance hemodialysis. Journal of stroke and cerebrovascular diseases : the official journal of National Stroke Association. 2007 Jan-Feb;16(1):30-3. PubMed PMID: 17689389.

72. Zhang JB, Ju XH, Wang J, Sun HR, Li F. Serum cystatin C and cerebral microbleeds in patients with acute cerebral stroke. Journal of clinical neuroscience : official journal of the Neurosurgical Society of Australasia. 2014 Feb;21(2):268-73. PubMed PMID: 24139136. 


Chapter 2

\section{Markers of vascular inflammation and progression of MRI features of cerebral small vessel disease in lacunar stroke patients}

Ellen C. van Overbeek ${ }^{1}$, Julie Staals ${ }^{1,2}$, Rob P.W. Rouhl ${ }^{1}$, Jan G.M.C. Damoiseaux ${ }^{3}$, Jan Willem Cohen Tervaert ${ }^{2}$, Robert J. van Oostenbrugge ${ }^{1,2}$

${ }^{1}$ Department of Neurology, ${ }^{2}$ Cardiovascular Research Institute, ${ }^{3}$ Central Diagnostic Laboratory; Maastricht University Medical Center, Maastricht, the Netherlands 


\section{Abstract}

Background - Vascular inflammation is considered to play a role in the pathophysiology of cerebral small vessel disease (cSVD). Previous cross-sectional studies determined the association between blood inflammation markers and MRI manifestations of cSVD with inconsistent results.

Because longitudinal data would strengthen the causal interpretation of previous results, we studied whether markers of vascular inflammation are related to progression of MRI features of CSVD.

Methods - In 91 lacunar stroke patients we obtained baseline and 2-year follow-up brain MRI. We rated progression of white matter hyperintensities (WMH), cerebral microbleeds (CMBs) and lacunes. At baseline, blood levels of sP-selectin, sE-selectin, sVCAM-1, sICAM-1, neopterin and high sensitive C-reactive protein (hsCRP) were measured. We tested the association between these markers of vascular inflammation and progression of MRI features.

Results - We found no association between any marker of vascular inflammation and progression of MRI features of cSVD.

Conclusions - Despite these results, we do not exclude a pathophysiological role for vascular inflammation in the development and progression of cSVD. However, our results encourage to explore different pathways. 


\section{Introduction}

Cerebral small vessel disease (cSVD) is a common age-related disease that can result in lacunar stroke and/or "silent" radiologic features such as white matter hyperintensities (WMH), lacunes and cerebral microbleeds (CMBs)(1). Endothelial activation and vascular inflammation are thought to play a role in the pathogenesis of $\operatorname{cSVD}(2,3)$. Activated endothelial cells express adhesion molecules, such as E-selectin, P-selectin, VCAM-1 and ICAM-1, on their surface that enable interactions with leukocytes $(4,5)$. Circulating soluble forms of these adhesion molecules are considered as markers of vascular inflammation (2). Neopterin is a marker of T-cell mediated macrophage activation and promotes the expression of adhesion molecules on endothelial cells (3). Previous cross-sectional studies on the association between these blood markers of vascular inflammation and CSVD showed conflicting results (514).

Because longitudinal data would strengthen the causal interpretation of previous results, we studied whether baseline levels of sP-selectin, sE-selectin, sVCAM-1, SICAM-1, neopterin and hsCRP, were related to progression of MRI features of CSVD in a 2-year longitudinal study in lacunar stroke patients.

\section{Methods}

We included first-ever lacunar stroke patients (6). The study was approved by the medical ethical committee and all patients gave written informed consent. At baseline brain MRI was acquired and cardiovascular risk factors and on-medication 24-hour ambulatory blood pressure were recorded. Patients were offered a 2-year follow-up MRI. Baseline and follow-up MRI was performed with a 1.5 Tesla (T) or 3T scanner (Philips), including axial T2-weighted fast spin echo, fluid attenuated inversion recovery (FLAIR) and T2-weighted gradient recalled echo (GRE, Philips FFE) images. Only patients who were scanned with the same MRI field strength at baseline and follow-up were included. Baseline and follow-up MRI were visually scored for the presence and progression of lacunes, $\mathrm{WMH}$ and CMBs.

Blood was sampled 3 months after the initial event (to avoid acute phase effect). Commercially available enzyme-linked immunosorbent assay (ELISA) kits were used following manufacturer's instructions to measure sVCAM-1, sICAM-1, sP-selectin, sEselectin and neopterin. hsCRP was determined with nephelometry. Intra-assay and interassay variability of all assays was published before (6).

An elaborate description of methods is presented in the supplemental methods. 


\section{Statistical analysis}

Statistical analyses were performed using IBM SPSS Statistics 21. We assessed the association between levels of the markers (independent variable) and progression of $\mathrm{WMH}, \mathrm{CMBs}$ and lacunes at 2-years follow-up (dependent variable) by binary logistic regression analysis adjusting for age and sex. We additionally adjusted for baseline cardiovascular risk factors (hypertension, 24-hours mean arterial pressure (MAP), diabetes mellitus, hypercholesterolemia and current smoking). To avoid overcorrection with too many independent factors in the model, we added these factors one by one separately to the age and sex-adjusted model. We finally adjusted for baseline presence of extensive $\mathrm{WMH}, \mathrm{CMBs}$ or lacunes respectively. To correct for multiple testing ( 6 blood markers, 3 MRI markers), statistical significance was considered at $\mathrm{P}<0.0028$ (Bonferroni correction).

\section{Results}

\section{Patients}

We included 91 patients (table 1). Patient inclusion flow is presented in Supplemental Figure A. Most patients $(89,97.8 \%)$ had a $1.5 \mathrm{~T}$ and $2(2.2 \%)$ had a $3 \mathrm{~T} \mathrm{MRI}$ at baseline and follow-up.

Table 1. Baseline characteristics

\begin{tabular}{lc}
\hline & All patients \\
& $\mathrm{N}=91$ \\
\hline Male (\%) & $57(62.6)$ \\
Age (years) & $62.8( \pm 12.4)$ \\
Diabetes Mellitus (\%) & $10(11.0)$ \\
Hypercholesterolemia (\%) & $73(80.2)$ \\
Current smoking (\%) & $37(40.7)$ \\
Hypertension (\%) & $60(65.9)$ \\
24-hour MAP (mmHg) & $105.5( \pm 13.2)$ \\
Baseline MRI-features & \\
Extensive deep WMH, Fazekas 2+3 (\%) & $25(27.5)$ \\
Extensive periventricular WMH, Fazekas 3 (\%) & $23(25.3)$ \\
Lacunes (\%) & $61(67.0)$ \\
Microbleeds (\%) & $25(32.5)$ \\
\hline
\end{tabular}

Data are presented as mean ( $\pm S D$ ) or median (IQR); MAP mean arterial blood pressure; ${ }^{a} \mathrm{~N}=77$ 


\section{Progression of MRI features}

After 2-year follow-up, we found WMH progression in 43 (47.3\%), new CMBs in 9 (11.7\%) and new lacunes in 18 patients (19.8\%). Patients with WMH progression were significantly older than those without progression (mean age 67.5 and 58.5 years, respectively $(p<0.01)$ ) and had a significantly higher prevalence of extensive $\mathrm{WMH}$ at baseline. Patients with progression of lacunes were more often male compared to patients without progression ( $88.9 \%$ vs $61.6 \%, p<0.05)$ and had a higher prevalence of lacunes at baseline. Patients with CMBs progression had more often lacunes at baseline compared to patients without CMBs progression.

\section{Association between CSVD progression and blood markers of inflammation} hsCRP was missing in 7 and SVCAM-1 and sICAM-1 in 1 patient(s). The blood marker levels did not differ significantly between patients with or without progression of WMH, lacunes or CMBs (supplemental table A). In binary logistic regression analyses, we found no significant association between any marker and progression of $\mathrm{CMB}$, lacunes or WMH (table 2). Adjustment for vascular risk factors and baseline presence of the respective MRI marker did not change the overall results.

Table 2. Association between vascular inflammation markers and progression of MRI markers

\begin{tabular}{llll}
\hline & $\begin{array}{l}\text { Progression of white } \\
\text { matter hyperintensities; } \\
\mathrm{N}=91\end{array}$ & $\begin{array}{l}\text { Progression of } \\
\text { lacunes; } \\
\mathrm{N}=91\end{array}$ & $\begin{array}{l}\text { Progression of cerebral } \\
\text { microbleeds; } \\
\mathrm{N}=77^{*}\end{array}$ \\
\hline hsCRP ${ }^{\mathrm{a}}$ & $0.98(0.93-1.03)$ & $0.99(0.93-1.04)$ & $0.97(0.86-1.10)$ \\
Neopterin & $0.77(0.47-1.26)$ & $0.42(0.16-1.11)$ & $1.48(0.82-2.66)$ \\
sP-selectin & $0.97(0.92-1.01)$ & $1.02(0.97-1.06)$ & $1.02(0.96-1.07)$ \\
sE-selectin & $0.95(0.77-1.17)$ & $1.01(0.77-1.33)$ & $0.58(0.30-1.07)$ \\
s-ICAM-1 ${ }^{b}$ & $1.00(0.82-1.35)$ & $1.00(0.67-1.04)$ & $0.74(0.48-1.35)$ \\
s-VCAM-1 ${ }^{b}$ & $1.11(0.90-1.35)$ & $0.90(0.67-1.22)$ & $1.11(0.82-1.35)$ \\
\hline
\end{tabular}

Data are presented as odds ratio (OR) with 95\% confidential interval, adjusted for age and sex. OR are given per $n g / M L$ (neopterin), per $m g / L$ (hsCRP), per $10 \mathrm{ng} / \mathrm{ML}$ (sE-selectin and sP-selectin) or per $100 \mathrm{ng} / \mathrm{ML}$ (sVCAM-1 and sICAM-1); ${ }^{a} 7$ missing; ${ }^{b} 1$ missing. ${ }^{*}$ Gradient recalled echo images missing in 19 patients, therefore CMBs progression analyzed in 77 patients 


\section{Discussion}

In lacunar stroke patients, levels of neopterin, hsCRP, sE-selectin, sP-selectin, sICAM1 and sVCAM-1 were not related to progression of MRI features of cSVD after 2-year follow-up.

Earlier cross-sectional studies on association between levels of adhesion molecules and lacunar stroke or MRI features of CSVD, demonstrated inconsistent results (5-14). In a previous cross-sectional study of our group, we found an association between higher neopterin levels and perivascular spaces, and between higher sE-selectin levels and CMBs (6). We could not confirm this in our longitudinal study. However, there were methodological differences: in our baseline study we included a mix of lacunar stroke and hypertension patients and the results were not corrected for multiple testing. Other studies also overlooked to correct for multiple testing, or had other limitations, such as testing in the acute stroke phase $(7,9,10,13,14)$.

Furthermore, it is likely that negative findings have not been published.

One longitudinal community-based cohort study $(\mathrm{N}=296)$, found that higher levels of sICAM-1 were associated with WMH progression after 3 years (8). Another study in diabetic patients $(\mathrm{N}=190)$ found an association between sICAM-1 and progression of periventricular WMH and lacunes after 6 years (11). We found no association between sICAM-1 levels and progression of cSVD. The different results might be explained by differences in population sample size, duration of follow-up and/or the method of WMH progression rating.

Our study has some limitations. Neopterin, hsCRP and the adhesion molecules were measured only once and intra-individual changes over time may occur. Second, the sample size of our population is rather small and our results may be biased by selection of patients. However inclusion criteria were well-considered.

Despite our negative results, we still believe that vascular inflammation could play a role in the pathogenesis and progression of CSVD. It is possible that the differences in blood marker levels were too small to detect. Endothelial activation and inflammation within the small brain vessels may go undetected by measurements in blood samples. Furthermore we cannot exclude that our population was too small, the follow-up duration too short or the disease stage already too advanced to find an effect. Finally, one can think of other pathways in which inflammation and endothelial activation lead to cSVD for instance through TNF-alpha, IL-6 or von Willebrand factor (vWF). Our results encourage exploring different pathways and/or different plasma markers to unravel the role of vascular inflammation and endothelial activation in the development and progression of cSVD. 


\section{References}

1. Wardlaw JM. Blood-brain barrier and cerebral small vessel disease. Journal of the neurological sciences. 2010 Dec 15;299(1-2):66-71. PubMed PMID: 20850797.

2. Tervaert JW, Kallenberg CG. Cell adhesion molecules in vasculitis. Current opinion in rheumatology. 1997 Jan;9(1):16-25. PubMed PMID: 9110129.

3. Cirillo P, Pacileo M, S DER, Calabro P, Gargiulo A, Angri V, et al. Neopterin induces proatherothrombotic phenotype in human coronary endothelial cells. Journal of thrombosis and haemostasis : JTH. 2006 Oct;4(10):2248-55. PubMed PMID: 16842491.

4. Knottnerus IL, Ten Cate H, Lodder J, Kessels F, van Oostenbrugge RJ. Endothelial dysfunction in lacunar stroke: a systematic review. Cerebrovascular diseases. 2009;27(5):519-26. PubMed PMID: 19372654.

5. Wiseman S, Marlborough F, Doubal F, Webb DJ, Wardlaw J. Blood Markers of Coagulation, Fibrinolysis, Endothelial Dysfunction and Inflammation in Lacunar Stroke versus Non-Lacunar Stroke and Non-Stroke: Systematic Review and Meta-Analysis. Cerebrovascular diseases. 2014;37(1):64-75. PubMed PMID: 24401164.

6. Rouhl RP, Damoiseaux JG, Lodder J, Theunissen RO, Knottnerus IL, Staals J, et al. Vascular inflammation in cerebral small vessel disease. Neurobiology of aging. 2012 Aug;33(8):1800-6. PubMed PMID: 21601314.

7. Hassan A, Hunt BJ, O'Sullivan M, Parmar K, Bamford JM, Briley D, et al. Markers of endothelial dysfunction in lacunar infarction and ischaemic leukoaraiosis. Brain : a journal of neurology. 2003 Feb;126(Pt 2):424-32. PubMed PMID: 12538408.

8. Markus HS, Hunt B, Palmer K, Enzinger C, Schmidt H, Schmidt R. Markers of endothelial and hemostatic activation and progression of cerebral white matter hyperintensities: longitudinal results of the Austrian Stroke Prevention Study. Stroke; a journal of cerebral circulation. 2005 Jul;36(7):1410-4. PubMed PMID: 15905468.

9. Cherian P, Hankey GJ, Eikelboom JW, Thom J, Baker RI, McQuillan A, et al. Endothelial and platelet activation in acute ischemic stroke and its etiological subtypes. Stroke; a journal of cerebral circulation. 2003 Sep;34(9):2132-7. PubMed PMID: 12907813.

10. Lavallee PC, Labreuche J, Faille D, Huisse MG, Nicaise-Roland P, Dehoux M, et al. Circulating markers of endothelial dysfunction and platelet activation in patients with severe symptomatic cerebral small vessel disease. Cerebrovascular diseases. 2013;36(2):131-8. PubMed PMID: 24029712.

11. Umemura T, Kawamura T, Umegaki H, Mashita S, Kanai A, Sakakibara T, et al. Endothelial and inflammatory markers in relation to progression of ischaemic cerebral small-vessel disease and cognitive impairment: a 6-year longitudinal study in patients with type 2 diabetes mellitus. Journal of neurology, neurosurgery, and psychiatry. 2011 Nov;82(11):1186-94. PubMed PMID: 21478205.

12. Tsai NW, Chang WN, Shaw CF, Jan CR, Chang HW, Huang CR, et al. Levels and value of platelet activation markers in different subtypes of acute non-cardio-embolic ischemic stroke. Thrombosis research. 2009 Jun;124(2):213-8. PubMed PMID: 19233449.

13. Kozuka K, Kohriyama T, Nomura E, Ikeda J, Kajikawa H, Nakamura S. Endothelial markers and adhesion molecules in acute ischemic stroke--sequential change and differences in stroke subtype. Atherosclerosis. 2002 Mar;161(1):161-8. PubMed PMID: 11882328.

14. Shoamanesh A, Preis SR, Beiser AS, Vasan RS, Benjamin EJ, Kase CS, et al. Inflammatory biomarkers, cerebral microbleeds, and small vessel disease: Framingham Heart Study. Neurology. 2015 Feb 24;84(8):825-32. PubMed PMID: 25632086. Pubmed Central PMCID: 4345647. 


\section{Supplement - Methods \\ Patients}

First-ever lacunar stroke patients were enrolled in an ongoing lacunar stroke project as described before (1). The study was approved by the medical ethical committee and all patients gave written informed consent. We defined lacunar stroke as an acute stroke syndrome with a compatible lacunar lesion on MR imaging. If no MR lesion was visible, we used established clinical criteria for lacunar stroke (2). Brain $\mathrm{MRI}$ and blood samples were collected at baseline as described below. The vascular risk factors age, sex, diabetes mellitus, current smoking, hypercholesterolemia (defined as statin use at admission or total cholesterol level $>5 \mathrm{mmol} / \mathrm{L}$ ) and hypertension (defined as present in patient's medical history at admission) were recorded at admission. We performed baseline (on-medication) 24-hour ambulatory blood pressure monitoring (ABPM) after the acute stroke phase as described elsewhere(3). As blood pressure is associated with progression of cerebral microbleeds (CMBs), lacunes and white matter hyperintensities (WMH) (4-6), and could be an important confounder in the association between markers of inflammation and progression of CSVD, we selected only those patients in whom baseline 24-hour ABPM were available. Patients were offered a clinical follow-up brain MRI after 2 years.

\section{MRI acquisition}

Baseline and follow-up MR images were acquired with a 1.5 Tesla (T) or 3T MRI scanner (Philips, Eindhoven, the Netherlands). For this study standard axial T2weighted fast spin echo, fluid attenuated inversion recovery (FLAIR) and T2-weighted gradient recalled echo (GRE, Philips FFE) images were obtained. Scan parameters of the 1,5T scanner were as follows: field of view $23 * 23 \mathrm{~cm}$; T2: matrix $512 * 512$, TR shortest, TE 100 ms; FLAIR: matrix 512*512, TR 8000 ms, TE 120 ms; GRE: matrix $256 * 256$, TR shortest, TE $23 \mathrm{~ms}$; all with slice thickness $5 \mathrm{~mm}$ and gaps of $0.50 \mathrm{~mm}$. Scan parameters of the 3 T scanner were: field of view $23 * 23 \mathrm{~cm}$; T2: matrix $512 * 512$, TR 3000ms, TE 80 ms; FLAIR: matrix 512*512, TR 11000 ms, TE 125 ms; GRE: matrix 256*256, TR shortest, TE $16 \mathrm{~ms}$; all with slice thickness $5 \mathrm{~mm}$ and gaps of $0.50 \mathrm{~mm}$. Scanning parameters were unchanged between baseline and follow-up. Baseline MR images were obtained at a median of 30 days (interquartile range (IQR) 8- 76 days) after the event. Follow-up MR images were performed 2 years after the baseline imaging. Only the patients that were scanned with the same MRI field strength at baseline and follow-up were included in the study to prevent overestimation of progression in patients scanned on a 1.5T scanner at baseline and 3T scanner at 
follow-up, and to prevent underestimation of progression in patients scanned on a 3T scanner at baseline and 1.5T scanner at follow-up.

\section{$M R I$ rating}

At baseline WMH were assessed using the Fazekas scale(7). We defined presence of extensive WMH as T2-weighted (early) confluent deep hyperintensities (Fazekas 2 and 3) or irregular periventricular hyperintensities extending into the deep white matter (Fazekas 3). Follow-up MRI was assessed using the WMH change scale as proposed by Prins et al.(8). This scale rates progression of WMH by assessing white matter changes in three periventricular regions (frontal caps, lateral bands and occipital caps) and four deep regions (frontal, parietal, temporal, occipital). Increase of WMH in each region is defined as new lesions or increase of existing lesions. Progression of $\mathrm{WMH}$ was defined as an increase of $\mathrm{WMH}$ in any region. $\mathrm{CMBs}$ were assessed on T2-weighted GRE sequences and were defined as rounded hypointense lesions with a diameter $<10 \mathrm{~mm}$. Lacunes were assessed on T2-weighted and FLAIR images and defined as hyperintense lesions on $\mathrm{T} 2$ images with corresponding hypointense lesions with a hyperintense rim on FLAIR with a diameter $<20 \mathrm{~mm}$. These lesions had to be asymptomatic (not compatible with clinical findings). We assessed the presence of new CMBs and the presence of new lacunes at follow-up by side-byside comparison of baseline and follow-up MRI. Progression was defined as one or more new $\mathrm{CMBs}$ or lacunes. We could not measure progression of perivascular spaces, another important feature of cSVD, because an adequate method is lacking(9).

Two vascular neurologists (JS and RR), who were blinded for levels of the blood markers, independently assessed progression of WMH, CMBs and lacunes. In case of disagreement a consensus meeting was held. The inter-rater agreement, expressed by Cohen's kappa (к), was substantial for progression of WMH (0 .6 5 ), substantial for progression of lacunes (0.79) and excellent for detection of new CMBs (0.91).

\section{sP-selectin, sE-selectin, sVCAM-1, sICAM-1, Neopterin and hsCRP}

At baseline blood was sampled 3 months after the initial event as described previously (1). Commercially available enzyme-linked immunosorbent assay (ELISA) kits (BioSource, Europe, Nivelles, Belgium) were used according to manufacturer's instructions to measure sVCAM-1, sICAM-1, sP-selectin, and SE-selectin. Neopterin was measured using commercially-available enzyme-linked immunosorbent assay (ELISA) kits (IBL, Hamburg, Germany) according to manufacturer's instructions. hsCRP was determined with nephelometry, using the BN ProSpec (Siemens, Erlangen, Germany). Intra-assay and interassay variability of all assays was published before(1). 


\section{Statistical analysis}

Statistical analyses were performed using IBM SPSS Statistics 21. Levels of neopterin, hsCRP, and adhesion molecules are given as mean ( \pm standard deviation) or median (interquartile range) where appropriate. We compared levels of these markers between patients with and without progression of MRI features, by t-test or MannWhitney $U$ test. Significance was considered at $P<0.05$. Then, we assessed the association between levels of neopterin, hsCRP and adhesion molecules (independent variable) and progression of $\mathrm{WMH}, \mathrm{CMBs}$ and lacunes at 2-years followup (dependent variable) by binary logistic regression analysis adjusting for age and sex. We also performed analyses in which we, in addition to age and sex, adjusted for baseline cardiovascular risk factors (hypertension, ambulatory 24-hours mean arterial pressure (MAP), diabetes mellitus, hypercholesterolemia and current smoking). To avoid overcorrection with too many independent factors in the model, we added these factors one by one separately to the age and sex-adjusted model. We finally adjusted for baseline presence of extensive $\mathrm{WMH}, \mathrm{CMBs}$ or lacunes respectively. Odds ratios (OR) are given with 95\% confidence interval $(\mathrm{Cl})$. To correct for multiple testing ( 6 blood markers, $3 \mathrm{MRI}$ markers), statistical significance in the regression analyses was considered at $\mathrm{P}<0.0028$ (Bonferroni correction). 


\section{Supplement - References}

1. Rouhl RP, Damoiseaux JG, Lodder J, Theunissen RO, Knottnerus IL, Staals J, et al. Vascular inflammation in cerebral small vessel disease. Neurobiology of aging. 2012 Aug;33(8):1800-6. PubMed PMID: 21601314.

2. Bamford J, Sandercock P, Jones L, Warlow C. The natural history of lacunar infarction: the Oxfordshire Community Stroke Project. Stroke; a journal of cerebral circulation. 1987 MayJun;18(3):545-51. PubMed PMID: 3590244.

3. Staals J, van Oostenbrugge RJ, Knottnerus IL, Rouhl RP, Henskens LH, Lodder J. Brain microbleeds relate to higher ambulatory blood pressure levels in first-ever lacunar stroke patients. Stroke; a journal of cerebral circulation. 2009 Oct;40(10):3264-8. PubMed PMID: 19661468.

4. Klarenbeek P, van Oostenbrugge RJ, Rouhl RP, Knottnerus IL, Staals J. Higher ambulatory blood pressure relates to new cerebral microbleeds: 2-year follow-up study in lacunar stroke patients. Stroke; a journal of cerebral circulation. 2013 Apr;44(4):978-83. PubMed PMID: 23449261.

5. Gouw AA, van der Flier WM, Fazekas F, van Straaten EC, Pantoni L, Poggesi A, et al. Progression of white matter hyperintensities and incidence of new lacunes over a 3-year period: the Leukoaraiosis and Disability study. Stroke; a journal of cerebral circulation. 2008 May;39(5):1414-20. PubMed PMID: 18323505.

6. Goldstein IB, Bartzokis G, Guthrie D, Shapiro D. Ambulatory blood pressure and the brain: a 5-year follow-up. Neurology. 2005 Jun 14;64(11):1846-52. PubMed PMID: 15955932.

7. Schmidt R, Schmidt H, Haybaeck J, Loitfelder M, Weis S, Cavalieri M, et al. Heterogeneity in age-related white matter changes. Acta neuropathologica. 2011 Aug;122(2):171-85. PubMed PMID: 21706175.

8. Prins ND, van Straaten EC, van Dijk EJ, Simoni M, van Schijndel RA, Vrooman HA, et al. Measuring progression of cerebral white matter lesions on MRI: visual rating and volumetrics. Neurology. 2004 May 11;62(9):1533-9. PubMed PMID: 15136677.

9. Aribisala BS, Wiseman S, Morris Z, Valdes-Hernandez MC, Royle NA, Maniega SM, et al. Circulating inflammatory markers are associated with magnetic resonance imaging-visible perivascular spaces but not directly with white matter hyperintensities. Stroke; a journal of cerebral circulation. 2014 Feb;45(2):605-7. PubMed PMID: 24399375. Pubmed Central PMCID: 3906539. 
Supplement Figure A. Patient flowchart
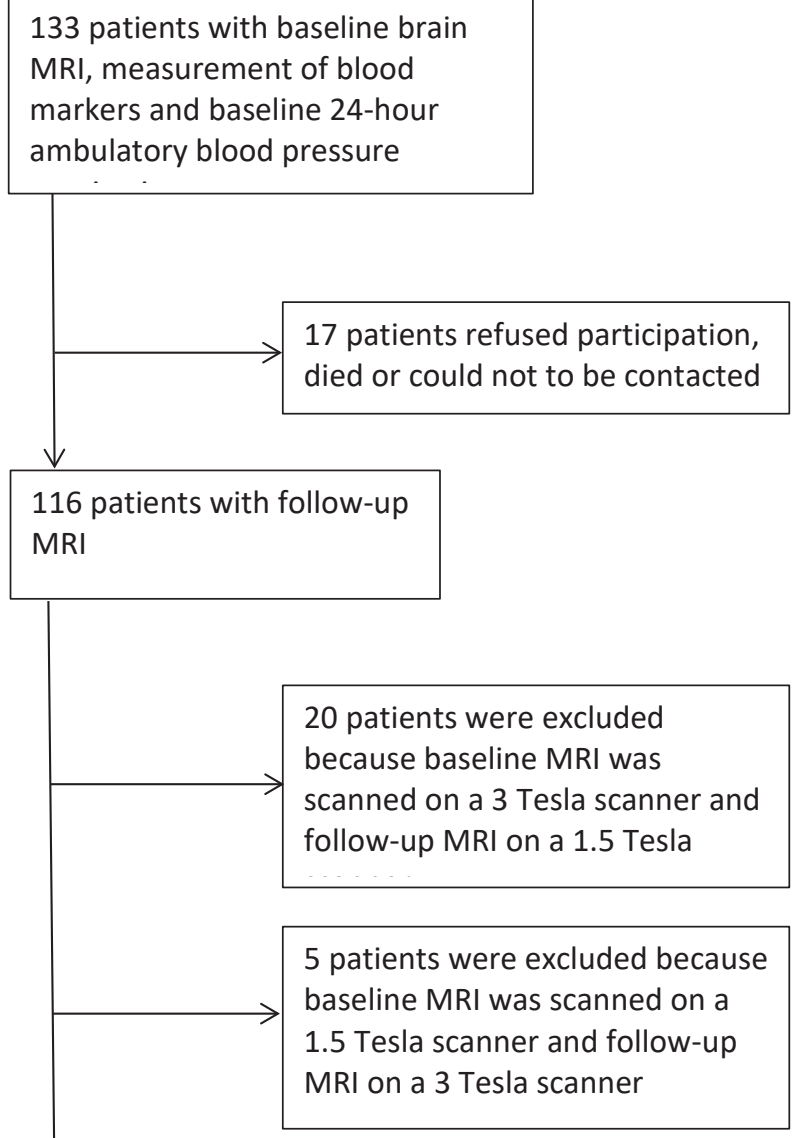

14 patients had no baseline and/or follow-up gradient echo images

91 patients for analyses on progression of white matter hyperintensities and lacunes

77 patients for analyses on progression of cerebral microbleeds 


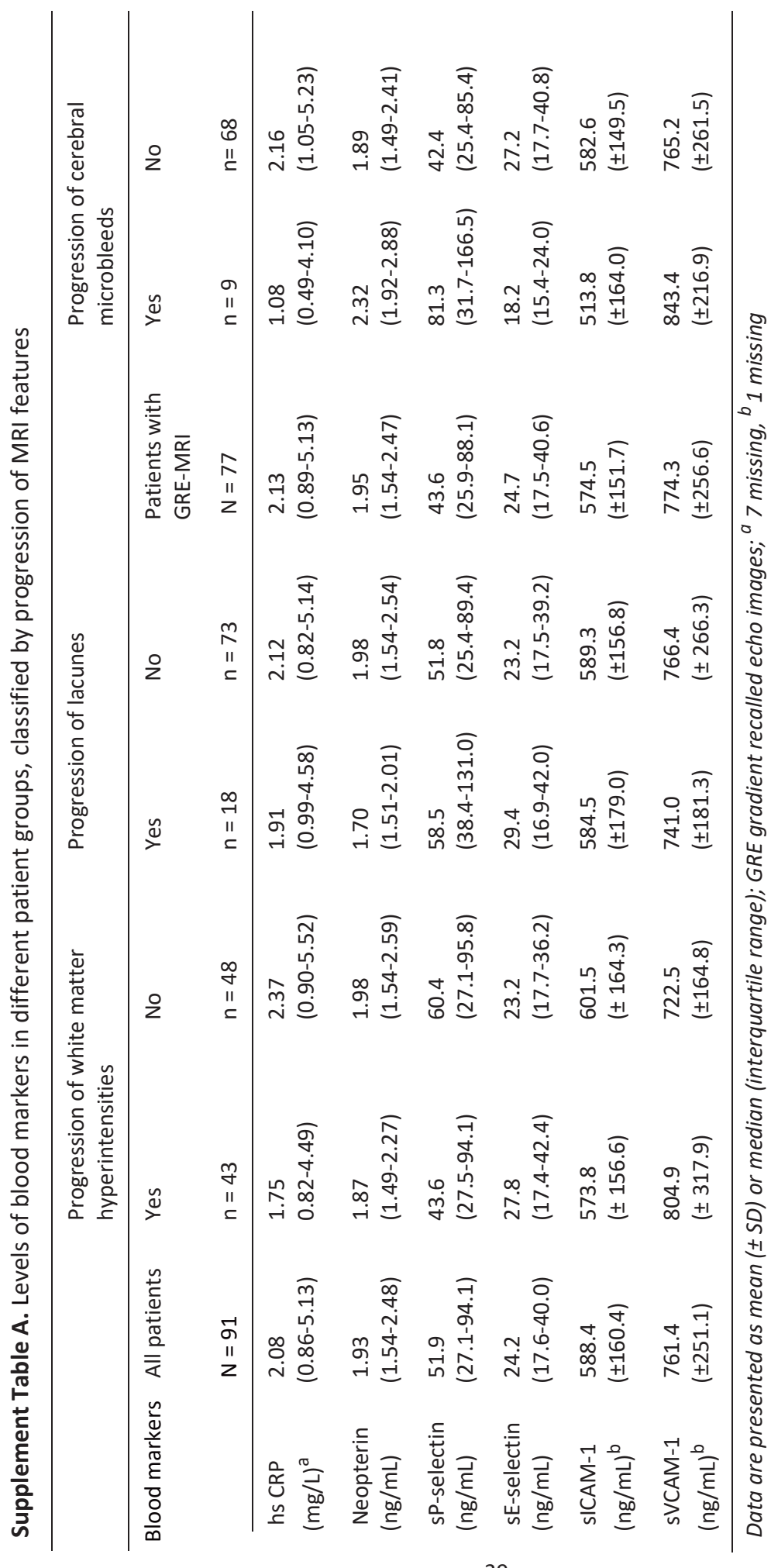





\section{Chapter 3}

\section{Plasma tPA-activity and progression of cerebral white matter hyperintensities in lacunar stroke patients}

Ellen C. van Overbeek ${ }^{1}$, Julie Staals ${ }^{1,2}$, Iris L.H. Knottnerus ${ }^{3}$, Hugo ten Cate ${ }^{2,4}$, Robert J. van Oostenbrugge $e^{1,2}$

${ }^{1}$ Department of Neurology, Maastricht University Medical Centre (MUMC), Maastricht, the Netherlands; ${ }^{2}$ Cardiovascular Research Institute Maastricht, MUMC, Maastricht, the Netherlands; ${ }^{3}$ Department of Neurology, Medisch Spectrum Twente, Enschede, the Netherlands; ${ }^{4}$ Department of Internal Medicine, MUMC, Maastricht, the Netherlands 


\section{Abstract}

Background - Tissue plasminogen activator (tPA)-activity and plasminogen activator inhibitor type 1 (PAI-1) antigen are considered to be haemostasis-related markers of endothelial activation and relate to presence of cerebral white matter hyperintensities (WMH) as was earlier shown in a cross-sectional study. We investigated whether PA-activity and PAI-1 levels are associated with $\mathrm{WMH}$ progression in a longitudinal study.

Methods - In 127 first-ever lacunar stroke patients in whom baseline brain MRI and plasma levels of tPA-activity and PAI-1-antigen were available, we obtained a 2-year follow-up MRI. We assessed WMH progression by a visual WMH change scale. We determined the relationship between levels of tPA-activity and PAI-1 and WMH progression, by logistic regression analysis.

Results - Plasma tPA-activity was associated with periventricular WMH progression (OR 2.36, 95\% Cl 1.01-5.49, with correction for age and sex and baseline presence of WMH), but not with deep or any (periventricular and/or deep) WMH progression. PAI-1 levels were lower in patients with WMH progression, but these results were not significant.

Conclusions - We found a relationship between plasma tPA-activity and progression of periventricular $\mathrm{WMH}$. More research is needed to determine whether there is a (direct) role of tPA in the development and progression of WMH. 


\section{Introduction}

Tissue plasminogen activator (tPA) and plasminogen activator inhibitor type 1 (PAI-1) antigen are components of the fibrinolytic system. It is hypothesized that TPA and PAI-1 are haemostasis-related markers of endothelial function (1-4). Endothelial dysfunction, probably systemic and not just in the cerebral vessels, is considered one of the main underlying initiating causes of cerebral small vessel disease (cSVD) (5). One of the most prevalent manifestations of cSVD are white matter hyperintensities (WMH) visible on brain MRI (5). WMH are associated with stroke risk, mortality, gait abnormalities and cognitive impairment (6). A better understanding of the pathogenesis and associated factors of WMH may help developing future treatment strategies.

Earlier, we showed that high levels of plasma tPA-activity and low levels of PAI-1 were cross-sectionally associated with extensive WMH in lacunar stroke patients (7). The aim of this study was to determine whether plasma tPA-activity and PAI-1 levels are associated with WMH progression.

\section{Methods}

\section{Ethics statement}

The study was approved by the medical ethics committee of the University Hospital Maastricht and Maastricht University (METC azM / UM). All patients gave written informed consent.

\section{Patients}

At baseline 149 first-ever lacunar stroke patients were included consecutively from a prospective ongoing lacunar stroke project as described before (7). Brain MRI and tPA-activity and PAI-1-antigen measurements were obtained at baseline. Patients with extensive vascular comorbidity, vasculitis and systemic lupus erythematosus, which can influence levels of tPA-activity and PAI-1, were excluded. Patients were offered a clinical brain MRI after 2 years of follow-up.

\section{MRI acquisition}

MR images were obtained with a1.5 Tesla (T) or 3T MRI scanner (Philips). For this study standard axial T2-weighted fast spin echo and fluid attenuated inversion recovery sequences were used. Scanning parameters were unchanged between baseline and follow-up.

Baseline MR images were obtained at a median of 30 days (interquartile range (IQR) 8-76 days) after the stroke event. Follow-up MR images were performed 2 years after the baseline imaging (median 25, IQR 24 - 26 months). 


\section{Baseline MRI scoring}

The presence of WMH at baseline was assessed using Fazekas scale. Presence of extensive white matter hyperintensities (WMH) was defined as T2-weighted (early) confluent deep hyperintensities (dWMH) (Fazekas 2 and 3) or irregular periventricular hyperintensities (pWMH) extending into the deep white matter (Fazekas 3) (8). These Fazekas scores are histopathologically related cSVD (9).

\section{Follow-up MRI scoring}

The WMH change scale as proposed by Prins et al. was used to assess progression of WMH on follow-up MRI (10). This scale enables to score white matter changes in three periventricular regions (frontal caps, lateral bands and occipital caps) and four deep regions (frontal, parietal, temporal, occipital). Increase of $\mathrm{WMH}$ in a region (+1) was defined as new lesions or increase of existing lesion. This adds up to a progression score ranging from -3 to +3 in periventricular regions and -4 to +4 in deep regions. WMH progression in the study was defined as a score $\geq 1$. Two experienced vascular neurologists, who were blinded for baseline levels of tPA-activity and PAI-1, independently assessed WMH progression. In case of disagreement a consensus meeting was held. The inter-rater agreement, expressed by Cohen's kappa ( $\mathrm{k}$ ), was substantial for total progression at follow-up (0.62).

\section{tPA-activity and PAI-1}

\section{Samples}

At baseline, but at least 3 months after the acute ischemic event, fasting blood samples were drawn in all patients by venepuncture of a vein in the antecubital fossa. Because the levels of tPA-activity and PAI-1 are characterized by diurnal variation, samples were drawn between 8:30 a.m. and 10:00 a.m. in all patients. Prescribed medication including antiplatelet agents and statins were continued at time of blood withdrawal. The first tube was discarded to minimize puncture-related coagulation activation. Consecutively the blood was divided over a tube containing citrate anticoagulant at low $\mathrm{pH}$ (to prevent formation of tPA-PAl-1 complex and preserving components of the fibrinolytic system; Stabilyte tube; Biopool) and a tube containing $3.2 \%$ sodium citrate. Platelet-poor plasma was prepared by a 2 -step centrifugation process ( 5 minutes at $2000 \mathrm{~g}$ and 10 minutes at $11000 \mathrm{~g}$ at room temperature). Plasma aliquots were stored at $-80^{\circ} \mathrm{C}$ and defrosted at $37^{\circ} \mathrm{C}$ before analysis. 


\section{Laboratory Assays}

A chromolize tPA kit (Biopool) was used to determine tPA-activity. PAI-1 antigen levels were measured by TECHNOZYM PAI-1 antigen enzyme-linked immunosorbant assay reagent kit by Technoclone (commercially available). The coefficients of variation for tPA-activity and PAI- 1 was $<10 \%$ and $3 \%$ to $10 \%$, respectively.

\section{Statistical analysis}

Statistical analyses were performed using IBM SPSS Statistics 21. Differences between groups were determined using $\chi^{2}$-test, $t$ test, or Mann-Whitney test, where appropriate. Categorical variables are presented as frequencies (\%), normally distributed data as mean \pm SD and variables with skewed distributions are presented as median and interquartile ranges.

We assessed the relationship between plasma levels of tPA-activity and levels of PAI1 (independent variables) and WMH progression (dependent variable) by binary logistic regression analysis adjusted for age and sex. We performed three separate analyses: pWMH progression, dWMH progression and progression of $\mathrm{WMH}$ in any (periventricular and/or deep) region respectively. In additional exploratory analyses we adjusted for cardiovascular risk factors (hypertension, diabetes mellitus, hypercholesterolemia and current smoking), 24-hour mean arterial pressure (MAP) at follow-up and presence of extensive deep or periventricular WMH at baseline by adding them one at a time to the model.

Odds ratios (OR) are given with 95\% confidence interval (Cl). Statistical significance was considered at $P<0.05$.

\section{Results}

\section{Patients}

Of 149 included first-ever lacunar stroke patients at baseline, follow-up MRI at 2 years (mean $25.2 \pm 2.2$ months) was obtained in 132 patients. Two patients died of non-neurological cause and 15 patients had no follow-up MRI. Another 5 patients were excluded because of inadequate scan data, leaving 127 (85.2\%) patients in our analyses. Baseline characteristics of these patients are presented in table 1 . Any (periventricular and/or deep) WMH progression was present in 61 (48\%) patients. Patients with WMH progression were significantly older and had more extensive WMH at baseline. Thirthy-three (26\%) patients had pWMH progression and 50 (39\%) had dWMH progression. 


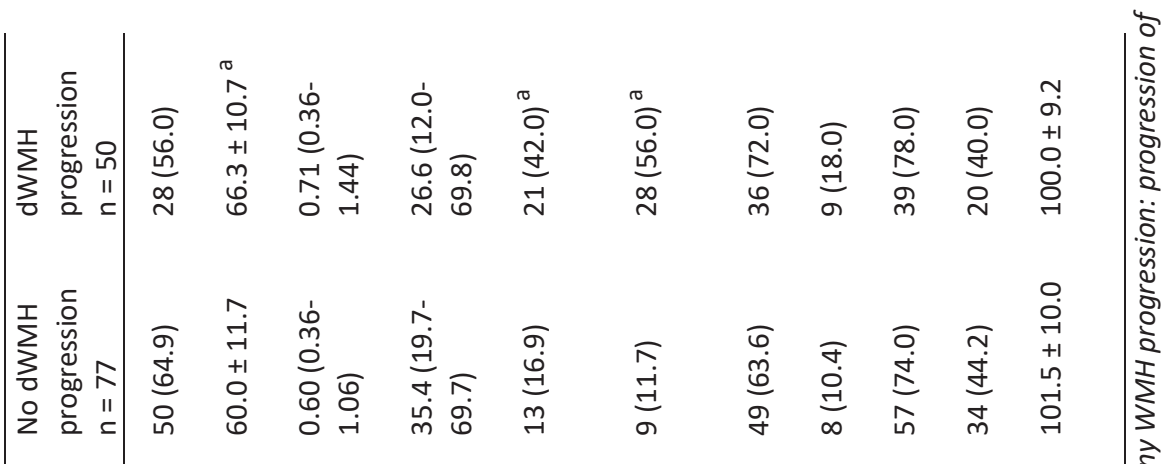

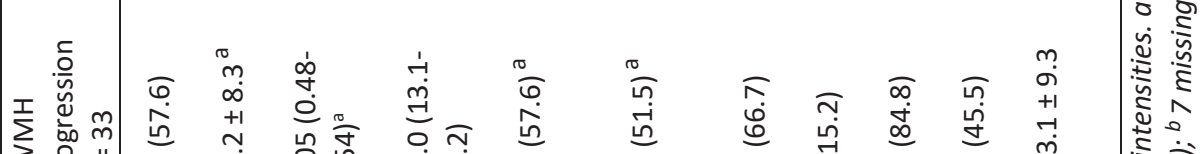

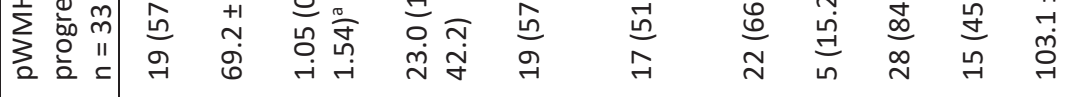

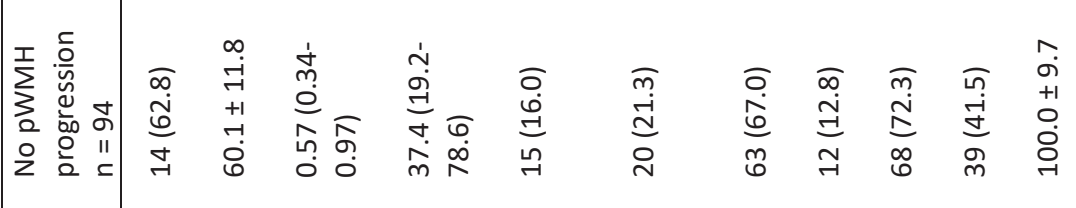



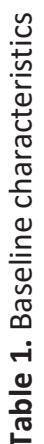

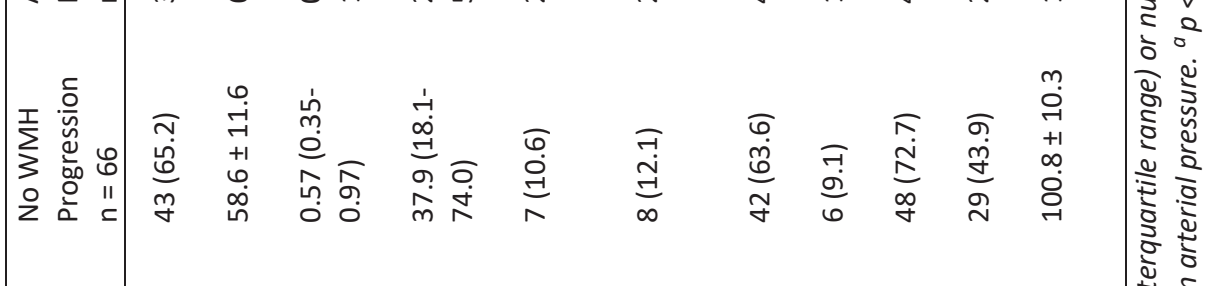

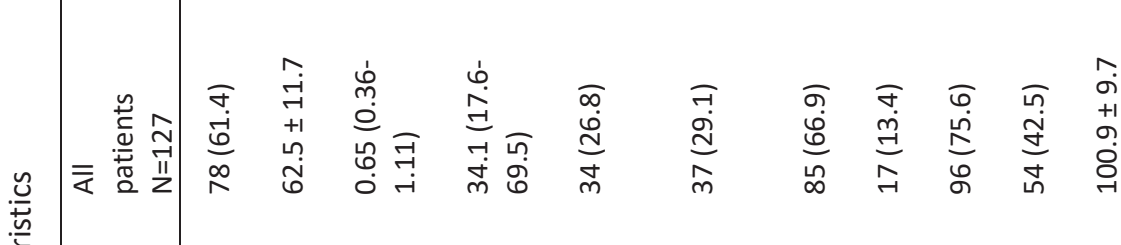

竞离

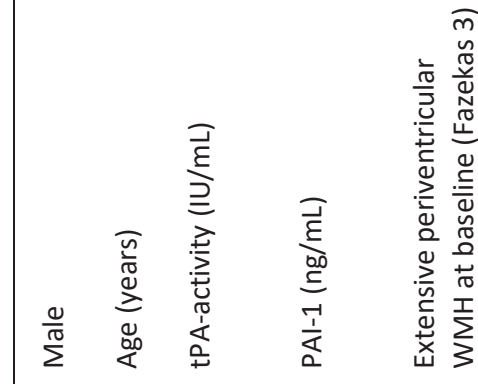

mats

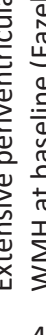

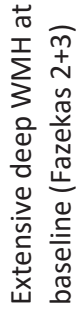

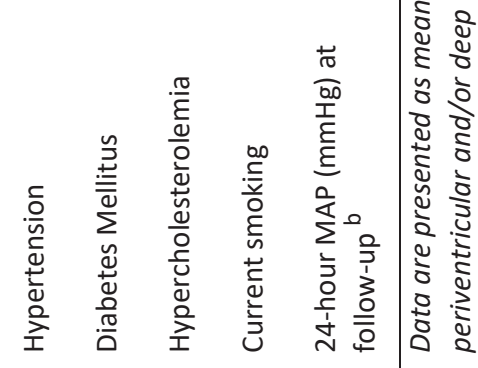




\section{WMH progression and tPA-activity and PAI-1}

Plasma tPA-activity was higher in patients with pWMH progression compared to those without (Table 1). In logistic regression analyses with correction for age and sex, tPA-activity was associated with pWMH progression (OR 2.55, 95\% CI 1.14-5.71, table 2). Correction for age, sex and 24-hour MAP also gave a significant association between tPA-activity and pWMH progression (OR 2.34, 95\% $\mathrm{Cl} 1.03-5.34$ ), and the results were similar with correction for sex, age and any of the cardiovascular risk factors (including hypertension), as well as with correction for age, sex and the presence of extensive pWMH at baseline (OR 2.36, 95\% CI 1.01-5.49). Plasma tPAactivity was also associated to any (periventricular and/or deep) WMH progression and dWMH progression. However, in regression analyses with adjustment for sex and age there was no significant association between plasma tPA-activity and dWMH or any (periventricular and/or deep) WMH progression. PAl-1 levels were (not significantly) lower in patients with WMH progression compared to those without progression (Table 1). However there was no significant association between PAI-1 levels and WMH progression in regression analysis (Table 2).

Table 2. Binary logistic regression analysis with progression of white matter hyperintensities as dependent variable

\begin{tabular}{lllllll}
\hline & $\begin{array}{l}\text { Any WMH } \\
\text { progression }\end{array}$ & & $\begin{array}{l}\text { Periventricular } \\
\text { WMH } \\
\text { progression }\end{array}$ & & \multicolumn{2}{c}{$\begin{array}{l}\text { Deep WMH } \\
\text { progression }\end{array}$} \\
\hline & Unadjusted & $\begin{array}{l}\text { Adjusted } \\
\text { for sex and } \\
\text { age }\end{array}$ & Unadjusted & $\begin{array}{l}\text { Adjusted for } \\
\text { sex and age }\end{array}$ & Unadjusted & $\begin{array}{l}\text { Adjusted for } \\
\text { sex and age }\end{array}$ \\
& & & & & \\
\hline tPA- & $2.38(1.18-$ & $1.89(0.89-$ & $3.10(1.47-$ & $2.55(1.14-$ & $2.16(1.09-$ & $1.77(0.86-$ \\
activity & $4.81)^{\mathrm{a}}$ & $4.02)$ & $6.54)^{\mathrm{a}}$ & $5.71)^{\mathrm{a}}$ & $4.29)^{\mathrm{a}}$ & $3.65)$ \\
$(\mathrm{IU} / \mathrm{mL})$ & & & & & & \\
PAl-1 & $1.00(0.99-$ & $1.00(0.99-$ & $0.99(0.98-$ & $1.00(0.98-$ & $1.00(0.99-$ & $1.00(0.99-$ \\
$(\mathrm{ng} / \mathrm{mL})$ & $1.00)$ & $1.00)$ & $1.00)$ & $1.00)$ & $1.00)$ & $1.01)$ \\
\hline
\end{tabular}

All results are presented as OR $(95 \% \mathrm{Cl})$. WMH: White matter hyperintensities. Any WMH progression: periventricular and/or deep WMH progression. ${ }^{a} p<0.05$

\section{Discussion}

We found that higher baseline plasma tPA-activity was associated with progression of pWMH after 2 years of follow-up in lacunar stroke patients. Our results are in concordance with our previous cross-sectional findings (7). Until now, longitudinal studies on the relation between TPA and WMH were lacking.

Endothelial cells are a source of plasma tPA (11). It has been proposed that increased levels of plasma tPA-activity may reflect increased endothelial activation state, or 
endothelial dysfunction (1-4). Endothelial dysfunction is thought to be an important initiating cause of cSVD, resulting in WMH (5). Moreover, endothelial dysfunction in cSVD is considered not to be an isolated process in the brain, but a general systemic microvascular dysfunction (12). SVD in the brain has been associated with SVD in other organs such as kidneys and retinal vessels (12). cSVD has also been associated with other plasma markers for endothelial dysfunction $(1,13)$.

Although hypothesized before by others that tPA-activity might be regarded as a marker of (systemic) endothelial activation linked to cSVD, our study cannot show whether the association between progression of $\mathrm{WMH}$ and plasma tPA-activity is the result of endothelial activation and one can only speculate about it. Other factors besides endothelial dysfunction may also influence plasma tPA-activity. These include inflammation, seasonal variation, tPA gene polymorphisms and others (11). These factors could also be involved in the link between tPA and cSVD.

Reflecting on the association between TPA and CSVD, we might also consider the local effect: tPA is locally expressed within the brain and release of tPA in the neurovascular unit may induce increased permeability of the blood-brain barrier (1416). This may promote leakage of plasma components into the perivascular space and damage of the white matter $(5,17)$. However, it is unclear whether plasma levels of tPA-activity reflect local concentrations within the brain parenchyma and the microvasculature of the brain. Also, the effects of tPA in the brain are multiple $(14,18)$ and there are also data that suggest that neuronal released tPA has a neuroprotective role (14). In animal studies, it was shown that tPA expression in the white matter is decreased with aging and this was accompanied by an increased vulnerability of the white matter to ischemic damage (19). Furthermore, as once said, we only found an association between plasma tPA-activity and progression of pWMH and cannot conclude anything on cause-effect relationships.

Few other studies reported on the association between TPA and CSVD. We found earlier that plasma tPA-activity was higher in lacunar stroke patients with WMH compared to patients without WMH (7). Also, plasma tPA was found to be higher in lacunar (small vessel) stroke patients compared to non-stroke individuals (1). A tPA gene polymorphism has been associated with lacunar stroke subtype (20). Higher levels of plasma tPA have also been found in other cardiovascular diseases or risk factors, such as in diabetes (21), myocardial infarction (22) and familial hyperlipidemia (23).

Next to the association between pWMH and plasma tPA-activity, we also found an association between plasma tPA-activity and dWMH, however these results lost significance after correction for sex and age. Perhaps the effect is small and a larger population is needed to confirm an association. On the other hand, several studies 
report different neuropathological findings, risk factors and rates of progression between $\mathrm{dWMH}$ and $\mathrm{pWMH}$, which could indicate differences in underlying pathophysiology (24). Also, presence or progression of $\mathrm{pWMH}$, but not dWMH, has been related to cognitive decline (24).

Although we found plasma PAI-1 levels to be lower in patient with progression of $\mathrm{WMH}$, these results were not significant. PAI-1inhibits tPA-activity and it is also hypothesized that PAI-1 may play a role in maintaining the blood-brain barrier by directly enhancing endothelial tight junction properties $(25,26)$.

Our study has some limitations. Plasma tPA-activity and PAI-1-antigen levels were only measured once at baseline. However, a previous study found that the plasma levels of tPA and PAI-1 did not significantly change over time in stroke patients (27). Furthermore, blood was drawn after the acute stroke phase as we were not aiming to measure results of acute ischemic injury. Secondly, MR imaging was performed on a 1.5T or a 3T scanner. In most patients $(106,83.5 \%)$, baseline and follow-up scans were performed on the same type of scanner. In 21 (16.5\%) patients a 3T baseline and 1.5T follow-up scan was done, which could have led to underestimation of WMH progression. Finally, we did not use volumetric WMH measurements, nonetheless we used a visual $\mathrm{WMH}$ change scale known to be highly correlated to changes in $\mathrm{WMH}$ volume $(10,28)$.

\section{Conclusions}

We found a relationship between plasma tPA-activity and pWMH progression in firstever lacunar stroke patients. More research is needed to determine whether there is a (direct) role of tPA in the development and progression of $\mathrm{WMH}$. 


\section{References}

1. Wiseman S, Marlborough F, Doubal F, Webb DJ, Wardlaw J. Blood Markers of Coagulation, Fibrinolysis, Endothelial Dysfunction and Inflammation in Lacunar Stroke versus Non-Lacunar Stroke and Non-Stroke: Systematic Review and Meta-Analysis. Cerebrovascular diseases. 2014;37(1):64-75. PubMed PMID: 24401164.

2. Barac A, Campia U, Panza JA. Methods for evaluating endothelial function in humans. Hypertension. 2007 Apr;49(4):748-60. PubMed PMID: 17309954.

3. Lowe GD, Danesh J, Lewington S, Walker M, Lennon L, Thomson A, et al. Tissue plasminogen activator antigen and coronary heart disease. Prospective study and meta-analysis. European heart journal. 2004 Feb;25(3):252-9. PubMed PMID: 14972427.

4. Wannamethee SG, Sattar N, Rumley A, Whincup PH, Lennon L, Lowe GD. Tissue plasminogen activator, von Willebrand factor, and risk of type 2 diabetes in older men. Diabetes care. 2008 May;31(5):995-1000. PubMed PMID: 18235054.

5. Wardlaw JM, Smith C, Dichgans M. Mechanisms of sporadic cerebral small vessel disease: insights from neuroimaging. Lancet Neurol. 2013 May;12(5):483-97. PubMed PMID: 23602162. Pubmed Central PMCID: 3836247.

6. Kuo HK, Lipsitz LA. Cerebral white matter changes and geriatric syndromes: is there a link? The journals of gerontology Series A, Biological sciences and medical sciences. 2004 Aug;59(8):818-26. PubMed PMID: 15345732.

7. Knottnerus IL, Govers-Riemslag JW, Hamulyak K, Rouhl RP, Staals J, Spronk HM, et al. Endothelial activation in lacunar stroke subtypes. Stroke; a journal of cerebral circulation. 2010 Aug;41(8):1617-22. PubMed PMID: 20595673.

8. Fazekas F, Chawluk JB, Alavi A, Hurtig HI, Zimmerman RA. MR signal abnormalities at $1.5 \mathrm{~T}$ in Alzheimer's dementia and normal aging. AJR American journal of roentgenology. 1987 Aug;149(2):351-6. PubMed PMID: 3496763.

9. Fazekas F, Kleinert R, Offenbacher H, Schmidt R, Kleinert G, Payer F, et al. Pathologic correlates of incidental MRI white matter signal hyperintensities. Neurology. 1993 Sep;43(9):1683-9. PubMed PMID: 8414012.

10. Prins ND, van Straaten EC, van Dijk EJ, Simoni M, van Schijndel RA, Vrooman HA, et al. Measuring progression of cerebral white matter lesions on MRI: visual rating and volumetrics. Neurology. 2004 May 11;62(9):1533-9. PubMed PMID: 15136677.

11. Kruithof EK, Dunoyer-Geindre S. Human tissue-type plasminogen activator. Thrombosis and haemostasis. 2014 Aug;112(2):243-54. PubMed PMID: 24718307.

12. Thompson CS, Hakim AM. Living beyond our physiological means: small vessel disease of the brain is an expression of a systemic failure in arteriolar function: a unifying hypothesis. Stroke; a journal of cerebral circulation. 2009 May;40(5):e322-30. PubMed PMID: 19228835.

13. Markus HS, Hunt B, Palmer K, Enzinger C, Schmidt H, Schmidt R. Markers of endothelial and hemostatic activation and progression of cerebral white matter hyperintensities: longitudinal results of the Austrian Stroke Prevention Study. Stroke; a journal of cerebral circulation. 2005 Jul;36(7):1410-4. PubMed PMID: 15905468.

14. Yepes M. Tissue-type plasminogen activator is a neuroprotectant in the central nervous system. Frontiers in cellular neuroscience. 2015;9:304. PubMed PMID: 26347605. Pubmed Central PMCID: 4538299.

15. Kidwell CS, Latour L, Saver JL, Alger JR, Starkman S, Duckwiler G, et al. Thrombolytic toxicity: blood brain barrier disruption in human ischemic stroke. Cerebrovascular diseases. 2008;25(4):338-43. PubMed PMID: 18303253.

16. Yepes M, Sandkvist M, Moore EG, Bugge TH, Strickland DK, Lawrence DA. Tissue-type plasminogen activator induces opening of the blood-brain barrier via the LDL receptorrelated protein. The Journal of clinical investigation. 2003 Nov;112(10):1533-40. PubMed PMID: 14617754. Pubmed Central PMCID: 259131. 
17. Huisa BN, Caprihan A, Thompson J, Prestopnik J, Qualls CR, Rosenberg GA. Long-Term BloodBrain Barrier Permeability Changes in Binswanger Disease. Stroke; a journal of cerebral circulation. 2015 Sep;46(9):2413-8. PubMed PMID: 26205374. Pubmed Central PMCID: 4550546.

18. Docagne F, Parcq J, Lijnen R, Ali C, Vivien D. Understanding the functions of endogenous and exogenous tissue-type plasminogen activator during stroke. Stroke; a journal of cerebral circulation. 2015 Jan;46(1):314-20. PubMed PMID: 25395410.

19. Correa F, Gauberti M, Parcq J, Macrez R, Hommet Y, Obiang P, et al. Tissue plasminogen activator prevents white matter damage following stroke. The Journal of experimental medicine. 2011 Jun 6;208(6):1229-42. PubMed PMID: 21576385. Pubmed Central PMCID: 3173251.

20. Tuttolomondo A, Di Raimondo D, Forte GI, Casuccio A, Vaccarino L, Scola L, et al. Single nucleotide polymorphisms (SNPs) of pro-inflammatory/anti-inflammatory and thrombotic/fibrinolytic genes in patients with acute ischemic stroke in relation to TOAST subtype. Cytokine. 2012 Jun;58(3):398-405. PubMed PMID: 22425140.

21. Hernestal-Boman J, Norberg M, Jansson JH, Eliasson M, Eriksson JW, Lindahl B, et al. Signs of dysregulated fibrinolysis precede the development of type 2 diabetes mellitus in a population-based study. Cardiovascular diabetology. 2012;11:152. PubMed PMID: 23249721. Pubmed Central PMCID: 3538597.

22. Tzoulaki I, Murray GD, Lee AJ, Rumley A, Lowe GD, Fowkes FG. Relative value of inflammatory, hemostatic, and rheological factors for incident myocardial infarction and stroke: the Edinburgh Artery Study. Circulation. 2007 Apr 24;115(16):2119-27. PubMed PMID: 17404162.

23. Karasek D, Vaverkova H, Halenka M, Slavik L, Novotny D. Endothelial haemostatic markers in members of families with familial combined hyperlipidemia. Thrombosis research. 2009;123(3):466-75. PubMed PMID: 18417194.

24. Schmidt R, Schmidt H, Haybaeck J, Loitfelder M, Weis S, Cavalieri M, et al. Heterogeneity in age-related white matter changes. Acta neuropathologica. 2011 Aug;122(2):171-85. PubMed PMID: 21706175.

25. Tjarnlund-Wolf A, Brogren $\mathrm{H}$, Lo EH, Wang X. Plasminogen activator inhibitor-1 and thrombotic cerebrovascular diseases. Stroke; a journal of cerebral circulation. 2012 Oct;43(10):2833-9. PubMed PMID: 22879095. Pubmed Central PMCID: 3712849.

26. Dohgu S, Takata F, Matsumoto J, Oda M, Harada E, Watanabe T, et al. Autocrine and paracrine up-regulation of blood-brain barrier function by plasminogen activator inhibitor-1. Microvascular research. 2011 Jan;81(1):103-7. PubMed PMID: 21036181.

27. Lindgren A, Lindoff C, Norrving B, Astedt B, Johansson BB. Tissue plasminogen activator and plasminogen activator inhibitor-1 in stroke patients. Stroke; a journal of cerebral circulation. 1996 Jun;27(6):1066-71. PubMed PMID: 8650716.

28. Gouw AA, van der Flier WM, van Straaten EC, Pantoni L, Bastos-Leite AJ, Inzitari D, et al. Reliability and sensitivity of visual scales versus volumetry for evaluating white matter hyperintensity progression. Cerebrovascular diseases. 2008;25(3):247-53. PubMed PMID: 18216467. 



\section{Chapter 4}

\section{Vitamin B12 and progression of white matter lesions \\ A 2-year follow-up study in first- ever lacunar stroke patients}

Ellen C. van Overbeek ${ }^{1}$, Julie Staals ${ }^{1,2}$, Robert J. van Oostenbrugge $e^{1,2}$

${ }^{1}$ Department of Neurology, Maastricht University Medical Centre (MUMC), Maastricht, the Netherlands; ${ }^{2}$ Cardiovascular Research Institute Maastricht, MUMC, Maastricht, the Netherlands 


\section{Abstract}

Background - In cross-sectional studies periventricular white matter hyperintensities (WMH) were related to low plasma levels of vitamin B12. Whether low vitamin B12 levels are also related to progression of $\mathrm{WMH}$ is still unknown. We studied baseline vitamin B12 levels and its association with progression of WMH over 2 years of follow-up in first-ever lacunar stroke patients.

Methods - In 107 first-ever lacunar stroke patients in whom baseline brain MRI and vitamin B12 status were available, we obtained a follow-up brain MRI after 2 years. We assessed progression of periventricular WMH (pWMH) and deep WMH (dWMH) using a visual WMH change scale. We studied the relationship between baseline levels of plasma vitamin B12 and progression of WMH after 2 years of follow-up by binary logistic regression analyses.

Results - Vitamin B12 deficiency was more frequent in patients with progression of pWMH compared to those without progression $(41.9 \%$ and $19.7 \%$ respectively, $p=$ 0.02). Corrected for sex and age, progression of pWMH was associated with lower baseline levels of vitamin B12 (OR 1.42 per 50 unit decrease, $95 \% \mathrm{Cl} 1.00-1.92$ ). Vitamin B12 levels were not associated with progression of dWMH.

Conclusions - In conclusion, progression of pWMH after 2 years of follow-up relates to low levels of vitamin B12 at baseline in first-ever lacunar stroke patients. Whether this population could benefit from vitamin B12 supplementation is unknown and requires further investigation. 


\section{Introduction}

Lacunar infarcts and white matter hyperintensities (WMH) are common features of cerebral small vessel disease (CSVD) $(1,2)$. Derangement of the blood-brain barrier (BBB) is thought to be an important underlying initiating cause of CSVD $(1,2)$. One of the factors that may play a role in maintaining the integrity of the BBB is vitamin B12 (3-5).

In a cross-sectional population-based study vitamin B12 status was associated with severity of periventricular $\mathrm{WMH}$ ( $\mathrm{pWMH}$ ) and, to a lesser extent, also with deep $\mathrm{WMH}$ (dWMH) (6). Furthermore, we found pWMH to be related to low vitamin B12 levels in patients with small vessel (i.e. lacunar) stroke (7). However the association between vitamin B12 and WMH has not yet been confirmed in longitudinal studies. Progression of $\mathrm{WMH}$ is associated with gait abnormalities, cognitive impairment and urinary disturbances, and therefore it could be important to identify associated factors that may be treatable $(8,9)$.

The aim of this study was to determine whether low levels of vitamin B12 are related to progression of WMH over 2 years of follow-up in lacunar stroke patients to further confirm a cause-and-effect relationship.

\section{Methods}

\section{Ethics statement}

Data were collected from a substudy of an ongoing lacunar stroke project that was approved by the local medical ethical committee (METC, Maastricht). All patients gave written informed consent.

\section{Patients}

At baseline we included 124 first-ever lacunar stroke patients of whom vitamin B12 levels and brain MRI were available, as described before (7). We defined lacunar stroke as an acute stroke syndrome with a compatible, small, deep infarct on MRI. In case MR imaging showed no symptomatic lesion, lacunar stroke was defined using the established criteria of specific lacunar syndromes (10). Patients with potential cardiac embolic source of stroke or carotid stenosis were not included. At baseline vascular risk factors such as age, sex, diabetes mellitus, current smoking, total cholesterol level $>5.0 \mathrm{mmol} / \mathrm{l}$ and hypertension (based on patients medical history at admission) were recorded. All patients were offered a clinical follow-up MRI after 2 years as well as 24-hour ambulatory blood pressure monitoring. 


\section{MRI scoring}

MR images at baseline and follow-up were obtained with a 1.5 Tesla (T) or 3 T MR scanner (Philips) and consisted of axial T2 weighted and FLAIR sequence with fixed scanning parameters that were unchanged between baseline and follow-up. A symptomatic lacunar infarct was defined as a hyperintense lesion of $<20 \mathrm{~mm}$ in diameter on T2 and FLAIR images, with its site compatible to the clinical syndrome. DWI was not part of the scan protocol at that time. Asymptomatic lacunar infarcts were defined as hyperintense lesions on T2 images with corresponding hypo-intense lesions with a hyperintense rim on FLAIR and a diameter of $<20 \mathrm{~mm}$. Baseline MRI was scored for pWMH and dWMH using the Fazekas scale (11). We defined the presence of pWMH as Fazekas scale 3 (irregular periventricular hyperintensities extending into the deep white matter). The presence of dWMH was defined as (early) confluent deep WMH, Fazekas scale 2 or 3 . These Fazekas scores are histopathologically related to cerebral SVD $(12,13)$.

WMH progression on follow-up MRI was scored using the WMH change scale as proposed by Prins et al (14). This scale scores white matter changes in three periventricular regions (frontal caps, lateral bands and occipital caps) and four deep regions (frontal, parietal, temporal, occipital). Increase of WMH was defined as new lesions or increase of existing lesions. In each region we assessed whether there was an increase in $\mathrm{WMH}(+1)$, or no change in $\mathrm{WMH}(0)$. Although not seen in our cohort, a decrease in WMH (-1) could also be scored, adding up to a total score ranging from -3 to +3 in periventricular regions and -4 to +4 in deep regions. Progression was defined as a total periventricular score $\geq 1$ or a total deep score $\geq 1$ (14). The WMH progression was assessed by two vascular neurologists, who were blinded for vitamin B12 status, independently. The inter-rater agreement for total progression was



\section{Vitamin B12}

Blood samples were taken within 3 months after stroke. Plasma levels of vitamin B12 at baseline were assayed using a solid-phase time-resolved fluoroimmunoassay on an Auto Delfia immunoanalyser (PerkinElmer) as described elsewhere (7). Vitamin B12 level > $150 \mathrm{pmol} / \mathrm{L}$ was defined as normal (7).

\section{Statistical analysis}

Statistical analysis was performed using PASW Statistics 18. Differences between groups were determined using $\chi^{2}$-test, $t$ test, or Mann-Whitney test, where appropriate. We assessed the relationship between low levels of plasma vitamin B12 at baseline (independent factor) and progression of WMH at 2-years follow-up 
(dependent factor) by binary logistic regression analysis adjusted for age and sex. Furthermore we performed additional exploratory analyses in which we adjusted for cardiovascular risk factors (hypertension, diabetes mellitus, hypercholesterolemia and current smoking), 24-hour mean arterial pressure (MAP) at follow-up and presence of extensive deep or periventricular $\mathrm{WMH}$ at baseline by adding them one at a time to the model. Odds ratios (OR) are given with $95 \%$ confidence interval $(\mathrm{Cl})$. Statistical significance was considered at $P<0.05$.

\section{Results}

\section{Patients}

Of 124 included first-ever lacunar stroke patients at baseline, a 2-year follow-up MRI (mean $24.9 \pm 1,8$ months) was obtained in 110 as 3 patients declined a follow-up MRI, 2 patients died (of non-neurological cause) and 9 patients were lost to follow-up. Another 3 patients were excluded because of inadequate scan data, leaving 107 (86.3\%) patients for further analysis. Characteristics of patients who were not included in follow-up were comparable to those of the included patients concerning age, sex and baseline vitamin B12 levels. Extensive WMH (both pWMH and dWMH) at baseline were slightly more frequent in patients who were not included. Eighty-seven patients were scanned at an 1.5 T MRI scanner both at baseline and follow-up. Baseline MR was performed at a 3 T scanner in 20 patients, and at follow-up 18 of these patients were scanned at an $1.5 \mathrm{~T}$ scanner and 2 patients were scanned at a $3 \mathrm{~T}$ scanner.

Baseline characteristics of all 107 patients are presented in table 1 . Mean vitamin B12 level was $208 \mathrm{pmol} / \mathrm{L}( \pm 82$ ) and 28 patients (26.2\%) had vitamin B12 level < $150 \mathrm{pmol} / \mathrm{L}$. Patients with low levels of vitamin B12 did not routinely receive supplementation, however 2 patients received treatment sometime within the 2-year follow-up period, resulting in vitamin B12 levels above 300 pmol/L. Thirty-one patients (29.0\%) had extensive pWMH (Fazekas 3) at baseline and 33 patients $(30.8 \%)$ had extensive dWMH (Fazekas $2+3$ ) at baseline.

\section{Progression of WMH}

Progression of pWMH was seen in 31 patients (29.0\%) and progression of dWMH was seen in 42 patients (39.3\%). Patients with WMH progression at follow-up were significantly older compared to patients with no progression (68.1 \pm 9.5 vs. $59.1 \pm$ 12.2 years old, $\mathrm{p}<0.01$ ). In patients with progression of $\mathrm{pWMH}$ at follow-up extensive pWMH (fazekas 3 ) at baseline was more frequent compared to patients without pWMH progression (18 (58.1\%) vs. $13(17.1 \%), p<0.01)$. Also in patients with 


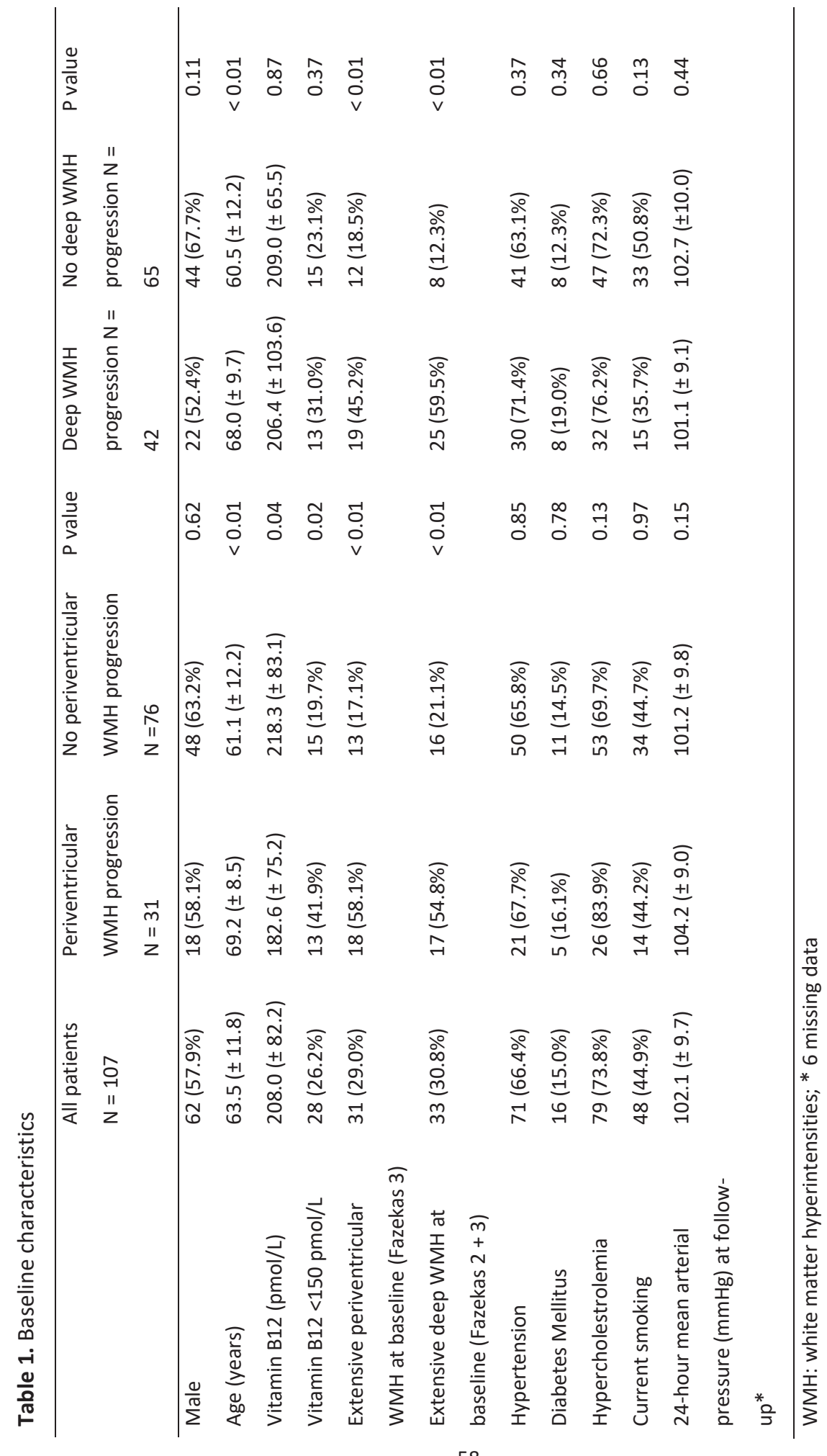


progression of dWMH, extensive dWMH (fazekas $2+3$ ) at baseline was more frequent compared to patients without dWMH (25 (59.5\%) vs. 8 (12.3\%), p < 0.01). At follow-up, blood pressure monitoring was performed in 101 patients (94.4\%). 24hours MAP values were not significantly higher in patients with $\mathrm{pWMH}$ or dWMH progression (table 1).

\section{Vitamin $B 12$ and progression of WMH}

Vitamin B12 plasma levels were significantly lower in patients who showed progression of pWMH and these patients also had more often vitamin B12 level $<150$ $\mathrm{pmol} / \mathrm{L}$ (table 1). Vitamin B12 levels did not differ between patients with or without dWMH progression.

In table 2 we present the results of logistic regression analyses. Lower baseline levels of plasma vitamin B12 were associated with progression of pWMH (OR 1.42 (per 50 $\mathrm{pmol} / \mathrm{L}$ decrease in vitamin $\mathrm{B} 12$ level), $95 \% \mathrm{Cl} 1.00-1.92)$. This association remained significant after correction for sex and age (OR 1.42 (per 50 pmol/L decrease in vitamin B12 level), 95\% Cl 1.05-2.02). Adding cardiovascular risk factors (not shown), 24-hour MAP at follow-up (OR 1.49, (per 50 pmol/L decrease in vitamin B12 level) 95\% $\mathrm{Cl}$ 1.11-2.13) and baseline presence of extensive pWMH (OR 1.49, (per 50 $\mathrm{pmol} / \mathrm{L}$ decrease in vitamin $\mathrm{B} 12$ level) $95 \% \mathrm{Cl} 1.05-2.13$ ) to the model one at a time provided similar results.

Table 2. Binary logistic regression analysis with progression of periventricular white matter hyperintensities as dependent factor

\begin{tabular}{llll}
\hline \multicolumn{3}{l}{ Progression of periventricular white matter hyperintensities } \\
\hline & Model 1: Unadjusted, & $\begin{array}{l}\text { Model 2: Adjusted for } \\
\text { sex and age, OR (95\% } \\
\text { Cl) }\end{array}$ & $\begin{array}{l}\text { Model 3: Adjusted for } \\
\text { sex, age and baseline } \\
\text { pWMH, OR (95\% Cl) }\end{array}$ \\
\hline $\begin{array}{l}\text { Vitamin B } 12 \text { level } \\
\text { (pmol/L decrease) }\end{array}$ & $1.01(1.00-1.01)^{*}$ & $1.01(1.00-1.01)^{*}$ & $1.01(1.00-1.02)^{*}$ \\
$\begin{array}{l}\text { Vitamin B12 level }(50 \\
\text { pmol/L decrease) }\end{array}$ & $1.42(1.00-1.92)^{*}$ & $1.42(1.05-2.02)^{*}$ & $1.49(1.05-2.13)^{*}$ \\
$\begin{array}{l}\text { Vitamin B12 <150 } \\
\text { pmol/L }\end{array}$ & $2.94(1.18-7.30)^{*}$ & $3.05(1.16-8.24)^{*}$ & $2.56(1.02-8.06)^{*}$ \\
\hline
\end{tabular}

${ }^{*} \mathrm{p}<0.05 . \mathrm{pWMH}$ : periventricular white matter hyperintensities. 
Vitamin B12 deficiency < $150 \mathrm{pmol} / \mathrm{L}$ was also associated with progression of $\mathrm{pWMH}$ (OR 2.94, 95\% Cl: 1.18-7.30). This association also remained after correction for sex and age (OR 3.05, 95\% 1.16-8.24) and after adding cardiovascular risk factors (not shown), 24-hour MAP at follow-up (OR 2.89, 95\% Cl 1.03-8.09) and baseline presence of extensive pWMH (OR 2.56, 95\% Cl 1.02-8.06) to the model. Progression of dWMH was not associated with absolute vitamin B12 level, nor with vitamin B12 < 150pmol/L.

\section{Discussion}

We found that low baseline plasma levels of vitamin B12 relate to progression of pWMH, but not dWMH, after 2 years of follow-up in patients with first-ever lacunar stroke.

Previous cross-sectional studies already showed that the severity of $\mathrm{pWMH}$, was related to low vitamin B12 levels, whereas dWMH were not $(6,7)$. These studies were done in patients with lacunar stroke and in a healthy population $(6,7)$. Our study is the first longitudinal study that explored the association between vitamin B12 level and progression of $\mathrm{WMH}$ and confirms the association between $\mathrm{pWMH}$ and vitamin B12.

The different results for pWMH and dWMH are intriguing. pWMH are thought to differ from dWMH in MRI appearance, underlying neuropathology and vascular supply $(12,13)$. Differences between $\mathrm{pWMH}$ and dWMH were also found concerning genetic and vascular risk factors, and progression rate $(12,13)$. This supports the idea that differences in pathophysiology may be present and seemingly the role of risk factors such as vitamin B12 may differ. It should be said however that the relatively small study sample size and the rather low prevalence of vitamin B12 deficiency in our study can not definitely rule out an association between low vitamin B12 levels and $\mathrm{dWMH}$ and the separation between deep and periventricular $\mathrm{WMH}$ still remains controversial.

The precise actions of vitamin B12 in the brain and in the pathophysiology of cerebral WMH still need to be illuminated. Effects of vitamin B12 are complex and mostly attributed to its role in lowering homocysteine levels (15-17). Hyperhomocysteinemia is related to both endothelial dysfunction and $\mathrm{WMH}(15,16)$. Unfortunately, we did not measure levels of homocysteine in our study. Nevertheless vitamin B12 also seems to effect the white matter beyond the homocysteine lowering effect $(3,18)$. It has been hypothesized that vitamin B12 directly affects myelin structure and function 
$(3,6,18)$. It may also be that vitamin B12 affects the integrity of the BBB. Dysfunction of the BBB is the most recent theory on the cause of cSVD-related $\mathrm{WMH}(1,2)$. Although structural BBB derangement has never been proven in vitamin B12 deficiency, it is possible that BBB permeability is increased at a functional level; while structural integrity is retained (3). In vitamin B12 deficient rats increased TNF-alpha and decreased IL-6 levels in the central nervous system have been found $(3,4)$. TNFalpha increases BBB permeability (19). In humans the cerebrospinal fluid / serum albumin ratio, which is considered to reflect the permeability of the $B B B$, was decreased in patients treated with vitamin B12-B6-folate combination (5).

Our results imply that patients with cSVD could benefit from supplementation of vitamin B12 to prevent further progression of WMH over time. In a subgroup analysis of the VISP trial it was found that B-vitamin therapy improved survival free of cardiovascular events in those patients with a non-disabling stroke who were more likely to respond to vitamin B12-supplementation (namely excluding those likely to have vitamin B12 malabsorption, those who received parenteral vitamin B12 and other vitamin B12 supplements, and those with renal failure)(20). A subgroup analysis of the VITATOPS trial, that studied the effect of B-vitamin in patients with recent stroke or TIA, suggested that vitamin B12 supplementation might reduce the risk of stroke in patients with lacunar stroke (21). In another substudy of the VITATOPS trial that assessed progression of WMH in patients with recent stroke or TIA, only those patients with severe cSVD (that is in patients with a Fazekas score of $\mathrm{dWMH} \geq 2$ and (acute or old) lacunes) at baseline, benefited from Bvitamin supplementation in terms that WMH progression was reduced (22). Within the VITATOPS trial however all patients received B-vitamin supplementation irrespectively of the initial serum levels of these vitamins. One might expect a greater effect of B-vitamin supplementation in patients with low levels of vitamin B12. Furthermore, higher dosage than used in both trials might be needed for optimal effects. In our study, patients with low levels of vitamin B12 did not routinely receive supplementation. Two patients with baseline levels of $102 \mathrm{pmol} / \mathrm{L}$ and $635 \mathrm{pmol} / \mathrm{L}$ respectively, received treatment sometime within the 2-year follow-up period. Despite treatment, both patients showed progression of WMH over time. Additional studies are needed to investigate whether supplementation of vitamin B12 may reduce progression of WMH in lacunar stroke patients with low levels of vitamin B12.

We found a rather high prevalence of vitamin B12 deficiency of $26.2 \%$ in our study population compared to previously reported prevalences, although ranges of 12 to 
$30 \%$ have been mentioned (23). Also one cannot rule out that vitamin B12 deficiency is more frequent in a population of patients with symptomatic small vessel disease compared to general stroke populations or community based populations.

In a general population study, high blood pressure levels preceded $\mathrm{WMH}$ progression and therefore blood pressure might be a confounder in the association between vitamin B12 and WMH progression (24). We adjusted our data for 24-hour MAP at follow-up which did not alter our results. This further strengthens our conclusions. However, it has to be said that adjusting for blood pressure levels at follow-up does not account for other factors such as blood pressure levels in the past, duration of hypertension, different drug classes that were used and changes in blood pressure levels.

Among the strengths of our study is a well-defined population of first-ever lacunar stroke patients. Considering the strict inclusion criteria this study was conducted in a reasonable sized population. However our study also has limitations. First, vitamin B12 was only measured once at baseline. Vitamin B12 levels may have altered over time and we cannot exclude that patients used over-the-counter vitamins. Secondly, plasma vitamin B12 may not be the most accurate marker to identify low intracellular concentrations of vitamin B12. Markers of vitamin B12 status are methyl malonic acid (MMA), total homocysteine (tHcy) and holotranscobalamin (HoloTC), which tests were not routinely performed in our study. However, in studies, using elevated levels of MMA as a gold standard, it has been shown that plasma vitamin B12 levels were adequate for identifying patients with functional vitamin B12 deficiency (25). One might consider differences in field strength of MRI (1.5T and 3T) to be a third limitation. In 89 patients, baseline and follow-up scans were performed on the same type of scanner (87 patients had 1.5T MRI at both baseline and follow-up, 2 patients had $3 \mathrm{~T}$ at baseline and follow-up). In 18 patients we compared $3 \mathrm{~T}$ baseline scan with a 1.5T follow-up scan. In these patients WMH progression could have been underestimated but not overestimated. However, Wardlaw et al. found no objective evidence that lesion detection is increased in 3T, and furthermore, repeating our main analysis in those 87 patients with both scans at 1.5T yielded largely unchanged conclusions (results not shown) (26). Fourthly we assessed the progression of WMH using a visual scale. Volumetric measurements were not available. The visual WMH change scale we used was found to be highly correlated to changes in white matter hyperintensities volume and it is the best alternative visual scale for measuring $\mathrm{WMH}$ progression $(14,27)$. Furthermore Diffusion-Weighted Imaging (DWI) was not routinely included in our baseline MRI protocol, so in some of our patients we could 
not identify or could have wrongly identified the symptomatic lacunar infarct. However, the strict clinical criteria for lacunar syndromes minimize the chance that we wrongly included a lacunar stroke. Finally we did not include any clinical outcome measure, but this was beyond the aim of our study. A larger scale, prospective study is needed to further confirm the clinical relevance of the association of progression of WMH and vitamin B12.

In conclusion, progression of pWMH at 2-years follow-up relates to low levels of vitamin B12 at baseline in first-ever lacunar stroke patients. Whether this welldefined population could benefit from vitamin B12 supplementation is yet unknown and requires further investigation. 


\section{References}

1. Wardlaw JM. Blood-brain barrier and cerebral small vessel disease. Journal of the neurological sciences. 2010 Dec 15;299(1-2):66-71. PubMed PMID: 20850797.

2. Farrall AJ, Wardlaw JM. Blood-brain barrier: ageing and microvascular disease--systematic review and meta-analysis. Neurobiology of aging. 2009 Mar;30(3):337-52. PubMed PMID: 17869382.

3. Scalabrino G. The multi-faceted basis of vitamin B12 (cobalamin) neurotrophism in adult central nervous system: Lessons learned from its deficiency. Progress in neurobiology. 2009 Jul;88(3):203-20. PubMed PMID: 19394404.

4. Gianazza E, Veber D, Eberini I, Buccellato FR, Mutti E, Sironi L, et al. Cobalamin (vitamin B12)deficiency-induced changes in the proteome of rat cerebrospinal fluid. The Biochemical journal. 2003 Aug 15;374(Pt 1):239-46. PubMed PMID: 12769818. Pubmed Central PMCID: 1223583.

5. Lehmann M, Regland B, Blennow K, Gottfries CG. Vitamin B12-B6-folate treatment improves blood-brain barrier function in patients with hyperhomocysteinaemia and mild cognitive impairment. Dementia and geriatric cognitive disorders. 2003;16(3):145-50. PubMed PMID: 12826740.

6. de Lau LM, Smith AD, Refsum H, Johnston C, Breteler MM. Plasma vitamin B12 status and cerebral white-matter lesions. Journal of neurology, neurosurgery, and psychiatry. 2009 Feb;80(2):149-57. PubMed PMID: 18977824.

7. Pieters B, Staals J, Knottnerus I, Rouhl R, Menheere P, Kessels A, et al. Periventricular white matter lucencies relate to low vitamin B12 levels in patients with small vessel stroke. Stroke; a journal of cerebral circulation. 2009 May;40(5):1623-6. PubMed PMID: 19286604.

8. Kuo HK, Lipsitz LA. Cerebral white matter changes and geriatric syndromes: is there a link? The journals of gerontology Series A, Biological sciences and medical sciences. 2004 Aug;59(8):818-26. PubMed PMID: 15345732.

9. Poggesi A, Gouw A, van der Flier W, Pracucci G, Chabriat H, Erkinjuntti T, et al. Cerebral white matter changes are associated with abnormalities on neurological examination in nondisabled elderly: the LADIS study. Journal of neurology. 2013 Apr;260(4):1014-21. PubMed PMID: 23180181.

10. Bamford J, Sandercock $P$, Jones $L$, Warlow $C$. The natural history of lacunar infarction: the Oxfordshire Community Stroke Project. Stroke; a journal of cerebral circulation. 1987 MayJun;18(3):545-51. PubMed PMID: 3590244.

11. Fazekas F, Chawluk JB, Alavi A, Hurtig HI, Zimmerman RA. MR signal abnormalities at $1.5 \mathrm{~T}$ in Alzheimer's dementia and normal aging. AJR American journal of roentgenology. 1987 Aug;149(2):351-6. PubMed PMID: 3496763.

12. Fazekas F, Kleinert R, Offenbacher H, Schmidt R, Kleinert G, Payer F, et al. Pathologic correlates of incidental MRI white matter signal hyperintensities. Neurology. 1993 Sep;43(9):1683-9. PubMed PMID: 8414012.

13. Schmidt R, Schmidt H, Haybaeck J, Loitfelder M, Weis S, Cavalieri M, et al. Heterogeneity in age-related white matter changes. Acta neuropathologica. 2011 Aug;122(2):171-85. PubMed PMID: 21706175.

14. Prins ND, van Straaten EC, van Dijk EJ, Simoni M, van Schijndel RA, Vrooman HA, et al. Measuring progression of cerebral white matter lesions on MRI: visual rating and volumetrics. Neurology. 2004 May 11;62(9):1533-9. PubMed PMID: 15136677.

15. Vermeer SE, van Dijk EJ, Koudstaal PJ, Oudkerk M, Hofman A, Clarke R, et al. Homocysteine, silent brain infarcts, and white matter lesions: The Rotterdam Scan Study. Ann Neurol. 2002 Mar;51(3):285-9. PubMed PMID: 11891822.

16. Hassan A, Hunt BJ, O'Sullivan M, Bell R, D'Souza R, Jeffery S, et al. Homocysteine is a risk factor for cerebral small vessel disease, acting via endothelial dysfunction. Brain : a journal of neurology. 2004 Jan;127(Pt 1):212-9. PubMed PMID: 14607791. 
17. Spence JD, Stampfer MJ. Understanding the complexity of homocysteine lowering with vitamins: the potential role of subgroup analyses. JAMA. 2011 Dec 21;306(23):2610-1. PubMed PMID: 22187282.

18. Scalabrino G. Cobalamin (vitamin B(12)) in subacute combined degeneration and beyond: traditional interpretations and novel theories. Experimental neurology. 2005 Apr;192(2):46379. PubMed PMID: 15755562.

19. Mayhan WG. Cellular mechanisms by which tumor necrosis factor-alpha produces disruption of the blood-brain barrier. Brain research. 2002 Feb 15;927(2):144-52. PubMed PMID: 11821008.

20. Spence JD, Bang H, Chambless LE, Stampfer MJ. Vitamin Intervention For Stroke Prevention trial: an efficacy analysis. Stroke; a journal of cerebral circulation. 2005 Nov;36(11):2404-9. PubMed PMID: 16239629.

21. VITATOPS Trial Study Group. B vitamins in patients with recent transient ischaemic attack or stroke in the VITAmins TO Prevent Stroke (VITATOPS) trial: a randomised, double-blind, parallel, placebo-controlled trial. Lancet Neurol. 2010 Sep;9(9):855-65. PubMed PMID: 20688574.

22. Cavalieri M, Schmidt R, Chen C, Mok V, de Freitas GR, Song S, et al. B vitamins and magnetic resonance imaging-detected ischemic brain lesions in patients with recent transient ischemic attack or stroke: the VITAmins TO Prevent Stroke (VITATOPS) MRI-substudy. Stroke; a journal of cerebral circulation. 2012 Dec;43(12):3266-70. PubMed PMID: 23093615.

23. Spence JD. Nutrition and stroke prevention. Stroke; a journal of cerebral circulation. 2006 Sep;37(9):2430-5. PubMed PMID: 16873712.

24. Verhaaren BF, Vernooij MW, de Boer R, Hofman A, Niessen WJ, van der Lugt A, et al. High blood pressure and cerebral white matter lesion progression in the general population. Hypertension. 2013 Jun;61(6):1354-9. PubMed PMID: 23529163.

25. Refsum H, Smith AD, Ueland PM, Nexo E, Clarke R, McPartlin J, et al. Facts and recommendations about total homocysteine determinations: an expert opinion. Clinical chemistry. 2004 Jan;50(1):3-32. PubMed PMID: 14709635.

26. Wardlaw JM, Brindle W, Casado AM, Shuler K, Henderson M, Thomas B, et al. A systematic review of the utility of 1.5 versus 3 Tesla magnetic resonance brain imaging in clinical practice and research. European radiology. 2012 Nov;22(11):2295-303. PubMed PMID: 22684343.

27. Gouw AA, van der Flier WM, van Straaten EC, Pantoni L, Bastos-Leite AJ, Inzitari D, et al. Reliability and sensitivity of visual scales versus volumetry for evaluating white matter hyperintensity progression. Cerebrovascular diseases. 2008;25(3):247-53. PubMed PMID: 18216467. 



\section{Chapter 5}

\section{Decreased kidney function is associated with progression of cerebral microbleeds in lacunar stroke patients}

Ellen C. van Overbeek ${ }^{1}$, Julie Staals ${ }^{1,2}$, Robert J. van Oostenbrugge ${ }^{1,2}$

${ }^{1}$ Department of Neurology, Maastricht University Medical Centre (MUMC), Maastricht, the Netherlands; ${ }^{2}$ Cardiovascular Research Institute Maastricht, MUMC, Maastricht, the Netherlands 


\begin{abstract}
Background - It is hypothesized that impaired kidney function and cerebral microbleeds (CMBs) represent microvascular damage in different organs. Several cross-sectional studies found impaired kidney function to be associated with the presence of CMBs. To further confirm the association between both small vessel diseases, we aimed to determine whether kidney function is related to progression of CMBs in a longitudinal study design.
\end{abstract}

Methods - In 89 lacunar stroke patients, baseline brain MRI (including gradient-echo images), baseline glomerular filtration rate (eGFR), blood pressure measurements, and follow-up brain MRI after 2 years were available. Presence of CMBs on baseline and follow-up MRI was scored visually. CMBs progression was defined as the presence of any new microbleed on follow-up MRI. The association between CMBs progression (dependent variable) and eGFR (independent variable) was assessed by logistic regression analysis.

Results - CMBs progression was present in 17 patients (19.1\%). Lower eGFR was associated with CMBs progression (OR 1.55 per $10 \mathrm{ml} / \mathrm{min} / 1.73 \mathrm{~m}^{2}$ decrease, $95 \% \mathrm{Cl}$ 1.05-2.30, with correction for sex and age). After additional correction for baseline presence of CMBs, or correction for cardiovascular risk factors, including blood pressure, this result remained significant.

Conclusions - In this longitudinal study, we found an independent association between lower eGFR and CMBs progression. CMBs and impaired kidney function are both seen as manifestations of microvascular organ damage and our findings further strengthen the association between both small vessel pathologies and also the assumption that small vessel disease could be considered a multi-system disorder. 


\section{Introduction}

The brain and kidneys are both susceptible for microvascular damage, probably due to their hemodynamic similarities $(1,2)$. Cerebral microbleeds (CMBs) are one of the important MRI manifestations of cerebral small vessel disease, whereas impaired kidney function, which can be measured by estimated glomerular filtration rate (eGFR), is considered to be a reflection of small vessel disease of the kidney $(1,2)$. Previously, several studies linked chronic kidney disease in (pre)dialysis patients to the presence of CMBs and in several cross-sectional studies in stroke patients, hypertensive patients and in the general population, impaired kidney function was associated with the presence of CMBs (3-13). Thus far, there are no longitudinal data on the relation between decreased kidney function and progression of CMBs. To strengthen the association between both small vessel pathologies, we performed a longitudinal study to determine if decreased kidney function was related to CMBs progression after two years of follow-up in lacunar stroke patients.

\section{Methods}

\section{Study design and setting}

This is a retrospective cohort study in lacunar stroke patients. Consecutive first-ever lacunar stroke patients participated, with informed consent, in a lacunar stroke research project, which was approved by the local medical ethical committee and performed according to the institutional guidelines. The patients were included from May 2003 to January 2008 from the Maastricht University Medical Center and the Orbis Medical Center, the Netherlands. For the present study, in short, we collected data of brain MRI and kidney function that were performed at baseline, and a followup MRI that was performed after 2 years.

\section{Participants}

Lacunar stroke was defined as an acute stroke syndrome with a compatible, small $(<20 \mathrm{~mm})$, deep infarct on brain MRI in pons, thalamus, internal capsula or basal ganglia. In case MRI showed no recent lesion we defined lacunar stroke clinically using the established criteria of lacunar stroke syndromes (14). To increase the likelihood that the lacunar syndrome had resulted from cerebral small vessel disease, patients with potential cardiac embolic source of stroke (mostly atrial fibrillation) or with severe carotid stenosis (> 70\%) were excluded. Vascular risk factors such as age, sex, diabetes mellitus, current smoking, hypercholesterolemia (defined as statin use at admission or total cholesterol level $>5 \mathrm{mmol} / \mathrm{L}$ ), hypertension (defined as present in patient's medical history at admission) and medication use were recorded at admission. We performed baseline on-medication 24-hour ambulatory blood 
pressure monitoring after the acute stroke phase as described elsewhere (15). After 2 years, patients were offered a clinical follow-up brain MRI and 24-hour ambulatory blood pressure monitoring.

We selected only those patients in whom a baseline and follow-up brain MRI with gradient-echo images, baseline eGFR and blood pressure measurements were available.

\section{Brain MRI}

At baseline and follow-up, MR images were obtained with a 1.5 or 3 Tesla MR scanner (Philips, the Netherlands). We obtained standard axial T2-weighted fast spin echo, fluid attenuated inversion recovery (FLAIR) and T2-weighted gradient recalled echo (GRE, Philips FFE) images. DWI-images were not yet standard at that time. Scan parameters of the 1,5T scanner were as follows: field of view $23 * 23 \mathrm{~cm}$; T2: matrix 512*512, TR shortest, TE 100 ms; FLAIR: matrix 512*512, TR 8000 ms, TE 120 ms; GRE: matrix 256*256, TR shortest, TE $23 \mathrm{~ms}$; all with slice thickness $5 \mathrm{~mm}$ and gaps of $0.50 \mathrm{~mm}$. Scan parameters of the 3 T scanner were: field of view $23 * 23 \mathrm{~cm}$; T2: matrix 512*512, TR 3000ms, TE 80 ms; FLAIR: matrix 512*512, TR 11000 ms, TE 125 ms; GRE: matrix 256*256, TR shortest, TE $16 \mathrm{~ms}$; all with slice thickness $5 \mathrm{~mm}$ and gaps of $0.50 \mathrm{~mm}$. Scanning parameters were unchanged between baseline and follow-up. For this study we included only those patients that were scanned with the same MRI field strength at baseline and follow-up. This was done to exclude overestimation of CMBs progression in patients scanned on a 1.5T scanner at baseline and 3T scanner at follow-up, and to prevent underestimation of CMBs progression in patients scanned on a 3T scanner at baseline and 1.5T scanner at follow-up. CMBs were defined as punctate hypointense lesions on gradient-echo images with a diameter < $10 \mathrm{~mm}$, in lobar, deep and infratentorial regions. Symmetrical hypointensities in the basal ganglia, likely to represent calcification, sulcal flow voids from cortical vessels and other hypointensities, that were likely to be caused by partial volume artifacts from bone, were disregarded. At baseline, CMBs were visually scored by two vascular neurologists who were unaware of kidney function, and disagreement was solved by consensus. Inter-observer agreement for detection of CMBs was substantial at baseline ( $\mathrm{k}=0.68$ ). Baseline and 6 \& 8 -up MR images were visually compared side-byside. Progression of $\mathrm{CMBs}$ was defined as the presence of any new microbleed on follow-up MRI. Inter-observer agreement of CMBs progression was excellent ( $\mathrm{k}=0.91)$. 


\section{Estimated glomerular filtration rate}

Serum levels of creatinine that were measured routinely during stroke admission were used for this study. eGFR was calculated using the Chronic Kidney Disease Epidemiology Collaboration (CKD-EPI) equation (16).

\section{Statistical analysis}

Statistical analysis was performed using IBM SPSS Statistics 21. We compared the eGFR between patients with and without CMBs presence at baseline and between patients with and without CMBs progression by t-test. We assessed the association of eGFR (independent variable) with CMBs presence at baseline and with CMBs progression at follow-up (dependent variables) by binary logistic regression analysis (unadjusted, model 1 ), then adjusting for age and sex (model 2). In model 3, we adjusted for age, sex and baseline 24-hour mean arterial pressure (MAP) (model 3a) or pulse pressure (PP) (model $3 \mathrm{~b}$ ), because blood pressure is considered the main risk factor for small vessel disease in general. In model 4, which was only performed for CMBs progression, we adjusted for age, sex and baseline CMBs presence. We also performed some exploratory analyses in which we adjusted for age, sex and other cardiovascular risk factors (hypertension, diabetes mellitus, hypercholesterolemia, current smoking), 24-hour MAP or PP at follow-up and use of antihypertensive drugs (any antihypertensive drug and angiotensin receptor blockers (ARB) and/or angiotensin converting enzyme (ACE) inhibitors) at admission (baseline) and followup. We added these factors one by one separately to the age and sex-adjusted model to avoid overcorrection with too many independent factors in the model. Significance was considered at $\mathrm{P}<0.05$.

\section{Results}

\section{Participants}

As described elsewhere, baseline MRI including GRE images and blood pressure measurements were available in 134 patients (17). We excluded 26 patients because of inadequate or different field strength follow-up MRI, 12 patients were lost to follow-up (refused participation, died or could not be contacted), and in another 7 patients eGFR was missing. In total 89 patients were eligible for further analyses. There were no significant differences between the 89 patients that were included in this study and the patients that were not included, regarding eGFR, age, sex, baseline presence of CMBs and cardiovascular risk factors. Patient characteristics are presented in table 1 . Mean eGFR was $74.4( \pm 17.6) \mathrm{ml} / \mathrm{min} / 1.73 \mathrm{~m}^{2}$ and 17 patients (19.1\%) had eGFR $<60 \mathrm{ml} / \mathrm{min} / 1.73 \mathrm{~m}^{2}$. Baseline MR images were obtained as soon as possible after the acute event (median 4 weeks, interquartile range (IQR) 1-10) and 
follow-up MR images were performed at a median of 26 months (IQR 25-28) after the baseline MRI. In 86 patients (96.6\%), baseline and follow-up scans were performed on the 1.5T scanner, and in 3 patients, baseline and follow-up scans were performed on the 3T scanner.

\section{Kidney function and baseline presence of $\mathrm{CMBs}$}

At baseline, CMBs were present in 33 patients (37.1\%), of whom 17 had only deep CMBs, 7 had only lobar CMBs, 7 had a combination of deep and lobar CMBs and 2 had infratentorial CMBs. 22 patients had one CMBs and 11 patients had multiple (2 to 17) CMBs. Patients with CMBs had significantly higher levels of 24-hour MAP at baseline (110.1 \pm 11.9 and $103.0 \pm 13.0 \mathrm{mmHg}$ respectively, $\mathrm{P}<0.01$, table 1$)$. Although eGFR was lower in patients with CMBs compared to patients without CMBs $\left(72.0 \pm 19.6\right.$ and $75.8 \pm 16.4 \mathrm{ml} / \mathrm{min} / 1.73 \mathrm{~m}^{2}$ respectively, table 1$)$, this was not significant. In regression analysis we found no significant association between eGFR and CMBs presence at baseline (table 2).

\section{Kidney function and CMBs progression}

At follow-up, CMBs progression was seen in 17 of 89 patients (19.1\%). Most patients $(n=11)$ had 1 new microbleed. Patients with CMBs progression had significantly more often CMBs presence at baseline (70.6\% vs. $29.2 \%, P<0.01)$ and higher 24 -hour PP $(64.2 \pm 9.1$ vs. $56.5 \pm 11.4, P<0.01$, table 1$)$. We found significant lower eGFR in patients with $\mathrm{CMBs}$ progression compared to patients without CMBs progression $\left(64.3 \pm 20.7\right.$ and $76.8 \pm 16.1 \mathrm{ml} / \mathrm{min} / 1.73 \mathrm{~m}^{2}$ respectively, $\mathrm{P}<0.01$, table 1$)$. In regression analysis with correction for sex and age, lower eGFR was related to CMBs progression (OR 1.55 per $10 \mathrm{ml} / \mathrm{min} / 1.73 \mathrm{~m}^{2}$ decrease, $95 \% \mathrm{Cl}$ 1.05-2.30 (model 2 , table 2)). This result remained significant after additional correction for baseline 24-hour MAP (model 3A) or 24-hour PP (model 3B), and also after additional correction for baseline CMBs presence (model 4, table 2, OR 1.57 per $10 \mathrm{ml} / \mathrm{min} / 1.73 \mathrm{~m}^{2}$ decrease, $95 \% \mathrm{Cl} 1.02-2.40$ ). Correction for the other vascular risk factors, 24-hour MAP or PP at follow-up or use of antihypertensive drugs in addition to age and sex did not change this result substantially (results not shown).

\section{Discussion}

In this longitudinal study on the relation between kidney function and CMBs, we found that lower eGFR was associated with CMBs progression after two years of follow-up in lacunar stroke patients, independent of age, gender, 24-hour MAP (or $\mathrm{PP}$ ) and baseline presence of CMBs. Although the cross-sectional association was not significant in our study, the association between decreased kidney function or 


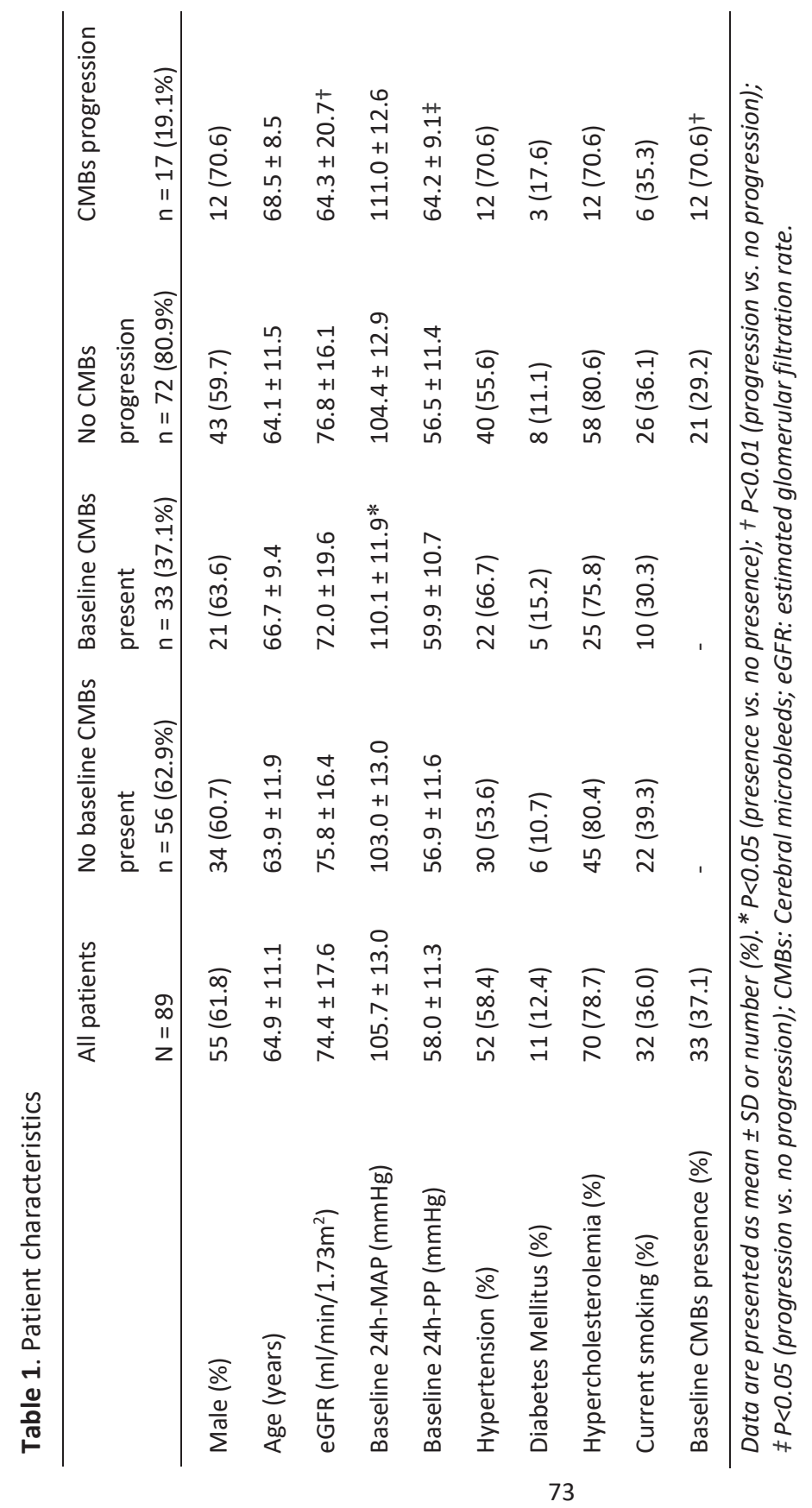


Table 2. Binary logistic regression analysis with baseline $\mathrm{CMBs}$ presence or $\mathrm{CMBs}$ progression as dependent variable and lower eGFR as independent variable

\begin{tabular}{|c|c|c|c|c|c|}
\hline & $\begin{array}{l}\text { Model } 1 . \\
\text { Unadjusted }\end{array}$ & $\begin{array}{l}\text { Model } 2 . \\
\text { Adjusted for } \\
\text { sex \& age }\end{array}$ & $\begin{array}{l}\text { Model 3A. } \\
\text { Adjusted for } \\
\text { sex, age and } \\
24 \text { h-MAP }\end{array}$ & $\begin{array}{l}\text { Model 3B. } \\
\text { Adjusted for } \\
\text { sex, age and } \\
24 \mathrm{~h}-\mathrm{PP}\end{array}$ & $\begin{array}{l}\text { Model } 4 . \\
\text { Adjusted for } \\
\text { sex, age and } \\
\text { presence of } \\
\text { baseline CMB }\end{array}$ \\
\hline $\begin{array}{l}\text { Baseline presence } \\
\text { of } \mathrm{CMBs}\end{array}$ & & & & & \\
\hline eGFR* & $\begin{array}{l}1.13(0.88- \\
1.46)\end{array}$ & $\begin{array}{l}1.07 \text { (0.79- } \\
1.44)\end{array}$ & $\begin{array}{l}1.03(0.75- \\
1.41)\end{array}$ & $\begin{array}{l}1.05 \text { (0.78- } \\
1.43)\end{array}$ & - \\
\hline $\begin{array}{l}\text { Progression of } \\
\mathrm{CMBs}\end{array}$ & & & & & \\
\hline eGFR* & $\begin{array}{l}1.55(1.09- \\
2.20) \dagger\end{array}$ & $\begin{array}{l}1.55(1.05- \\
2.30)+\end{array}$ & $\begin{array}{l}1.50(1.00- \\
2.24)+\end{array}$ & $\begin{array}{l}1.57(1.03- \\
2.38)+\end{array}$ & $\begin{array}{l}1.57(1.02- \\
2.40)+\end{array}$ \\
\hline
\end{tabular}

*All results are presented as OR $(95 \% \mathrm{Cl})$ per $10 \mathrm{ml} / \mathrm{min} / 1.73 \mathrm{~m}^{2}$ decrease in eGFR. eGFR: estimated glomerular filtration rate; CMBs: Cerebral microbleeds. $+P<0.05$

chronic kidney disease and the presence of $\mathrm{CMBs}$ was demonstrated in several other cross-sectional studies (4,6-13). We are now able to confirm the relationship between kidney function and CMBs in a longitudinal study design. This further strengthens the association between both small vessel diseases.

Impaired kidney function and CMBs represent small vessel disease in different organs $(1,2)$. It is thought that brain and kidneys are both susceptible for small vessel disease due to their anatomic and hemodynamic similarities $(18,19)$. Both the glomerular afferent arterioles of the juxtamedullary nephrons and the small perforating arteries of the brain are low resistance vessels that arise from larger high-pressure arteries and are exposed to high blood volume (19). These small vessels maintain high vascular tone and are susceptible for microvascular damage, especially in increasing age, when fluctuations of blood pressure within the cardiac cycle (reflected by PP) increases $(19,20)$. Shared risk factors, most importantly blood pressure and PP, may therefore explain the association between decreased kidney function and CMBs. Another proposed hypothesis, linking CMBs to decreased kidney function, is that small vessel disease is a manifestation of an underlying multi-system endothelial disorder affecting the small vessels, not only in the kidneys and the brain, but also the heart and retina (21). Endothelial dysfunction may be initiated by (low levels of) nitric 
oxid, which can lead to disturbances in maintaining the microcirculation (22). In the brain, endothelial dysfunction can lead to leakage of the blood brain barrier and subsequent brain damage $(2,23)$. Endothelial dysfunction and nitric oxid deficiency have also been shown in chronic kidney disease $(24,25)$.

While finding an association between eGFR and CMBs progression, we did not find a cross-sectional association between eGFR and the baseline presence of CMBs in our population. However, our sample size is rather small. Furthermore the point estimates are consistent and in the right direction. Therefore, we think that our crosssectional findings, together with the longitudinal findings, are not disconcordant with previous studies.

Interestingly, previous cross-sectional studies found a stronger association between eGFR and deep CMBs, compared to lobar CMBs (12). Lobar CMBs are associated with cerebral amyloid angiopathy, whereas deep CMBs are considered to be a feature of systemic hypertension-related small vessel disease (26). In a subgroup analyses in our population we did not find a relationship between eGFR and progression of deep CMBs (results not shown). However, our sample size is small; only 10 (11.2\%) of 89 patients had progression of deep CMBs. In a larger population such an association might be more easily detected.

Among the strengths of our study are the longitudinal study design, the homogeneity of the study cohort, and the availability of blood pressure measurements. Blood pressure is an important confounder in the association between eGFR and presence and progression of CMBs. Although we had no information about duration and severity of pre-existent hypertension, nor blood pressure control during follow-up, we were able to adjust for diagnosis of hypertension (medical history), and 24-hour MAP or PP both at baseline and at follow-up, which is more than in any other study. Furthermore, we could adjust for the use of antihypertensive drugs, particularly ARB and ACE-inhibitors, both at the start of the study and at the end of follow-up. ARB and $A C E-i n h i b i t o r s$ are considered to have a protective effect on kidneys (27). In the brain, ARB and ACE-inhibitors may influence the occurrence and recurrence of stroke beyond the effect of lowering the blood pressure (28). Blood pressure lowering therapy with an ACE inhibitor was shown to reduce the progression of cerebral white matter lesions (29). Whether these drugs also influence the occurrence and progression of CMBs is unknown. Correction for the use of antihypertensive drugs in general and for the use of ARB and ACE-inhibitors specifically at baseline and followup did not influence our overall results. 
Our study also has some limitations. First and most importantly, serum levels of creatinine were measured only once during admission. Repeated measurements in the post-acute phase would have added to reliability. However, we believe that the measurements of kidney function in the acute phase are most likely to reflect preadmission chronic function as acute stroke has no influence on kidney function itself. Also, cystatin $\mathrm{C}$ and micro-albuminuria may be useful markers to determine kidney function and detect chronic kidney disease $(9,30)$. However these tests were not routinely performed in our sample. Thirdly, the sample size of the present study is rather small. This was partly due to the exclusion of 26 patients that were scanned with different MR field strengths between baseline and follow-up. Because selection bias could have influenced our results, we performed a sensitivity analysis including all patients with a follow-up MRI, ignoring the differences in field strength $(n=118)$. Point estimates were consistent, but statistical significance disappeared in the final model correcting for baseline presence of CMBs (model 3A: OR 1.40 per $10 \mathrm{ml} / \mathrm{min} / 1.73 \mathrm{~m}^{2}$ decrease, $95 \% \mathrm{Cl} 1.01-1.92$; model 3B: OR $1.37 \mathrm{per}$ $10 \mathrm{ml} / \mathrm{min} / 1.73 \mathrm{~m}^{2}$ decrease, $95 \% \mathrm{Cl} 1.00-1.88$; model 4: OR $1.37 \mathrm{per}$ $10 \mathrm{ml} / \mathrm{min} / 1.73 \mathrm{~m}^{2}$ decrease, $95 \% \mathrm{Cl}$ 0.96-1.92). Nonetheless, in our opinion exclusion of patients with different field strength between baseline and follow-up was important, because comparing CMBs between MR images with different field strengths is considered to be unreliable (26). The included patients had baseline and follow-up MRI on the same scanner, which was $1.5 \mathrm{~T}$ in most patients (97\%). A subgroup analysis excluding 3 patients scanned at 3T did not change the overall results. Fourthly, due to the sample size of the population, the results of the regression analyses should be interpreted with some caution as we included a maximum of 4 variables with a sample size of 89 patients with 17 outcome events.

\section{Conclusions}

We found an independent association between lower eGFR and CMBs progression after 2 years of follow-up in lacunar stroke patients. CMBs and impaired kidney function are both seen as manifestations of microvascular organ damage. Our findings further strengthen the association between both small vessel pathologies and the assumption that small vessel disease could be considered a multi-system disorder. 


\section{References}

1. Turner ST, Rule AD, Schwartz GL, Kullo IJ, Mosley TH, Jack CR, et al. Risk factor profile for chronic kidney disease is similar to risk factor profile for small artery disease. Journal of hypertension. 2011 Sep;29(9):1796-801. PubMed PMID: 21720267. Pubmed Central PMCID: 3651813

2. Wardlaw JM. Blood-brain barrier and cerebral small vessel disease. Journal of the neurological sciences. 2010 Dec 15;299(1-2):66-71. PubMed PMID: 20850797.

3. Toyoda G, Bokura H, Mitaki S, Onoda K, Oguro H, Nagai A, et al. Association of mild kidney dysfunction with silent brain lesions in neurologically normal subjects. Cerebrovascular diseases extra. 2015 Jan-Apr;5(1):22-7. PubMed PMID: 25873927. Pubmed Central PMCID: 4376920.

4. Shima H, Ishimura E, Naganuma T, Yamazaki T, Kobayashi I, Shidara K, et al. Cerebral microbleeds in predialysis patients with chronic kidney disease. Nephrology, dialysis, transplantation : official publication of the European Dialysis and Transplant Association - European Renal Association. 2010 May;25(5):1554-9. PubMed PMID: 20037183.

5. Watanabe A. Cerebral microbleeds and intracerebral hemorrhages in patients on maintenance hemodialysis. Journal of stroke and cerebrovascular diseases : the official journal of National Stroke Association. 2007 Jan-Feb;16(1):30-3. PubMed PMID: 17689389.

6. Naganuma T, Takemoto Y, Yamasaki T, Shima H, Shoji T, Ishimura E, et al. Factors associated with silent cerebral microbleeds in hemodialysis patients. Clinical nephrology. 2011 Apr;75(4):346-55. PubMed PMID: 21426889.

7. Zhang JB, Liu LF, Li ZG, Sun HR, Ju XH. Associations Between Biomarkers of Renal Function With Cerebral Microbleeds in Hypertensive Patients. American journal of hypertension. 2014 Dec 12. PubMed PMID: 25498995.

8. Zhang JB, Ju XH, Wang J, Sun HR, Li F. Serum cystatin C and cerebral microbleeds in patients with acute cerebral stroke. Journal of clinical neuroscience : official journal of the Neurosurgical Society of Australasia. 2014 Feb;21(2):268-73. PubMed PMID: 24139136.

9. Akoudad S, Sedaghat S, Hofman A, Koudstaal PJ, van der Lugt A, Ikram MA, et al. Kidney function and cerebral small vessel disease in the general population. International journal of stroke : official journal of the International Stroke Society. 2015 Mar 5. PubMed PMID: 25753173

10. Ovbiagele B, Liebeskind DS, Pineda S, Saver JL. Strong independent correlation of proteinuria with cerebral microbleeds in patients with stroke and transient ischemic attack. Archives of neurology. 2010 Jan;67(1):45-50. PubMed PMID: 20065128.

11. Cho AH, Lee SB, Han SJ, Shon YM, Yang DW, Kim BS. Impaired kidney function and cerebral microbleeds in patients with acute ischemic stroke. Neurology. 2009 Nov 17;73(20):1645-8. PubMed PMID: 19917986.

12. Song TJ, Kim J, Lee HS, Nam CM, Nam HS, Kim YD, et al. Distribution of cerebral microbleeds determines their association with impaired kidney function. Journal of clinical neurology. 2014 Jul;10(3):222-8. PubMed PMID: 25045375. Pubmed Central PMCID: 4101099.

13. Ryu WS, Lee SH, Kim CK, Kim BJ, Yoon BW. The relation between chronic kidney disease and cerebral microbleeds: difference between patients with and without diabetes. International journal of stroke : official journal of the International Stroke Society. 2012 Oct;7(7):551-7. PubMed PMID: 22243603.

14. Bamford J, Sandercock P, Jones L, Warlow C. The natural history of lacunar infarction: the Oxfordshire Community Stroke Project. Stroke; a journal of cerebral circulation. 1987 MayJun;18(3):545-51. PubMed PMID: 3590244.

15. Staals J, van Oostenbrugge RJ, Knottnerus IL, Rouhl RP, Henskens LH, Lodder J. Brain microbleeds relate to higher ambulatory blood pressure levels in first-ever lacunar stroke patients. Stroke; a journal of cerebral circulation. 2009 Oct;40(10):3264-8. PubMed PMID: 19661468.

16. Levey AS, Stevens LA, Schmid CH, Zhang YL, Castro AF, 3rd, Feldman HI, et al. A new equation to estimate glomerular filtration rate. Annals of internal medicine. 2009 May 5;150(9):604-12. PubMed PMID: 19414839. Pubmed Central PMCID: 2763564. 
17. Klarenbeek P, van Oostenbrugge RJ, Lodder J, Rouhl RP, Knottnerus IL, Staals J. Higher ambulatory blood pressure relates to enlarged Virchow-Robin spaces in first-ever lacunar stroke patients. Journal of neurology. 2013 Jan;260(1):115-21. PubMed PMID: 22772305. Pubmed Central PMCID: 3535366.

18. Mogi M, Horiuchi M. Clinical Interaction between Brain and Kidney in Small Vessel Disease. Cardiology research and practice. 2011;2011:306189. PubMed PMID: 21274446. Pubmed Central PMCID: 3025374.

19. Ito $S$, Nagasawa T, Abe M, Mori T. Strain vessel hypothesis: a viewpoint for linkage of albuminuria and cerebro-cardiovascular risk. Hypertension research : official journal of the Japanese Society of Hypertension. 2009 Feb;32(2):115-21. PubMed PMID: 19262469.

20. O'Rourke MF, Safar ME. Relationship between aortic stiffening and microvascular disease in brain and kidney: cause and logic of therapy. Hypertension. 2005 Jul;46(1):200-4. PubMed PMID: 15911742.

21. Thompson CS, Hakim AM. Living beyond our physiological means: small vessel disease of the brain is an expression of a systemic failure in arteriolar function: a unifying hypothesis. Stroke; a journal of cerebral circulation. 2009 May;40(5):e322-30. PubMed PMID: 19228835.

22. Knottnerus IL, Ten Cate H, Lodder J, Kessels F, van Oostenbrugge RJ. Endothelial dysfunction in lacunar stroke: a systematic review. Cerebrovascular diseases. 2009;27(5):519-26. PubMed PMID: 19372654.

23. Wiseman S, Marlborough F, Doubal F, Webb DJ, Wardlaw J. Blood Markers of Coagulation, Fibrinolysis, Endothelial Dysfunction and Inflammation in Lacunar Stroke versus Non-Lacunar Stroke and Non-Stroke: Systematic Review and Meta-Analysis. Cerebrovascular diseases. 2014;37(1):64-75. PubMed PMID: 24401164.

24. Baylis C. Nitric oxide deficiency in chronic kidney disease. American journal of physiology Renal physiology. 2008 Jan;294(1):F1-9. PubMed PMID: 17928410.

25. Caglar K, Yilmaz MI, Saglam M, Cakir E, Kilic S, Sonmez A, et al. Serum fetuin-a concentration and endothelial dysfunction in chronic kidney disease. Nephron Clinical practice. 2008;108(3):c23340. PubMed PMID: 18334823.

26. Yates PA, Villemagne VL, Ellis KA, Desmond PM, Masters CL, Rowe CC. Cerebral microbleeds: a review of clinical, genetic, and neuroimaging associations. Frontiers in neurology. 2014 Jan 6;4:205. PubMed PMID: 24432010. Pubmed Central PMCID: 3881231.

27. Ting RZ, Luk AO, Chan JC. Treatment and landmark clinical trials for renoprotection. Contributions to nephrology. 2011;170:184-95. PubMed PMID: 21659771.

28. Papademetriou V. Inhibition of the renin-angiotensin-aldosterone system to prevent ischemic and atherothrombotic events. American heart journal. 2009 Jun;157(6 Suppl):S24-30. PubMed PMID: 19450721.

29. Dufouil C, Chalmers J, Coskun O, Besancon V, Bousser MG, Guillon P, et al. Effects of blood pressure lowering on cerebral white matter hyperintensities in patients with stroke: the PROGRESS (Perindopril Protection Against Recurrent Stroke Study) Magnetic Resonance Imaging Substudy. Circulation. 2005 Sep 13;112(11):1644-50. PubMed PMID: 16145004.

30. Oh MY, Lee H, Kim JS, Ryu WS, Lee SH, Ko SB, et al. Cystatin C, a novel indicator of renal function, reflects severity of cerebral microbleeds. BMC neurology. 2014;14:127. PubMed PMID:

24925313. Pubmed Central PMCID: 4077563. 




\section{Chapter 6}

\section{High MRI burden of cerebral small vessel disease is associated with higher long-term mortality in lacunar stroke patients}

Ellen C. van Overbeek ${ }^{1}$, Robert J. van Oostenbrugge ${ }^{1,2}$, Julie Staals ${ }^{1,2}$

${ }^{1}$ Department of Neurology, Maastricht University Medical Centre (MUMC), Maastricht, the Netherlands; ${ }^{2}$ Cardiovascular Research Institute Maastricht, MUMC, Maastricht, the Netherlands 


\section{Abstract}

Background - Individual MRI markers of cerebral small vessel disease (cSVD) are associated with mortality, but the total impact of small vessel disease (SVD) has not been tested. We investigated whether total MRI burden, as a more complete estimate of the full impact of cSVD, is related to all-cause long-term mortality.

Methods - We collected a cohort of 146 lacunar stroke patients between 2003 and 2008. We assessed the survival status as of September 2015. On baseline brain MRI, the presence of white matter hyperintensities, lacunes, microbleeds and perivascular spaces were visually scored and summed in an ordinal total SVD score (0-4). We used a Cox-regression model to calculate the risk of mortality, with adjustment for age, sex and cardiovascular risk factors.

Results - After a mean follow-up of $9.6( \pm 1.4)$ years, 33 patients $(22.6 \%)$ had died. A maximum score of 4 on the total SVD scale predicted higher mortality (Hazard ratio (HR) $12.32,95 \% \mathrm{Cl}$ 1.58-96.27, score 0 as reference). These results did not alter after additional correction for sex, age and cardiovascular risk factors. A score of 1 to 3 also showed increased mortality rates and HRs, but these results were not significant.

Conclusions - Long-term all-cause mortality was higher in patients with a maximum score on the total SVD score compared to patients without MRI markers of CSVD. A study in a larger cohort is warranted to confirm that increasing SVD score, over the whole range, is related to higher long-term mortality. 


\section{Introduction}

Cerebral small vessel disease (CSVD) is a common age-related disease that may result in lacunar stroke and/or "silent" radiologic features such as white matter hyperintensities (WMH), lacunes, cerebral microbleeds (CMBs) and visible perivascular spaces (PVS) (1). Although these "silent" lesions do not cause acute symptoms, many studies show associations with decline in cognitive and motor performances (2-4). Furthermore several studies found that these individual MRI markers of cSVD relate to long-term mortality. (5-8)

Recently a total SVD scale was developed which is an ordinal score of the total burden of SVD on brain MRI (9). The total score provides a more complete estimate of the full impact of cSVD on the brain than individual MRI markers.

We investigated whether the total burden of SVD on MRI is associated with long-term all-cause mortality in a cohort of lacunar stroke patients during a mean follow-up of almost 10 years.

\section{Methods}

\section{Patients}

This is a retrospective study of a cohort of first-ever lacunar stroke patients. The patients were consecutively included in a lacunar stroke project from May 2003 to January 2008 from the Maastricht University Medical Center and the Orbis Medical Center, the Netherlands as described in detail elsewhere (10). This study was approved by the local medical ethical committee and performed according to the institutional guidelines. At baseline brain MRI was performed and cardiovascular risk factors were recorded as described elsewhere (10). Survival status was recorded on September 1, 2015 and we registered date of death if the patient had died.

\section{Brain MRI}

Brain MRI at baseline was obtained with a 1.5 Tesla (T) or 3T MR (Philips) scanner and for this study we used axial T2-weighted fast spin echo images, axial fluid attenuated inversion recovery and T2-weighted gradient echo images. MRI was visually scored for the presence of lacunes, CMBs, extent of basal ganglia PVS and extent of WMH. As described previously, we counted each of the four MRI features and determined the total MRI burden of cSVD on an ordinal scale from 0 to 4 (9). MRI sequence parameters and an elaborate description of the MRI scoring can be found in the supplemental methods. 


\section{Statistical methods}

Statistical analyses were performed using IBM SPSS Statistics 22. Kaplan-Meier survival plots were constructed for the SVD scale and we performed log rank tests for significance. Cox regression models were used to calculate hazard ratios (HR) to estimate the risk of mortality associated with the SVD score. The models were adjusted for sex, age and cardiovascular risk factors (diabetes mellitus, hypercholesterolemia, smoking and baseline 24-hour mean arterial pressure).

\section{Results}

At baseline there were 157 lacunar stroke patients in the cohort. 11 patients were excluded for this study because of missing gradient recalled echo (GRE) images, leaving 146 patients at baseline. Mean follow-up duration was $9.6( \pm 1.4)$ years during which $33(22.6 \%)$ patients died. One patient was followed up to 22 months after stroke. All others were followed until end of study, or death. Baseline characteristics are presented in table 1. Patients who had died at end of follow-up were more often male and were older. Figure 1 shows Kaplan Meier survival curves for the different scores on the total SVD scale (Log Rank (Mantel-Cox; linear trend): 5.82; $<<0.05$ ). $45.5 \%$ of patients with a maximum SVD score of 4 compared to $4.5 \%$ of patients with a score of 0 died during follow-up with a mean survival duration of $5.2( \pm 2.5)$ years.

Table 1. Patient characteristics

\begin{tabular}{llll}
\hline & Total & Alive & Deceased \\
& $\mathrm{N}=146$ & $\mathrm{n}=113$ & $\mathrm{n}=33$ \\
\hline Male $(\mathrm{n}(\%))$ & $88(60.3)$ & $62(54.9)$ & $26(78.8) \dagger$ \\
Age (years) & $64.8( \pm 11.2)$ & $62.8( \pm 10.9)$ & $72.1( \pm 9.2) \ddagger$ \\
24-hour mean arterial blood & $105.6( \pm 12.3)$ & $106.2( \pm 12.6)$ & $103.8( \pm 11.4)$ \\
pressure $(\mathrm{mmHg})$ & & & \\
Diabetes $(\mathrm{n}(\%))$ & $20(13.7)$ & $14(12.4)$ & $6(18.2)$ \\
Hypercholesterolemia $(\mathrm{n}(\%))$ & $115(78.8)$ & $92(81.4)$ & $23(69.7)$ \\
Smoking $(\mathrm{n}(\%))$ & $58(39.7)$ & $42(37.2)$ & $16(48.5)$ \\
\hline
\end{tabular}

* 4 missing; $+p<0.05 ; \neq p<0.001$

Cox regression analysis of the SVD scale provided estimated HRs presented in table 2. The highest score of 4 on the total SVD scale was associated with higher mortality (HR $11.93,95 \% \mathrm{Cl} 1.53-93.23$, score 0 as reference). This result remained after correction for sex, age and cardiovascular risk factors (HR 9.25, 95\% $\mathrm{Cl} 1.08-79.53$ ). Although an SVD score of 1, 2 and 3 also showed increased mortality rates (18.5, 28.3 and $13.8 \%$ respectively) compared to score $0(4.5 \%)$, the HRs are not significant. 
Table 2. Total SVD scale and all-cause mortality

\begin{tabular}{clll}
\hline & $\begin{array}{l}\text { Deceased } \\
\mathrm{n} / \mathrm{N}\end{array}$ & $\begin{array}{l}\text { Hazard ratio }(95 \% \mathrm{Cl}) \\
\text { unadjusted }\end{array}$ & $\begin{array}{l}\text { Hazard ratio }(95 \% \mathrm{Cl}), \\
\text { adjusted* }\end{array}$ \\
\hline Total SVD score & & & \\
\hline 0 & $1 / 22(4.5 \%)$ & 1.00 (Reference) & 1.00 (Reference) \\
1 & $5 / 27(18.5 \%)$ & $4.85(0.57-41.55)$ & $2.74(0.30-25.29)$ \\
2 & $13 / 46(28.3 \%)$ & $7.03(0.92-53.75)$ & $3.11(0.37-26.33)$ \\
3 & $4 / 29(13.8 \%)$ & $2.93(0.33-26.25)$ & $1.92(0.20-18.41)$ \\
4 & $10 / 22(45.5 \%)$ & $12.32(1.58-96.27) \dagger$ & $9.25(1.08-79.53) \dagger$ \\
\hline
\end{tabular}

*Adjusted for sex, age, diabetes, hypercholesterolemia, smoking and 24-hour mean arterial blood pressure; $+p<0.05$

Figure 1. Kaplan-Meier survival curves for the total SVD score

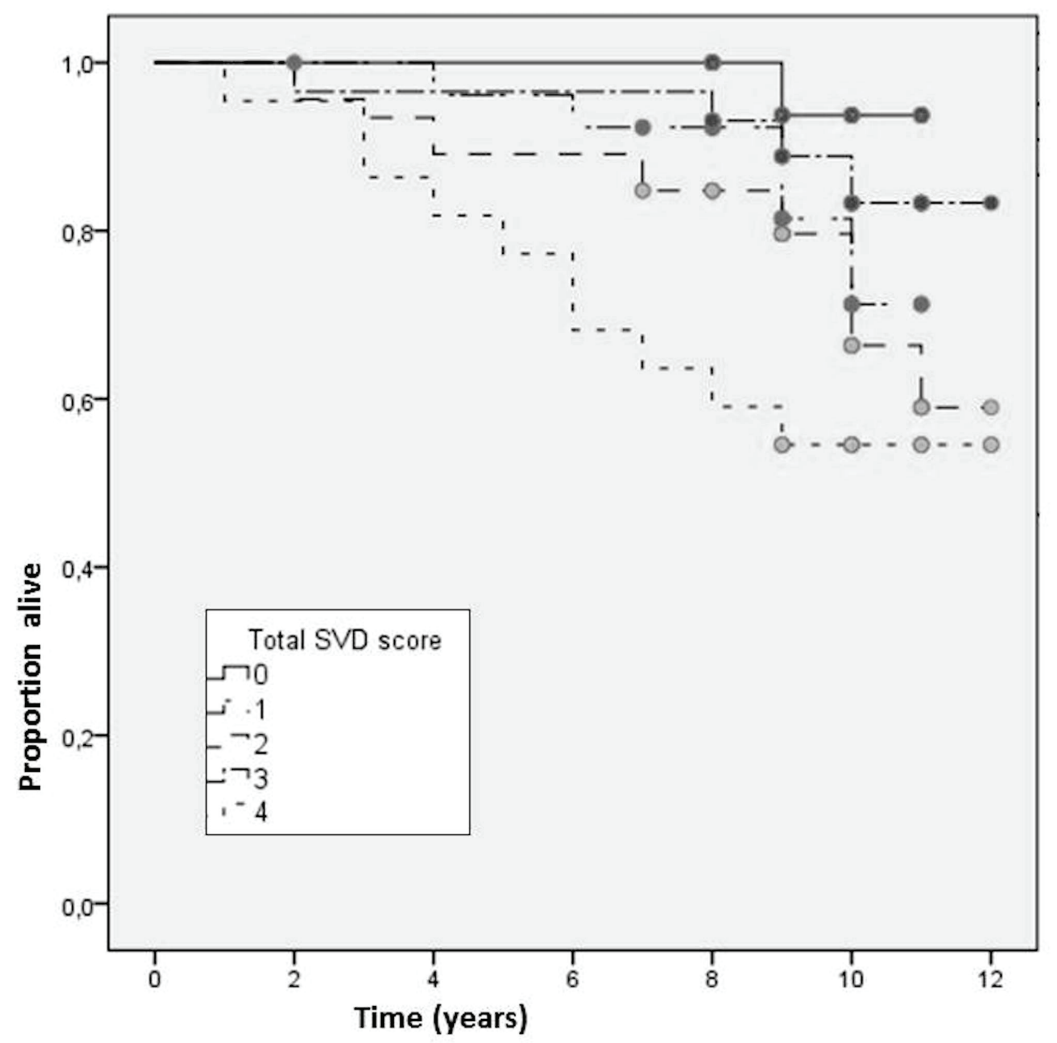

Log Rank (Mantel-Cox; linear trend): 5.82; $p<0.05$ 


\section{Discussion}

We found that severe SVD, presented by extensive presence of baseline MRI features was associated with higher long-term all-cause mortality in lacunar stroke patients. Previous studies found an association between individual MRI markers of SVD and long-term mortality (5-8). These results probably reflect disease severity rather than a direct causal relation. Mortality probably depends on SVD related co-morbidity such as decreased cognitive functioning, gait disturbances and other disabilities, which are all associated with individual MRI markers of cSVD (2-4, 11-13). Cardiovascular comorbidity and increased stroke risk also have been related to MRI markers of cerebral SVD and lead to increased mortality (13). Assuming that it is not the individual MRI marker itself but the underlying disease in its full extent that adds to the increased morbidity, a total SVD score reflects more realistically the association between SVD and mortality.

We found a significant higher mortality in patients with the highest burden of SVD (score of 4). Extensive MRI burden may signify those vulnerable patients with worse prognosis after lacunar stroke. Although the HR for mortality was also higher in patients with a score of 1, 2 or 3, these results were not significant. Probably our sample size is too small and a study in a larger cohort is warranted to find significant HRs over the whole range of the total SVD score.

Strengths of our study are the well-defined population with symptomatic CSVD, and extended follow-up duration. There are also limitations. The total SVD score is a simple visual score and therefore a useful tool for both research and clinical use, however in its present development stage it should be applied with caution (11). Other variables such as atrophy and number of CMBs (instead of just presence) have also been reported in association with higher mortality risk but are not incorporated in the SVD score nor in our study $(5,6)$. Furthermore, patients were scanned at different field strengths and this might have influenced SVD score. Secondly we have no information on preventive therapies that were prescribed to our patients, and therapy compliance. These might have affected outcome and mortality. Another limitation is that we had no information on cause of death and comorbidity during follow-up. Finally we used an existing cohort, previously enrolled in a lacunar stroke research project. This may have led to an inclusion bias, for the participating patients might have been younger and healthier than patients who declined participation.

Although long-term all-cause mortality was higher in patients with a maximum score on the total SVD score compared to patients without MRI markers of cSVD, a study in a larger cohort is warranted to confirm that increasing SVD score, over the whole range, is related to higher long-term mortality. 


\section{References}

1. Wardlaw JM, Smith C, Dichgans M. Mechanisms of sporadic cerebral small vessel disease: insights from neuroimaging. Lancet Neurol. 2013 May;12(5):483-97. PubMed PMID: 23602162. Pubmed Central PMCID: 3836247.

2. Smith EE, O'Donnell M, Dagenais G, Lear SA, Wielgosz A, Sharma M, et al. Early cerebral small vessel disease and brain volume, cognition, and gait. Ann Neurol. 2015 Feb;77(2):251-61. PubMed PMID: 25428654. Pubmed Central PMCID: 4338762.

3. Huijts M, Duits A, Staals J, Kroon AA, de Leeuw PW, van Oostenbrugge RJ. Basal ganglia enlarged perivascular spaces are linked to cognitive function in patients with cerebral small vessel disease. Current neurovascular research. 2014 May;11(2):136-41. PubMed PMID: 24606607.

4. Poels MM, Ikram MA, van der Lugt A, Hofman A, Niessen WJ, Krestin GP, et al. Cerebral microbleeds are associated with worse cognitive function: the Rotterdam Scan Study. Neurology. 2012 Jan 31;78(5):326-33. PubMed PMID: 22262748.

5. Henneman WJ, Sluimer JD, Cordonnier C, Baak MM, Scheltens P, Barkhof F, et al. MRI biomarkers of vascular damage and atrophy predicting mortality in a memory clinic population. Stroke; a journal of cerebral circulation. 2009 Feb;40(2):492-8. PubMed PMID: 19109551.

6. Akoudad S, Ikram MA, Koudstaal PJ, Hofman A, van der Lugt A, Vernooij MW. Cerebral microbleeds and the risk of mortality in the general population. Eur J Epidemiol. 2013 Oct;28(10):815-21. PubMed PMID: 24072508.

7. Kerber KA, Whitman GT, Brown DL, Baloh RW. Increased risk of death in community-dwelling older people with white matter hyperintensities on MRI. Journal of the neurological sciences. 2006 Dec 1;250(1-2):33-8. PubMed PMID: 16889799.

8. Bokura H, Kobayashi S, Yamaguchi S, lijima K, Nagai A, Toyoda G, et al. Silent brain infarction and subcortical white matter lesions increase the risk of stroke and mortality: a prospective cohort study. Journal of stroke and cerebrovascular diseases : the official journal of National Stroke Association. 2006 Mar-Apr;15(2):57-63. PubMed PMID: 17904049.

9. Staals J, Makin SD, Doubal FN, Dennis MS, Wardlaw JM. Stroke subtype, vascular risk factors, and total MRI brain small-vessel disease burden. Neurology. 2014 Sep 30;83(14):1228-34. PubMed PMID: 25165388. Pubmed Central PMCID: 4180484.

10. Staals J, van Oostenbrugge RJ, Knottnerus IL, Rouhl RP, Henskens LH, Lodder J. Brain microbleeds relate to higher ambulatory blood pressure levels in first-ever lacunar stroke patients. Stroke; a journal of cerebral circulation. 2009 Oct;40(10):3264-8. PubMed PMID: 19661468.

11. Staals J, Booth T, Morris Z, Bastin ME, Gow AJ, Corley J, et al. Total MRI load of cerebral small vessel disease and cognitive ability in older people. Neurobiology of aging. 2015 Oct;36(10):2806-11. PubMed PMID: 26189091.

12. Inzitari D, Simoni M, Pracucci G, Poggesi A, Basile AM, Chabriat H, et al. Risk of rapid global functional decline in elderly patients with severe cerebral age-related white matter changes: the LADIS study. Archives of internal medicine. 2007 Jan 8;167(1):81-8. PubMed PMID: 17210882.

13. Vermeer SE, Longstreth WT, Jr., Koudstaal PJ. Silent brain infarcts: a systematic review. Lancet Neurol. 2007 Jul;6(7):611-9. PubMed PMID: 17582361. 


\section{Supplemental methods}

\section{Brain MRI}

All patients had clinical MR imaging with a 1.5 or 3 Tesla MR scanner (Philips, Eindhoven, the Netherlands). Standard axial T2-weighted fast spin echo, fluid attenuated inversion recovery (FLAIR) and T2-weighted gradient recalled echo (GRE, Philips FFE) images were obtained. Scan parameters of the 1,5T scanner were as follows: field of view $23 * 23 \mathrm{~cm}$; T2: matrix $512 * 512$, TR shortest, TE $100 \mathrm{~ms}$; FLAIR: matrix 512*512, TR 8000 ms, TE 120 ms; GRE: matrix 256*256, TR shortest, TE 23 ms; all with slice thickness $5 \mathrm{~mm}$ and gaps of $0.50 \mathrm{~mm}$. And scan parameters of the 3T scanner were: field of view $23 * 23 \mathrm{~cm}$; T2: matrix $512 * 512$, TR $3000 \mathrm{~ms}$, TE $80 \mathrm{~ms}$; FLAIR: matrix 512*512, TR 11000 ms, TE 125 ms; GRE: matrix 256*256, TR shortest, TE $16 \mathrm{~ms}$; all with slice thickness $5 \mathrm{~mm}$ and gaps of $0.50 \mathrm{~mm}$. DWl-images were not routinely performed at that time.

\section{MRI scoring}

The different MRI markers of small vessel disease (SVD) were rated visually by two vascular neurologists. Scans were assessed for (asymptomatic) lacunes, cerebral microbleeds (CMBs), white matter hyperintensities (WMH) and enlarged perivascular spaces (PVS). Lacunes were defined as rounded or ovoid hyperintense (CSF signal intensity) lesions on T2 and hypointense with a hyperintense rim on FLAIR. Lacunes are $>3$ and $<20-\mathrm{mm}$ diameter and located in the basal ganglia, internal capsule, centrum semiovale, or brainstem. One point was given if $>/=1$ lacune was present. CMBs were defined as small $(<5 \mathrm{~mm})$, homogeneous, round foci of low signal intensity on gradient echo images in cerebellum, brainstem, basal ganglia, white matter, or cortico-subcortical junction. CMBs were differentiated from vessel flow voids and mineral depositions in the globi pallidi. One point was given if $>/=1 \mathrm{CMBs}$ was present. Deep and periventricular white matter hyperintensities (WMH) were rated on FLAIR using the Fazekas scale (1). If periventricular WMH Fazekas 3 and/or deep WMH Fazekas 2-3 were scored, one point was added to the total SVD scale. Finally, PVS in the basal ganglia were defined as small $(<3 \mathrm{~mm})$ punctate hyperintensities on T2 images. We rated PVS on the slide with the highest number in 1 hemisphere and graded them using a formerly-used 3-category semiquantitative ordinal scale. One point was awarded if moderate to severe PVS were present. The score of each of the $4 \mathrm{MRI}$ features was added up to the total SVD score, ranging from 0 to 4 .

Inter-observer reliability (calculated with Cohen's kappa) for the different MRI markers were published before and were substantial to good (2-4). 


\section{References}

1. Fazekas F, Chawluk JB, Alavi A, Hurtig HI, Zimmerman RA. MR signal abnormalities at $1.5 \mathrm{~T}$ in Alzheimer's dementia and normal aging. AJR American journal of roentgenology. 1987 Aug;149(2):351-6. PubMed PMID: 3496763

2. Klarenbeek P, van Oostenbrugge RJ, Lodder J, Rouhl RP, Knottnerus IL, Staals J. Higher ambulatory blood pressure relates to enlarged Virchow-Robin spaces in first-ever lacunar stroke patients. Journal of neurology. 2013 Jan;260(1):115-21. PubMed PMID: 22772305. Pubmed Central PMCID: 3535366.

3. Pieters B, Staals J, Knottnerus I, Rouhl R, Menheere P, Kessels A, et al. Periventricular white matter lucencies relate to low vitamin B12 levels in patients with small vessel stroke. Stroke; a journal of cerebral circulation. 2009 May;40(5):1623-6. PubMed PMID: 19286604.

4. Staals J, van Oostenbrugge RJ, Knottnerus IL, Rouhl RP, Henskens LH, Lodder J. Brain microbleeds relate to higher ambulatory blood pressure levels in first-ever lacunar stroke patients. Stroke; a journal of cerebral circulation. 2009 Oct;40(10):3264-8. PubMed PMID: 19661468. 

Chapter 7

Summary

\section{General discussion}





\section{Introduction}

Cerebral small vessel disease (CSVD) is an umbrella term that covers all pathological processes of the small vessels in the brain. Although CSVD exists in several types, the most common type of cSVD is age- or vascular risk-factor related CSVD.(1) CSVD is related to cognitive, motor and mood disturbances and presents an increasing health problem in our aging population.(2-5) The disease leads to characteristic structural changes of the brain which can be seen on MR imaging such as lacunes, white matter hyperintensities (WMH), cerebral microbleeds (CMBs) and perivascular spaces (PVS).(6) Although several mechanisms have been proposed, the exact pathogenesis remains unclear. $(1,7)$ As a result, today's therapies are based on knowledge gained from experience in treating ischemic stroke in general and on controlling (modifiable) risk factors. More insight into etiological factors and pathophysiological mechanisms might eventually lead to more focussed and more effective prevention and therapy.

Endothelial dysfunction and subsequent blood-brain barrier (BBB) disruption seems to play an important role in the development of risk-factor related cSVD. $(7,8)$ In the past, research into endothelial function in CSVD mainly focussed on cross-sectional associations. Observational cross-sectional studies are sufficient to study characteristics among population subsets, but it only reflects a specific association at a single point in time. A longitudinal study design will learn more on cause-and-effect relationships. However, longitudinal studies investigating progression of CSVD over time are limited. By studying progression of MRI manifestations of CSVD in relation to markers of endothelial function and SVD in other organs we aimed to add knowledge to the understanding of the etiological mechanisms in the development and progression of CSVD.

We studied markers of endothelial function (haemostasis, inflammation) and vitamin B12 (linked to endothelial function) in relation to progression of the different MRI manifestations of CSVD. Also, we studied kidney function (as a marker of renal small vessel disease) in relation to progression of cSVD. We addressed our research objectives in a lacunar stroke cohort that was collected from May 2003 to January 2008 and had follow-up MR imaging 2 years later. Finally, we assessed the association between the total MRI burden of CSVD and long-term mortality in this lacunar stroke cohort.

\section{Summary}

In chapter $\mathbf{2}$ we investigated the association between blood markers of vascular inflammation (neopterin, VCAM-1, ICAM-1, E-selectin and P-selectin and hSCRP) and progression of MRI markers of CSVD after 2 years of follow-up in 91 patients with 
first-ever lacunar stroke. Although cross-sectional studies showed a relation between several of these markers and MRI manifestations, we did not find any significant association between baseline levels of the tested blood markers and progression of lacunes, WMH or CMBs. Our study therefore did not indicate these inflammatory blood markers as predictors of progression of cSVD. Despite our negative results, it is still not excluded that vascular inflammation plays a role in the pathogenesis of cSVD. It is possible that the variation in blood marker levels were too small to detect or the tested markers might have been too unspecific.

In chapter $\mathbf{3}$ we investigated the association between baseline plasma tissue plasminogen activator (tPA)-activity and plasminogen activator inhibitor type 1 (PAI1) and progression of WMH after 2-year follow-up in 127 lacunar stroke patients. Plasma tPA-activity and PAI-1 are components of the fibrinolytic system and it is hypothesized that these components are haemostasis-related markers of endothelial function. High tPA-activity and low levels of PAI-1 were cross-sectionally associated with extensive $\mathrm{WMH}$ in lacunar stroke patients. We found that higher baseline plasma tPA-activity was also associated with progression of periventricular WMH after 2 years of follow-up. PAI-1 was lower in lacunar stroke patients with WMH progression, however this was not significant. This is the first longitudinal study to confirm the association between tPA-activity and PAI-1 and progression of cSVD, and it encourages to perform more research into the role of the haemostatic endothelial pathway in the pathogenesis of CSVD.

In chapter 4 we studied the association between plasma vitamin B12 at baseline and progression of WMH after 2-year follow-up in 107 patients with first-ever lacunar stroke. Vitamin B12 is thought to affect the endothelial function and increase the permeability of the BBB. Our study is the first longitudinal study that explored the association between vitamin B12 level and progression of cSVD. We found that low baseline plasma levels of vitamin B12 relate to progression of periventricular $\mathrm{WMH}$, but not deep WMH, after 2 years of follow-up, as had been shown in cross-sectional studies. Whether our population or other patients with cSVD could benefit from supplementation of vitamin B12 is yet unknown.

In chapter $\mathbf{5}$ we determined the association between kidney function at baseline and progression of cSVD in terms of new CMBs after 2-year follow-up in 89 lacunar stroke patients. Chronic kidney disease or kidney failure are considered to result from small vessel disease of the kidney. Endothelial activation and vascular inflammation are likely to be systemic and may therefore simultaneously affect the brain and kidney. 
Also the anatomic and hemodynamic similarities between the brain and kidney could explain the co-occurrence of cerebral and renal small vessel disease. We found that lower eGFR was associated with progression of CMBs, independent of age, gender, blood pressure characteristics and baseline presence of CMBs. These results further strengthen the association between both small vessel diseases and encourage to consider cSVD as part of a multi-system endothelial disorder, instead of an isolated disease of the brain.

In chapter 6 we performed a longitudinal study on the association between the total burden of cSVD on MRI and long-term all-cause mortality in 146 patients with lacunar stroke. Follow-up was almost 10 years. The presence of $\mathrm{WMH}$, lacunes, $\mathrm{CMBs}$ and PVS were visually scored on brain MRI and summed in an ordinal total SVD score (04). Assuming that morbidity and mortality are associated with the full extent of the underlying disease and not individual MRI markers, it makes sense to study the association between mortality and the total SVD score. We found that mortality was significantly higher in patients with the highest burden of SVD (score of 4). Although the hazard ratio (HR) for mortality was also higher in patients with a score of 1, 2 or 3 , compared to 0 , these results were not significant. If this trend is confirmed in a larger cohort, the SVD score can be used to signify those vulnerable patients with worse prognosis after lacunar stroke.

\section{General discussion}

Reviewing the results of the studies in this thesis and the recent literature on cerebral small vessel disease (cSVD), several question remain. These questions, that can be categorised in three topics, are:

I. Endothelial dysfunction and cerebral small vessel disease: What do we know at present? What are the main obstacles in studying blood markers of endothelial dysfunction? How should we improve future studies on endothelial dysfunction in (progression of) cSVD?

II. Cerebral small vessel disease as part of a multi-system disorder: What do we know at present? How can we use this knowledge to improve research on cSVD in the future? Will this knowledge change our management of cerebral small vessel disease?

III. The evaluation of disease progression in cerebral small vessel disease: What do we know at present? How should we improve rating progression of cSVD? In future, how can we relate MRI progression of cSVD to clinical outcomes? 


\section{Endothelial dysfunction and cerebral small vessel disease}

\section{What do we know at present?}

Endothelial dysfunction is considered to be an important mechanism in the development and progression of cSVD. $(7,9)$ The vascular endothelium has many functions, such as regulation of coagulation and fibrinolysis pathways, regulation of vascular tone, inducing vascular inflammation and blood vessel repair and remodelling.(7) Activation or dysfunction of the endothelium can disrupt these functions.(7) Remodelling of the small vessels may lead to narrowing or rupture and local damage to the surrounding brain tissue. $(1,10)$ The endothelium also is an important constituent of the BBB.(10) It is thought that BBB disruption causes leakage of plasma components into the vessel wall and the brain parenchyma, causing damage to the surrounding brain tissue. $(1,10)$

Although there is growing evidence for a notable role of endothelial activation in cSVD, in general, studying blood markers has been somewhat disappointing. $(7,11)$ Markers of haemostasis that have been studied are tissue plasminogen activator (tPA), tPA-activity, plasminogen activator inhibitor type 1 (PAI-1), fibrinogen, D-dimer, von Willebrand factor ( $V W F$ ), prothrombin fragment $1+2$ (F 1+2), coagulation factor VIII, tissue factor and thrombomodulin, tissue factor pathway inhibitor (TFPI) and thrombin-antithrombin (TAT).(12-18) Most studies were cross-sectional. A longitudinal association was found only for tPA-activity and progression of WMH (this thesis, chapter 3).

The inflammation and endothelial activation markers that were studied in relation to cSVD are ICAM-1, VCAM-1, P-selectin, E-selectin, homocysteine and matrixmetalloproteinase 9 (MMP9), CRP, IL-6, IL-18, tissue necrosis factor (TNF)-alpha, asymmetric dimethyl arginine (ADMA), MPO, Lp-PLA2 and oxidized LDL.(14, 19-31) Again, the majority of the studies were cross-sectional. Two studies confirmed an association between ICAM-1 and progression of WMH $(20,21)$ and two studies showed an association between CRP-levels and progression of WMH and lacunes. $(21,24)$ We however, did not find an association between the blood markers CRP, ICAM-1, VCAM-1, P-selectin, E-selectin and neopterin and progression of WMH, $\mathrm{CMBs}$ or lacunes in lacunar stroke patients (this thesis, chapter 2).

Vitamin B12 is a factor that can interact with the endothelium and is linked to increased BBB permeability.(32-39) We showed that progression of periventricular $\mathrm{WMH}$ relates to low levels of vitamin B12 (this thesis, chapter 4).

So, although we could confirm a role for tPA-activity and vitamin B12 in progression of WMH in lacunar stroke patients after 2 years of follow-up, we could not find an association between blood markers of vascular inflammation and progression of 
cSVD. Still, we do not exclude a role for endothelial vascular inflammation in CSVD, because there are some limitations in our study approach which we will discuss.

\section{What are the main obstacles in studying blood markers of endothelial dysfunction?}

Testing blood markers is an easy, minimally invasive and relatively cheap way to study endothelial function. Nonetheless there are several pitfalls concerning the interpretation of the results.

When interpreting the levels of endothelial markers, one must be aware that these blood levels might only reflect the local conditions of the blood vessel of which the blood is drawn from. We do not know whether these values also reflect endothelial activation in the brain as a whole or the small vessels of the brain in particular. The local levels of markers that act on, or are released from the endothelium are probably small and may vary quickly over time. In the past few years cSVD is more and more considered to be part of a systemic condition with a chronic state of endothelial activation instead of a local brain disease. This assumption supports the use of blood testing to evaluate endothelial activation and dysfunction in relation to small vessel disease. But also indicates that systemic inflammation might overrule local endothelial activation within the brain. We will further elaborate on this topic in the next section.

Secondly, several interacting conditions need to be considered when evaluating blood levels of endothelial markers. Some of the blood markers have diurnal variations, which should be taken into account. Also blood markers may be influenced by vascular comorbidity and systemic inflammatory disease. Levels of endothelial markers sampled after an acute (lacunar) stroke, probably do not reflect the chronic conditions in which most of the manifestations of cSVD develop. Therefore evaluation is recommended several months after an acute stroke, to prevent an acute phase effect. Although careful selection and procedure will increase the reliability of the test results, it is probably impossible to exclude all interacting conditions.

Finally it is important to realise that inter-individual differences in blood levels are likely to be small and large patient samples are needed to find convincing effects. Studies with negative findings may have suffered a power problem.

\section{How should we improve future studies on endothelial dysfunction and (progression of) cerebral small vessel disease?}

Future studies that aim to study endothelial dysfunction using blood markers, should take additional important points into consideration. Studies should have a longitudinal design with sufficient follow-up. Furthermore, drawing conclusions about 
pathophysiological mechanisms from the presence (or absence) of an association with a single blood marker should be avoided. Future studies should study multiple biomarkers, and look for consistent associations with several connected blood markers. Correction for multiple testing should be applied.

Alternatively, instead of studying multiple single markers, compound scores of grouped markers from a particular mechanistic pathway may be used. However, although many researchers (including us) tried to group blood markers in different mechanistic categories, it is important to note that endothelial activation, coagulation, fibrinolysis, vascular inflammation and endothelial repair are parallel processes that interact. As mentioned before, it is also essential to realize that testing blood markers is likely to measure changes due to systemic vasculopathy and not cSVD alone.

Despite of the above mentioned suggestions for improving the use of blood markers for studying endothelial function, the question remains whether meticulously testing extensive panels of blood markers in large patient cohorts will lead to more substantial evidence linking CSVD and endothelial activation and dysfunction. Therefore, other ways to study endothelial function should certainly be considered, such as testing brain specific blood markers and biomarkers in the cerebrospinal fluid (CSF) and new imaging techniques.

CSF markers might be more sensitive to detect local brain processes than blood markers. Studies on CSF markers in CSVD are scarce. $(40,41)$ Most studies are conducted in patients with (pre)dementia. It may be worth to search for new biomarkers of CSVD within the CSF. However one must bear in mind that a lumbar puncture is invasive and a larger impediment for a (study)patient than a vena puncture. It will be difficult to collect information in large patient cohorts. New imaging techniques are being developed to examine the brain and its vasculature. High resolution imaging using 7T MRI provides a possibility to image the wall of the intracranial vessels. (42) Nonetheless the detection and interpretation of changes within the smaller vessels will be challenging.(42)

Probably the future lies in new imaging techniques that are developed not specifically to improve the detection of macroscopic structural changes, but to detect changes on a functional level. $(43,44)$ For example, using dynamic contrast enhanced (DCE) MRI, subtle leakage of contrast agent over the BBB can be quantified. Our research group recently demonstrated that patients with CSVD had a larger leaking brain volume compared to controls.(45) Longitudinal studies have yet to be performed. Another technique that might prove useful to add understanding to the endothelial function 
in cSVD is measuring cerebrovascular reactivity.(46) Regulation of vascular tone by the endothelium (or in other words the cerebrovascular reactivity) is reflected by the capacity of blood vessels to dilate. Currently, our research group is starting a study in which cerebrovascular reactivity is measured by blood oxygenation level-dependent (BOLD) MRI using CO2 breathing as vasodilatory stimulus. Molecular MR imaging techniques, for example using antibodies directed to inflammatory adhesion molecules that are conjugated to supermagnetic particles, have been applied in animals but not in humans yet. $(44,47-49)$ Radioactive ligands in combination with positron emission tomography (PET) and single photon emission computed tomography (SPECT) are another example of molecular imaging.(43) These imaging techniques still need to be refined and (further) adapted to human clinical studies. Once established they could provide numerous possibilities to study molecules and mechanisms involved in the development and progression of cSVD.

\section{Cerebral small vessel disease as part of a multi-system disorder}

\section{What do we know at present?}

For a long time, research in the field of cSVD was fully concentrated on the brain. Nowadays, small vessel disease is considered to be a multisystem disorder affecting the brain, kidneys, retina, skin, sublingual vasculature and probably also the heart.(50-56) This understanding has changed our perspective on small vessel disease from local to systemic and may also effect treatment strategies in the future. In search for a link between cSVD and small vessel disease in other organs, the association between kidney function and CSVD is best studied. A relation between manifestations of CSVD and kidney function was found in several cross-sectional studies, varying from population based studies to studies in hypertensive patients, (acute) stroke patients and patients with kidney disease. $(52,57-73)$ We confirmed the association between decreased kidney function and CMBs, one of the MRI manifestations of cSVD, in one of few longitudinal studies on this subject (this thesis, chapter 5).

Small vessel disease is thought to be the result of a chronic state of endothelial activation and inflammation. Endothelial dysfunction may be initiated by low levels of nitric oxid, which can lead to disturbances in the microcirculation.(8) In the brain, endothelial dysfunction may lead to leakage of the BBB and subsequent brain damage. In the kidney and other organs endothelial dysfunction will also lead to vulnerability of the small vessels and damage to the surrounding tissue. Endothelial dysfunction and nitric oxid deficiency have also been shown in chronic kidney disease. $(74,75)$ 
Hypertension, diabetes and age are known independent risk factors for the development of small vessel disease of the brain, kidneys and retina. The vasculature of the brain, kidneys and retina share anatomic and hemodynamic characteristics. $(50,51,76,77)$ The small perforating arteries of the brain and the glomerular afferent arterioles of the juxtamedullary nephrons are both low resistance vessel beds that arise from larger high-pressure arteries. These vessel beds are exposed to high blood volume and maintain high vascular tone. In increasing age the fluctuations of blood pressure within the cardiac cycle (pulse pressure) increases causing higher strain on the small vessels which makes them more susceptible to microvascular damage and might lead to endothelial activation or dysfunction. (77) This process is likely to occur simultaneously in different organs. The vascular beds of the brain may be extra vulnerable and the brain may very well be the first organ to be involved. In most people cSVD will develop unnoticed in the early phase of the disease.

\section{How can we use this knowledge to improve research on cerebral small vessel disease in the future?}

Other organ systems outside the brain may provide valuable information on the presence and severity of small vessel disease. Vascular beds that are more accessible than the vasculature of the brain, can be used to gather information on endothelial and hemodynamic changes in the cSVD patient. For example, the sublingual microvasculature is easily accessed and can be studied by intravital microscopy. (55) Clinical manifestations of small vessel disease outside the brain might be used as biomarkers or surrogate markers for brain damage and could help to identify those patients at risk to develop extensive brain damage. Such biomarkers include glycocalyx in the sublingual vasculature, kidney function, disease markers in the retina and in the future maybe also markers of local or systemic inflammation and endothelial activation.

Most available studies on small vessel disease confine to small vessel disease in one or two organs. In an ideal setting, the vascular beds of several organs are studied simultaneously. The Maastricht Study is a good example of an ongoing study that has included several imaging techniques and other diagnostic tools to collect information on multiple organ systems and achieve extensive bio-banking in a large cohort focusing on the etiology of type 2 diabetes.(78) A similar comprehensive study in a population-based cohort of individuals in the age of 40-70 years that is enriched with hypertensive patients and has a sufficient follow-up ( $>10$ years) would provide valuable information on the risk-factors and pathogenic mechanisms for developing cSVD and the interaction between different types of small vessel disease. Such a new comprehensive study however, is not easily performed and would be expensive and 
time consuming. Alternatively, large cohorts are formed by combining data from existing studies. The METACOHORTS is such an initiative and the collaboration group collected data on vascular disease and its contribution to cognitive decline from more than 90 studies leading to a sharing platform that consists of data of over 660,000 participants.(79)

\section{Will this knowledge change our management of cerebral small vessel disease?} It seems rational to strictly manage cardiovascular risk factors such as hypertension, smoking, hyperglycaemia and hyperlipidaemia in small vessel disease. Nonetheless protective effects of vascular risk management for the development and progression of cSVD are not yet established. There are no therapeutics that are proven to be effective in improving small vessel endothelial dysfunction, nor is it known whether this improvement will slow down progression of cSVD. Future treatment strategies could focus on anti-inflammatory agents or nitric oxid (NO) donors.

Although our results in chapter 4 provoke to hypothesize that patients with small vessel disease could benefit from vitamin B12 supplementation, previous studies on vitamin B supplementation and progression of CSVD only showed a possible effect in patients with severe cSVD.(80) So whether patients with small vessel disease benefit from treatment with vitamin B12 still needs to be established.

\section{The evaluation of disease progression in cSVD}

\section{What do we know at present?}

Longitudinal studies on CSVD are valuable to confirm cross-sectional associations and strengthen the cause-and-effect relationship. In longitudinal studies two important issues must be considered, being follow-up duration and disease stage. When deciding on follow-up duration, one must take into account that cSVD is a slowly progressive disease. Enough time must have passed to measure disease evolution. On the other hand longer follow-up duration will lead to drop out because of disability or death. This selection bias during follow-up is probably inevitable. Therefore the study population size must be substantial to lessen the impact of drop out or loss to followup. Secondly when conducting a follow-up study one must take into account that the stage of the disease at baseline will influence the results. Subjects with moderate to severe cSVD are especially at risk for further progression and disease progression probably accelerates in advanced stages, however progression may be difficult to measure in these cases due to ceiling effects. For instance, when the manifestations of CSVD on MRI are already extensive at baseline, progression at follow-up will be more difficult to detect. The different stages of the disease therefore need to be represented in a future study. 
In the past many different definitions and methods have been used to measure and describe the individual MRI manifestations of CSVD. In 2013 the standards for reporting vascular changes on neuroimaging (STRIVE) were introduced to reach consensus on definitions and imaging standards for markers and consequences of cSVD.(6) When applied, these recommendations will enable comparison between different studies and combining data for meta-analyses.

However, at this point there are no standards like the STRIVE for scoring progression of $\mathrm{WMH}, \mathrm{CMBs}$ and lacunes. Progression of $\mathrm{WMH}$ can be visually assessed. The Rotterdam progression scale is one of the most used visual progression rating scales and is highly correlated to changes in volume. $(81,82)$ Progression can also be automatically measured using computer software for volumetric measurements. Visual and volumetric measurements are considered to be complementary. $(6,83)$ Progression of CMBs and lacunes are usually defined as one or more new lesion(s). However the accuracy of this method depends on the skills of the researcher and the techniques and quality of the imaging. For PVS, there is no validated scale or method to rate progression. The available semi-quantitative rating scales for extent of PVS are not suitable to rate progression. So, at this moment, consensus on how to assess progression of CSVD and what methods should be used are lacking and are urgently needed.

Moreover it is important to bear in mind that CSVD is a dynamic process. Progression is often nonlinear showing acceleration, but sometimes also regression, over time. Although most patients with CSVD at baseline show progression of WMH on followup, some do not progress or even show reduction on follow-up. Future studies and preferably also rating scales should be equipped to detect these patients. $(84,85)$

\section{How should we improve rating progression of CSVD?}

Reaching consensus on the definition of progression of the different individual MRI manifestations and standardising the image acquisition, interpretation and reporting of progression of CSVD will prove valuable in the research field. Ideally a total progression score combining the individual MRI markers into one scale should be developed and validated. The recently developed total SVD score that sums the total burden of WMH, CMBs, lacunes and PVS, might act as a starting point to develop a total SVD progression score.

In addition one could think of other imaging markers such as brain atrophy. When follow-up duration is sufficient, this marker may also be valuable in the evaluation of progression of CSVD. Also with the development of new MRI techniques other markers will arise, including molecular biomarkers and parameters of BBB integrity. 
These markers may predict progression, but may also prove to be useful to assess progression over time.

\section{In future, how can we relate MRI progression of CSVD to clinical outcomes?}

It is important to note that not the severity of the MRI manifestations of cSVD and progression of these markers determine the outcome of the individual patient. It is the severity of the clinical consequences, such as cognitive disorders and motor and mood disturbances, and the risk of recurrent stroke and mortality that will determine the disability experienced by patients. MRI manifestations are just surrogate markers of the disease and its clinical consequences. We indeed showed that higher total SVD score on MRI is associated with higher long-term mortality (this thesis, chapter 6). It seems likely that progression of the MRI markers will also be related to more morbidity and mortality. Our group recently found an association between MRI progression of cSVD and cognitive decline in hypertensive patients. To add more clinical relevance to studies that use MRI progression as surrogate marker of cSVD, the association between MRI progression and the full impact on cognition, mobility and mood needs to be further confirmed. Future study protocols should include not only MRI progression as surrogate marker for disease progression, but also clinically relevant data, such as recurrent stroke, cognitive decline and mortality.

\section{Conclusion}

Evaluating the pathophysiological role of endothelial dysfunction in CSVD, including vascular inflammation and BBB permeability, remains a challenge. Although some blood markers like tPA and vitamin B12 are related to the presence and progression of cSVD in lacunar stroke patients, other markers could not be confirmed in our studies with a longitudinal study design. Larger follow-up studies and/or metaanalyses are needed to determine the role of endothelial dysfunction in CSVD. Also other (imaging) strategies to evaluate endothelial function need to be perfected. Small vessel disease is a systemic microangiopathy which may cause damage in different organs. In patients with (clinical) manifestations of cSVD clinicians should no longer only focus on the brain. Standard care should aim at the patient as a whole and treat risk factors accordingly. Also future studies into cSVD should consider including data on other vascular beds outside the brain.

We emphasize the importance of longitudinal study designs and combining the different MRI markers of cSVD, preferable in a standardised matter. A score that can assess progression of cSVD combining the different markers is urgently needed. 


\section{References}

1. Pantoni L. Cerebral small vessel disease: from pathogenesis and clinical characteristics to therapeutic challenges. Lancet Neurol. 2010 Jul;9(7):689-701. PubMed PMID: 20610345.

2. Staals J, Booth T, Morris Z, Bastin ME, Gow AJ, Corley J, et al. Total MRI load of cerebral small vessel disease and cognitive ability in older people. Neurobiology of aging. 2015 Oct;36(10):2806-11. PubMed PMID: 26189091.

3. van der Flier WM, van Straaten EC, Barkhof F, Verdelho A, Madureira S, Pantoni L, et al. Small vessel disease and general cognitive function in nondisabled elderly: the LADIS study. Stroke; a journal of cerebral circulation. 2005 Oct;36(10):2116-20. PubMed PMID: 16141425.

4. Smith EE, O'Donnell M, Dagenais G, Lear SA, Wielgosz A, Sharma M, et al. Early cerebral small vessel disease and brain volume, cognition, and gait. Ann Neurol. 2015 Feb;77(2):251-61. PubMed PMID: 25428654. Pubmed Central PMCID: 4338762.

5. Inzitari D, Simoni M, Pracucci G, Poggesi A, Basile AM, Chabriat $H$, et al. Risk of rapid global functional decline in elderly patients with severe cerebral age-related white matter changes: the LADIS study. Archives of internal medicine. 2007 Jan 8;167(1):81-8. PubMed PMID: 17210882.

6. Wardlaw JM, Smith EE, Biessels GJ, Cordonnier C, Fazekas F, Frayne R, et al. Neuroimaging standards for research into small vessel disease and its contribution to ageing and neurodegeneration. Lancet Neurol. 2013 Aug;12(8):822-38. PubMed PMID: 23867200. Pubmed Central PMCID: 3714437.

7. Poggesi A, Pasi M, Pescini F, Pantoni L, Inzitari D. Circulating biologic markers of endothelial dysfunction in cerebral small vessel disease: a review. Journal of cerebral blood flow and metabolism : official journal of the International Society of Cerebral Blood Flow and Metabolism. 2015 Jun 10. PubMed PMID: 26058695. Pubmed Central PMCID: 4758546.

8. Knottnerus IL, Ten Cate H, Lodder J, Kessels F, van Oostenbrugge RJ. Endothelial dysfunction in lacunar stroke: a systematic review. Cerebrovascular diseases. 2009;27(5):519-26. PubMed PMID: 19372654.

9. Wardlaw JM, Smith C, Dichgans M. Mechanisms of sporadic cerebral small vessel disease: insights from neuroimaging. Lancet Neurol. 2013 May;12(5):483-97. PubMed PMID: 23602162. Pubmed Central PMCID: 3836247.

10. Wardlaw JM. Blood-brain barrier and cerebral small vessel disease. Journal of the neurological sciences. 2010 Dec 15;299(1-2):66-71. PubMed PMID: 20850797.

11. Wiseman S, Marlborough F, Doubal F, Webb DJ, Wardlaw J. Blood Markers of Coagulation, Fibrinolysis, Endothelial Dysfunction and Inflammation in Lacunar Stroke versus Non-Lacunar Stroke and Non-Stroke: Systematic Review and Meta-Analysis. Cerebrovascular diseases. 2014;37(1):64-75. PubMed PMID: 24401164.

12. Knottnerus IL, Govers-Riemslag JW, Hamulyak K, Rouhl RP, Staals J, Spronk HM, et al. Endothelial activation in lacunar stroke subtypes. Stroke; a journal of cerebral circulation. 2010 Aug;41(8):1617-22. PubMed PMID: 20595673.

13. Knottnerus IL, Winckers K, Ten Cate H, Hackeng TM, Lodder J, Rouhl RP, et al. Levels of heparin-releasable TFPI are increased in first-ever lacunar stroke patients. Neurology. 2012 Feb 14;78(7):493-8. PubMed PMID: 22302552.

14. Miralbell J, Soriano JJ, Spulber G, Lopez-Cancio E, Arenillas JF, Bargallo N, et al. Structural brain changes and cognition in relation to markers of vascular dysfunction. Neurobiology of aging. 2012 May;33(5):1003 e9-17. PubMed PMID: 22014619.

15. Kario K, Matsuo T, Kobayashi H, Hoshide S, Shimada K. Hyperinsulinemia and hemostatic abnormalities are associated with silent lacunar cerebral infarcts in elderly hypertensive subjects. Journal of the American College of Cardiology. 2001 Mar 01;37(3):871-7. PubMed PMID: 11693764.

16. Gottesman RF, Cummiskey C, Chambless L, Wu KK, Aleksic N, Folsom AR, et al. Hemostatic factors and subclinical brain infarction in a community-based sample: the ARIC study. 
Cerebrovascular diseases. 2009;28(6):589-94. PubMed PMID: 19844099. Pubmed Central PMCID: 2914353.

17. Hassan A, Hunt BJ, O'Sullivan M, Parmar K, Bamford JM, Briley D, et al. Markers of endothelial dysfunction in lacunar infarction and ischaemic leukoaraiosis. Brain : a journal of neurology. 2003 Feb;126(Pt 2):424-32. PubMed PMID: 12538408.

18. Tomimoto H, Akiguchi I, Ohtani R, Yagi H, Kanda M, Shibasaki H, et al. The coagulationfibrinolysis system in patients with leukoaraiosis and Binswanger disease. Archives of neurology. 2001 Oct;58(10):1620-5. PubMed PMID: 11594920.

19. Rouhl RP, Damoiseaux JG, Lodder J, Theunissen RO, Knottnerus IL, Staals J, et al. Vascular inflammation in cerebral small vessel disease. Neurobiology of aging. 2012 Aug;33(8):1800-6. PubMed PMID: 21601314.

20. Markus HS, Hunt B, Palmer K, Enzinger C, Schmidt H, Schmidt R. Markers of endothelial and hemostatic activation and progression of cerebral white matter hyperintensities: longitudinal results of the Austrian Stroke Prevention Study. Stroke; a journal of cerebral circulation. 2005 Jul;36(7):1410-4. PubMed PMID: 15905468.

21. Umemura T, Kawamura T, Umegaki H, Mashita S, Kanai A, Sakakibara T, et al. Endothelial and inflammatory markers in relation to progression of ischaemic cerebral small-vessel disease and cognitive impairment: a 6-year longitudinal study in patients with type 2 diabetes mellitus. Journal of neurology, neurosurgery, and psychiatry. 2011 Nov;82(11):1186-94. PubMed PMID: 21478205.

22. Rouhl RP, van Oostenbrugge RJ, Theunissen RO, Knottnerus IL, Staals J, Henskens LH, et al. Autoantibodies against oxidized low-density lipoprotein in cerebral small vessel disease. Stroke; a journal of cerebral circulation. 2010 Nov;41(11):2687-9. PubMed PMID: 20947847.

23. Wright CB, Moon Y, Paik MC, Brown TR, Rabbani L, Yoshita M, et al. Inflammatory biomarkers of vascular risk as correlates of leukoariosis. Stroke; a journal of cerebral circulation. 2009 Nov;40(11):3466-71. PubMed PMID: 19696417. Pubmed Central PMCID: 3114944.

24. van Dijk EJ, Prins ND, Vermeer SE, Vrooman HA, Hofman A, Koudstaal PJ, et al. C-reactive protein and cerebral small-vessel disease: the Rotterdam Scan Study. Circulation. 2005 Aug 09;112(6):900-5. PubMed PMID: 16061741.

25. Aono $\mathrm{Y}$, Ohkubo T, Kikuya M, Hara A, Kondo T, Obara T, et al. Plasma fibrinogen, ambulatory blood pressure, and silent cerebrovascular lesions: the Ohasama study. Arteriosclerosis, thrombosis, and vascular biology. 2007 Apr;27(4):963-8. PubMed PMID: 17272746.

26. Notsu Y, Nabika T, Bokura H, Suyama Y, Kobayashi S, Yamaguchi S, et al. Evaluation of asymmetric dimethylarginine and homocysteine in microangiopathy-related cerebral damage. American journal of hypertension. 2009 Mar;22(3):257-62. PubMed PMID: 19057516.

27. Pikula A, Boger RH, Beiser AS, Maas R, DeCarli C, Schwedhelm E, et al. Association of plasma ADMA levels with MRI markers of vascular brain injury: Framingham offspring study. Stroke; a journal of cerebral circulation. 2009 Sep;40(9):2959-64. PubMed PMID: 19644064. Pubmed Central PMCID: 2749945.

28. Khan U, Hassan A, Vallance P, Markus HS. Asymmetric dimethylarginine in cerebral small vessel disease. Stroke; a journal of cerebral circulation. 2007 Feb;38(2):411-3. PubMed PMID: 17204687.

29. Kim Y, Kim YK, Kim NK, Kim SH, Kim OJ, Oh SH. Circulating matrix metalloproteinase-9 level is associated with cerebral white matter hyperintensities in non-stroke individuals. European neurology. 2014;72(3-4):234-40. PubMed PMID: 25248031.

30. Satizabal CL, Zhu YC, Mazoyer B, Dufouil C, Tzourio C. Circulating IL-6 and CRP are associated with MRI findings in the elderly: the 3C-Dijon Study. Neurology. 2012 Mar 06;78(10):720-7. PubMed PMID: 22357713.

31. Fornage M, Chiang YA, O'Meara ES, Psaty BM, Reiner AP, Siscovick DS, et al. Biomarkers of Inflammation and MRI-Defined Small Vessel Disease of the Brain: The Cardiovascular Health 
Study. Stroke; a journal of cerebral circulation. 2008 Jul;39(7):1952-9. PubMed PMID: 18436879. Pubmed Central PMCID: 2888487.

32. Hassan A, Hunt BJ, O'Sullivan M, Bell R, D'Souza R, Jeffery S, et al. Homocysteine is a risk factor for cerebral small vessel disease, acting via endothelial dysfunction. Brain : a journal of neurology. 2004 Jan;127(Pt 1):212-9. PubMed PMID: 14607791.

33. Spence JD, Stampfer MJ. Understanding the complexity of homocysteine lowering with vitamins: the potential role of subgroup analyses. JAMA. 2011 Dec 21;306(23):2610-1. PubMed PMID: 22187282.

34. Scalabrino G. Cobalamin (vitamin $\mathrm{B}(12)$ ) in subacute combined degeneration and beyond: traditional interpretations and novel theories. Experimental neurology. 2005 Apr;192(2):46379. PubMed PMID: 15755562.

35. Vermeer SE, van Dijk EJ, Koudstaal PJ, Oudkerk M, Hofman A, Clarke R, et al. Homocysteine, silent brain infarcts, and white matter lesions: The Rotterdam Scan Study. Ann Neurol. 2002 Mar;51(3):285-9. PubMed PMID: 11891822.

36. Scalabrino G. The multi-faceted basis of vitamin B12 (cobalamin) neurotrophism in adult central nervous system: Lessons learned from its deficiency. Progress in neurobiology. 2009 Jul;88(3):203-20. PubMed PMID: 19394404.

37. Gianazza E, Veber D, Eberini I, Buccellato FR, Mutti E, Sironi L, et al. Cobalamin (vitamin B12)deficiency-induced changes in the proteome of rat cerebrospinal fluid. The Biochemical journal. 2003 Aug 15;374(Pt 1):239-46. PubMed PMID: 12769818. Pubmed Central PMCID: 1223583.

38. Mayhan WG. Cellular mechanisms by which tumor necrosis factor-alpha produces disruption of the blood-brain barrier. Brain research. 2002 Feb 15;927(2):144-52. PubMed PMID: 11821008.

39. Lehmann M, Regland B, Blennow K, Gottfries CG. Vitamin B12-B6-folate treatment improves blood-brain barrier function in patients with hyperhomocysteinaemia and mild cognitive impairment. Dementia and geriatric cognitive disorders. 2003;16(3):145-50. PubMed PMID: 12826740.

40. Pantoni L, Inzitari D, Pracucci G, Lolli F, Giordano G, Bracco L, et al. Cerebrospinal fluid proteins in patients with leucoaraiosis: possible abnormalities in blood-brain barrier function. Journal of the neurological sciences. 1993 Apr;115(2):125-31. PubMed PMID: 8482973.

41. Sjogren $M$, Blomberg $M$, Jonsson $M$, Wahlund LO, Edman $A$, Lind K, et al. Neurofilament protein in cerebrospinal fluid: a marker of white matter changes. Journal of neuroscience research. 2001 Nov 01;66(3):510-6. PubMed PMID: 11746370.

42. Harteveld AA, van der Kolk AG, van der Worp HB, Dieleman N, Siero JC, Kuijf HJ, et al. Highresolution intracranial vessel wall MRI in an elderly asymptomatic population: comparison of 3T and 7T. European radiology. 2017 Apr;27(4):1585-95. PubMed PMID: 27387876. Pubmed Central PMCID: 5334422.

43. Gounis MJ, van der Marel K, Marosfoi M, Mazzanti ML, Clarencon F, Chueh JY, et al. Imaging Inflammation in Cerebrovascular Disease. Stroke; a journal of cerebral circulation. 2015 Oct;46(10):2991-7. PubMed PMID: 26351362. Pubmed Central PMCID: 4589518.

44. Quarantelli M. MRI/MRS in neuroinflammation: methodology and applications. Clinical and translational imaging. 2015;3:475-89. PubMed PMID: 26705534. Pubmed Central PMCID: 4679099.

45. Zhang CE, Wong SM, van de Haar HJ, Staals J, Jansen JF, Jeukens CR, et al. Blood-brain barrier leakage is more widespread in patients with cerebral small vessel disease. Neurology. 2017 Jan 31;88(5):426-32. PubMed PMID: 28031395.

46. Blair GW, Doubal FN, Thrippleton MJ, Marshall I, Wardlaw JM. Magnetic resonance imaging for assessment of cerebrovascular reactivity in cerebral small vessel disease: A systematic review. Journal of cerebral blood flow and metabolism : official journal of the International Society of Cerebral Blood Flow and Metabolism. 2016 May;36(5):833-41. PubMed PMID: 26884471. Pubmed Central PMCID: 4853842. 
47. McAteer MA, Sibson NR, von Zur Muhlen C, Schneider JE, Lowe AS, Warrick N, et al. In vivo magnetic resonance imaging of acute brain inflammation using microparticles of iron oxide. Nature medicine. 2007 Oct;13(10):1253-8. PubMed PMID: 17891147. Pubmed Central PMCID: 2917758.

48. Hoyte LC, Brooks KJ, Nagel S, Akhtar A, Chen R, Mardiguian S, et al. Molecular magnetic resonance imaging of acute vascular cell adhesion molecule-1 expression in a mouse model of cerebral ischemia. Journal of cerebral blood flow and metabolism : official journal of the International Society of Cerebral Blood Flow and Metabolism. 2010 Jun;30(6):1178-87. PubMed PMID: 20087364. Pubmed Central PMCID: 2949202.

49. Gauberti M, Montagne A, Marcos-Contreras OA, Le Behot A, Maubert E, Vivien D. Ultrasensitive molecular MRI of vascular cell adhesion molecule-1 reveals a dynamic inflammatory penumbra after strokes. Stroke; a journal of cerebral circulation. 2013 Jul;44(7):1988-96. PubMed PMID: 23743972.

50. Turner ST, Rule AD, Schwartz GL, Kullo IJ, Mosley TH, Jack CR, et al. Risk factor profile for chronic kidney disease is similar to risk factor profile for small artery disease. Journal of hypertension. 2011 Sep;29(9):1796-801. PubMed PMID: 21720267. Pubmed Central PMCID: 3651813.

51. Thompson CS, Hakim AM. Living beyond our physiological means: small vessel disease of the brain is an expression of a systemic failure in arteriolar function: a unifying hypothesis. Stroke; a journal of cerebral circulation. 2009 May;40(5):e322-30. PubMed PMID: 19228835.

52. Wada M, Nagasawa H, Iseki C, Takahashi Y, Sato H, Arawaka S, et al. Cerebral small vessel disease and chronic kidney disease (CKD): results of a cross-sectional study in communitybased Japanese elderly. Journal of the neurological sciences. 2008 Sep 15;272(1-2):36-42. PubMed PMID: 18541269.

53. Ruchoux MM, Brulin P, Leteurtre E, Maurage CA. Skin biopsy value and leukoaraiosis. Annals of the New York Academy of Sciences. 2000 Apr;903:285-92. PubMed PMID: 10818517.

54. Hughes AD, Falaschetti E, Witt N, Wijetunge S, Thom SA, Tillin T, et al. Association of Retinopathy and Retinal Microvascular Abnormalities With Stroke and Cerebrovascular Disease. Stroke; a journal of cerebral circulation. 2016 Nov;47(11):2862-4. PubMed PMID: 27729577. Pubmed Central PMCID: 5082730.

55. Martens RJ, Vink H, van Oostenbrugge RJ, Staals J. Sublingual microvascular glycocalyx dimensions in lacunar stroke patients. Cerebrovascular diseases. 2013;35(5):451-4. PubMed PMID: 23735841.

56. Edwards MS, Wilson DB, Craven TE, Stafford J, Fried LF, Wong TY, et al. Associations between retinal microvascular abnormalities and declining renal function in the elderly population: the Cardiovascular Health Study. American journal of kidney diseases : the official journal of the National Kidney Foundation. 2005 Aug;46(2):214-24. PubMed PMID: 16112039.

57. Akoudad S, Sedaghat S, Hofman A, Koudstaal PJ, van der Lugt A, Ikram MA, et al. Kidney function and cerebral small vessel disease in the general population. International journal of stroke : official journal of the International Stroke Society. 2015 Mar 5. PubMed PMID: 25753173.

58. Ikram MA, Vernooij MW, Hofman A, Niessen WJ, van der Lugt A, Breteler MM. Kidney function is related to cerebral small vessel disease. Stroke; a journal of cerebral circulation. 2008 Jan;39(1):55-61. PubMed PMID: 18048865.

59. Oksala NK, Salonen T, Strandberg T, Oksala A, Pohjasvaara T, Kaste M, et al. Cerebral small vessel disease and kidney function predict long-term survival in patients with acute stroke. Stroke; a journal of cerebral circulation. 2010 Sep;41(9):1914-20. PubMed PMID: 20671250.

60. Takahashi W, Tsukamoto Y, Takizawa S, Kawada S, Takagi S. Relationship between chronic kidney disease and white matter hyperintensities on magnetic resonance imaging. Journal of stroke and cerebrovascular diseases : the official journal of National Stroke Association. 2012 Jan;21(1):18-23. PubMed PMID: 20833078. 
61. Otani H, Kikuya M, Hara A, Terata S, Ohkubo T, Kondo T, et al. Association of kidney dysfunction with silent lacunar infarcts and white matter hyperintensity in the general population: the Ohasama study. Cerebrovascular diseases. 2010;30(1):43-50. PubMed PMID: 20431289.

62. Khatri M, Wright CB, Nickolas TL, Yoshita M, Paik MC, Kranwinkel G, et al. Chronic kidney disease is associated with white matter hyperintensity volume: the Northern Manhattan Study (NOMAS). Stroke; a journal of cerebral circulation. 2007 Dec;38(12):3121-6. PubMed PMID: 17962588. Pubmed Central PMCID: 2948438.

63. Yahalom G, Schwartz R, Schwammenthal Y, Merzeliak O, Toashi M, Orion D, et al. Chronic kidney disease and clinical outcome in patients with acute stroke. Stroke; a journal of cerebral circulation. 2009 Apr;40(4):1296-303. PubMed PMID: 19182072.

64. Watanabe A. Cerebral microbleeds and intracerebral hemorrhages in patients on maintenance hemodialysis. Journal of stroke and cerebrovascular diseases : the official journal of National Stroke Association. 2007 Jan-Feb;16(1):30-3. PubMed PMID: 17689389.

65. Shima H, Ishimura E, Naganuma T, Yamazaki T, Kobayashi I, Shidara K, et al. Cerebral microbleeds in predialysis patients with chronic kidney disease. Nephrology, dialysis, transplantation : official publication of the European Dialysis and Transplant Association European Renal Association. 2010 May;25(5):1554-9. PubMed PMID: 20037183.

66. Toyoda G, Bokura H, Mitaki S, Onoda K, Oguro H, Nagai A, et al. Association of mild kidney dysfunction with silent brain lesions in neurologically normal subjects. Cerebrovascular diseases extra. 2015 Jan-Apr;5(1):22-7. PubMed PMID: 25873927. Pubmed Central PMCID: 4376920.

67. Naganuma T, Takemoto Y, Yamasaki T, Shima H, Shoji T, Ishimura E, et al. Factors associated with silent cerebral microbleeds in hemodialysis patients. Clinical nephrology. 2011 Apr;75(4):346-55. PubMed PMID: 21426889.

68. Zhang JB, Ju XH, Wang J, Sun HR, Li F. Serum cystatin C and cerebral microbleeds in patients with acute cerebral stroke. Journal of clinical neuroscience : official journal of the Neurosurgical Society of Australasia. 2014 Feb;21(2):268-73. PubMed PMID: 24139136.

69. Zhang JB, Liu LF, Li ZG, Sun HR, Ju XH. Associations Between Biomarkers of Renal Function With Cerebral Microbleeds in Hypertensive Patients. American journal of hypertension. 2014 Dec 12. PubMed PMID: 25498995.

70. Ovbiagele B, Liebeskind DS, Pineda S, Saver JL. Strong independent correlation of proteinuria with cerebral microbleeds in patients with stroke and transient ischemic attack. Archives of neurology. 2010 Jan;67(1):45-50. PubMed PMID: 20065128.

71. Cho AH, Lee SB, Han SJ, Shon YM, Yang DW, Kim BS. Impaired kidney function and cerebral microbleeds in patients with acute ischemic stroke. Neurology. 2009 Nov 17;73(20):1645-8. PubMed PMID: 19917986.

72. Song TJ, Kim J, Lee HS, Nam CM, Nam HS, Kim YD, et al. Distribution of cerebral microbleeds determines their association with impaired kidney function. Journal of clinical neurology. 2014 Jul;10(3):222-8. PubMed PMID: 25045375. Pubmed Central PMCID: 4101099.

73. Ryu WS, Lee SH, Kim CK, Kim BJ, Yoon BW. The relation between chronic kidney disease and cerebral microbleeds: difference between patients with and without diabetes. International journal of stroke : official journal of the International Stroke Society. 2012 Oct;7(7):551-7. PubMed PMID: 22243603.

74. Baylis C. Nitric oxide deficiency in chronic kidney disease. American journal of physiology Renal physiology. 2008 Jan;294(1):F1-9. PubMed PMID: 17928410.

75. Caglar K, Yilmaz MI, Saglam M, Cakir E, Kilic S, Sonmez A, et al. Serum fetuin-a concentration and endothelial dysfunction in chronic kidney disease. Nephron Clinical practice. 2008;108(3):c233-40. PubMed PMID: 18334823.

76. Mogi M, Horiuchi M. Clinical Interaction between Brain and Kidney in Small Vessel Disease. Cardiology research and practice. 2011;2011:306189. PubMed PMID: 21274446. Pubmed Central PMCID: 3025374. 
77. Ito S, Nagasawa T, Abe M, Mori T. Strain vessel hypothesis: a viewpoint for linkage of albuminuria and cerebro-cardiovascular risk. Hypertension research : official journal of the Japanese Society of Hypertension. 2009 Feb;32(2):115-21. PubMed PMID: 19262469.

78. Schram MT, Sep SJ, van der Kallen CJ, Dagnelie PC, Koster A, Schaper N, et al. The Maastricht Study: an extensive phenotyping study on determinants of type 2 diabetes, its complications and its comorbidities. Eur J Epidemiol. 2014 Jun;29(6):439-51. PubMed PMID: 24756374.

79. METACOHORTS for the study of vascular disease and its contribution to cognitive decline and neurodegeneration: An initiative of the Joint Programme for Neurodegenerative Disease Research. Alzheimer's \& dementia : the journal of the Alzheimer's Association. 2016 Dec;12(12):1235-49. PubMed PMID: 27490018. Pubmed Central PMCID: 5399602.

80. Cavalieri M, Schmidt R, Chen C, Mok V, de Freitas GR, Song S, et al. B vitamins and magnetic resonance imaging-detected ischemic brain lesions in patients with recent transient ischemic attack or stroke: the VITAmins TO Prevent Stroke (VITATOPS) MRI-substudy. Stroke; a journal of cerebral circulation. 2012 Dec;43(12):3266-70. PubMed PMID: 23093615.

81. Prins ND, van Straaten EC, van Dijk EJ, Simoni M, van Schijndel RA, Vrooman HA, et al. Measuring progression of cerebral white matter lesions on MRI: visual rating and volumetrics. Neurology. 2004 May 11;62(9):1533-9. PubMed PMID: 15136677.

82. Gouw AA, van der Flier WM, van Straaten EC, Pantoni L, Bastos-Leite AJ, Inzitari D, et al. Reliability and sensitivity of visual scales versus volumetry for evaluating white matter hyperintensity progression. Cerebrovascular diseases. 2008;25(3):247-53. PubMed PMID: 18216467.

83. Valdes Hernandez Mdel C, Morris Z, Dickie DA, Royle NA, Munoz Maniega S, Aribisala BS, et al. Close correlation between quantitative and qualitative assessments of white matter lesions. Neuroepidemiology. 2013;40(1):13-22. PubMed PMID: 23075702.

84. Wardlaw JM, Chappell FM, Valdes Hernandez MDC, Makin SDJ, Staals J, Shuler K, et al. White matter hyperintensity reduction and outcomes after minor stroke. Neurology. $2017 \mathrm{Sep}$ 05;89(10):1003-10. PubMed PMID: 28794252. Pubmed Central PMCID: 5589793.

85. van Leijsen EMC, van Uden IWM, Ghafoorian M, Bergkamp MI, Lohner V, Kooijmans ECM, et al. Nonlinear temporal dynamics of cerebral small vessel disease: The RUN DMC study. Neurology. 2017 Oct 10;89(15):1569-77. PubMed PMID: 28878046. Pubmed Central PMCID: 5634663. 

Nederlandse samenvatting 



\section{Samenvatting}

Cerebrale small vessel disease (CSVD) is een overkoepelende term die gebruikt wordt voor verschillende ziekteprocessen waarbij de kleine vaten van de hersenen betrokken zijn. Er bestaan verschillende typen CSVD. De meest voorkomende vorm is gerelateerd aan vasculaire risicofactoren waaronder leeftijd, hypertensie (hoge bloeddruk) en diabetes mellitus (suikerziekte). De aanwezigheid van cSVD is geassocieerd met beroertes (zowel herseninfarcten als hersenbloedingen), cognitieve problemen, stemmingsklachten en veranderingen in het bewegingspatroon. Deze gezondheidsproblemen die gerelateerd zijn aan cSVD komen steeds frequenter voor in onze huidige, vergrijzende populatie.

cSVD leidt tot structurele veranderingen in het hersenweefsel. Deze uitingen van de ziekte kunnen in beeld worden gebracht met magnetic resonance imaging (MRI) en bestaan onder andere uit lacunes (kleine gebieden van weefselverlies), witte stofveranderingen, cerebrale microbloedingen en (verwijde) perivasculaire ruimtes. Hoewel er verschillende theorieën bestaan, is het exacte ontstaansmechanisme van deze veranderingen, en van CSVD, onbekend. $\mathrm{Er}$ is dan ook geen specifieke behandeling. De huidige behandelingen die gericht zijn op cSVD, zijn gebaseerd op de behandeling van een herseninfarct in het algemeen en het behandelen van beïnvloedbare risicofactoren zoals bloeddrukverlaging. Meer inzicht in pathofysiologische processen die CSVD veroorzaken is nodig en zal in de toekomst kunnen leiden tot meer gerichte en effectievere preventie en behandeling.

Endotheel disfunctie en de hierdoor veroorzaakte verstoring van de bloedhersenbarrière lijkt een belangrijke rol te spelen in het ontstaan van cSVD. Tot nu werd de associatie tussen endotheelfunctie en CSVD vooral onderzocht in crosssectionele studies. Hoewel dit type observationeel onderzoek waardevol is om kenmerken tussen verschillende patiëntengroepen te vergelijken, geeft het enkel informatie over een mogelijke associatie op het meetmoment. Longitudinaal onderzoek is van belang om meer duidelijkheid te krijgen over mogelijke oorzakelijke verbanden. Het aantal longitudinale onderzoeken dat zich richt op progressie van cSVD in de tijd is echter beperkt.

In deze thesis onderzochten we de relatie tussen toename van MRI-uitingen van CSVD en (bloed)markers van endotheelfunctie met als doel om meer inzicht te krijgen in de betrokkenheid daarvan in de processen die leiden tot het ontstaan en de progressie van cSVD. We bestudeerden hemostase- en inflammatiemarkers en vitamine B12 in relatie tot toename van de MRI-uitingen van CSVD. Ook onderzochten we nierfunctie, 
als marker van small vessel disease in de nieren, in relatie tot toename van cSVD op MRI. Deze onderzoeksdoelen werden bestudeerd in een cohort met patiënten met een klinische uiting van cSVD, namelijk een doorgemaakt lacunair herseninfarct. Deze patiënten werden geïncludeerd vanaf mei 2003 tot en met januari 2008. Alle patiënten kregen 2 jaar na eerste presentatie en MRI scan een controle MRI scan van de hersenen.

Tot slot onderzochten we de associatie tussen de ernst van cSVD (accumulatieve uitingen van cSVD op MRI) en de mortaliteit op lange termijn in hetzelfde cohort met patiënten met een lacunair herseninfarct.

In hoofdstuk 2 bestudeerden wij de associatie tussen (bloed)markers van inflammatie in de bloedvaten (neopterin, VCAM-1, ICAM-1, E-selectin and P-selectin and hsCRP) en toename van uitingen van cSVD op MRI na 2 jaar follow-up in 91 patiënten met een lacunair herseninfarct. Hoewel eerder cross-sectioneel onderzoek een relatie vond tussen enkele van de bovengenoemde markers en MRI-uitingen van cSVD, vonden wij geen enkele statistisch significante associatie. Onze studie kon dus geen van deze markers aanmerken als voorspeller van progressie van cSVD. Ondanks deze conclusie, sluiten wij een rol voor vasculaire inflammatie in het ontstaan en progressie van cSVD niet uit. Mogelijk was de variatie van de concentraties van de markers tussen patiënten te klein om te detecteren of zijn de markers niet specifiek genoeg. Anderzijds is het denkbaar dat verschillen in de concentraties klinisch niet relevant zijn. In de toekomst kan het zinvol zijn om het focus te verplaatsen naar andere markers, waarbij ook andere stappen in de processen van vasculaire inflammatie worden betrokken.

In hoofdstuk 3 onderzochten we de associatie tussen bloedwaarden van plasma tissue plasminogen activator (tPA)-activiteit en plasminogeen activator type 1 (PAI-1) en progressie van witte stofveranderingen op MRI na 2 jaar in een groep van 127 patiënten die een lacunair herseninfarct doormaakten. tPA en PAI-1 zijn onderdelen van het fibrinolytische systeem en ze worden beschouwd als hemostase-gerelateerde markers van endotheelfunctie. Hogere waarde van t-PA activiteit en lage waarden van PAl-1 werden in een eerder cross-sectioneel onderzoek gerelateerd aan uitgebreide witte stofveranderingen in deze patiëntengroep. In onze longitudinaal opgezette studie vonden we een associatie tussen de (baseline) tPA-activiteit en toename van periventriculaire witte stof veranderingen na 2 jaar. PAI- 1 waardes waren lager in de groep patiënten die toename hadden van witte stofveranderingen, echter deze resultaten waren niet statistisch significant. Onze studie is de eerste 
longitudinale studie die tPA-activiteit en PAI-1 waarde in het bloed heeft onderzocht in relatie tot progressie van CSVD en nodigt uit tot verder onderzoek naar de rol van deze markers in relatie tot endotheelfunctie en het ontstaan van cSVD.

In hoofdstuk 4 bestudeerden we de relatie tussen vitamine B12 in het bloed en toename van witte stofveranderingen na 2 jaar follow-up in een groep van 107 patiënten die een lacunair herseninfarct doormaakten. Er wordt gedacht dat vitamine B12 de endotheelfunctie kan beïnvloeden onder andere door het bewerkstelligen van een effect op de doorgankelijkheid van de bloedhersenbarrière. Onze studie is de eerste die zich richt op een mogelijke longitudinale associatie. We vonden dat een lagere baseline vitamine B12 waarde in het bloedplasma geassocieerd was met toename van periventriculaire witte stofveranderingen na 2 jaar follow-up. Er was geen verband tussen vitamine B12 en toename van diepe witte stofveranderingen. Of de onderzochte populatie ook baat zou kunnen hebben bij suppletie van vitamine B12 is nog onbekend.

In hoofdstuk $\mathbf{5}$ bestudeerden we de associatie tussen nierfunctie en toename van cerebrale microbloedingen na 2 jaar follow-up in 89 patiënten met een doorgemaakt lacunair herseninfarct. Chronische nierziekte wordt beschouwd als een gevolg van small vessel disease in de nieren. Endotheelactivatie en -inflammatie in de bloedvaten zijn vermoedelijk systemische processen en kunnen daarom parallel optreden in zowel hersenen als nieren. Ook zijn er hemodynamische en anatomische overeenkomsten tussen de vaten in de hersenen en de nieren, waardoor deze gelijktijdig kunnen worden aangedaan.

We vonden dat een lagere estimated glomerular filtration rate (eGFR, als maat voor nierfunctie) geassocieerd was met een toename van cerebrale microbloedingen, onafhankelijk van leeftijd, geslacht, bloeddruk en de aanwezigheid van microbloeding op baseline. Onze resultaten bevestigen de relatie tussen small vessel disease in de nieren en hersenen en ondersteunen daarmee de gedachte dat cSVD onderdeel is van een systemische aandoening van het endotheel waarbij meerdere orgaansystemen tegelijk betrokken kunnen zijn en niet alleen de hersenen.

In hoofdstuk 6 beschrijven we een longitudinaal onderzoek waarin wij gekeken hebben naar de totale ernst (accumulatieve uitingen) van cSVD op MRI en de lange termijn mortaliteit in een groep van 146 patiënten die een lacunair herseninfarct doormaakten. De follow-up duur was bijna 10 jaar. De aanwezigheid van witte stofveranderingen, lacunes, cerebrale microbloedingen en (verwijde) perivasculaire ruimtes werden visueel gescoord op een MRI hersenen die ten tijde van inclusie was 
verricht en de bevindingen werden verwerkt in een totale SVD score (0-4). Er van uitgaande dat morbiditeit en mortaliteit zijn geassocieerd met de ernst van de ziekte en niet met één enkele MRI uiting, maakt het zinvol om de totale score te gebruiken om mortaliteit op de lange termijn te onderzoeken. We toonden aan dat mortaliteit hoger was in de patiëntengroep met de hoogste score op de totale SVD schaal (score van 4). Hoewel de hazard ratio voor mortaliteit ook hoger was voor patiënten met een score van 1,2 of 3 in vergelijking met een score van 0 , waren deze resultaten niet statistisch significant. Als deze trend kan worden bevestigd in een groter cohort, dan kan de totale SVD score in de toekomst bruikbaar zijn om kwetsbare patiënten met een slechtere prognose na een lacunair herseninfarct te identificeren.

In hoofdstuk 7 wordt een algemene beschouwing en discussie van de resultaten uit deze thesis gegeven. 


Valorisatie 



\section{Inleiding}

Over het algemeen richt promotieonderzoek zich op een klein onderdeel binnen een specifiek vakgebied. Dit proefschrift is hierop geen uitzondering. Het is een wetenschappelijk document dat in de eerste plaats interessant zal zijn voor collega's werkzaam binnen de vasculaire neurologie en dan met name voor diegenen binnen het onderzoeksveld van de cerebrale small vessel disease (cSVD). Dit neemt niet weg dat het belangrijk is om wetenschappelijk onderzoek te plaatsen in een bredere maatschappelijke context. Daarom is aan dit proefschrift dit hoofdstuk over kennisvalorisatie toegevoegd. Kennisvalorisatie is het middel om de kennis uit een wetenschappelijk document te vertalen naar bruikbare kennis voor de maatschappij.

\section{Cerebrale small vessel disease en de maatschappelijke gevolgen van de ziekte}

In de laatste tien tot twintig jaar wordt er in toenemende mate onderzoek gedaan naar cSVD. Er is consensus ontstaan welke specifieke veranderingen van de hersenen op een MRI scan worden geduid als uitingen van cSVD. De aanwezigheid van tekenen van CSVD op een MRI scan geeft een verhoogd risico op cognitieve problemen, stemmingsklachten en veranderingen in het bewegingspatroon. Daarnaast wordt geschat dat $25 \%$ van de herseninfarcten wordt veroorzaakt door cSVD.

Een herseninfarct veroorzaakt vaak direct zichtbare en/of voor de patiënt direct merkbare beperkingen. Een plots ontstane verlamming van een arm of een spraakstoornis zal vrijwel zeker het functioneren van de patiënt in de maatschappij en de behoefte aan zorg en begeleiding beïnvloeden. De cognitieve, stemmings- en mobiliteitsproblemen die in de loop van de tijd door cSVD ontstaan, zijn niet altijd direct zichtbaar, maar deze beperkingen leiden op de langere termijn eveneens tot verlies van kwaliteit van leven, uitval op de arbeidsmarkt en een toegenomen zorgvraag met bijbehorende kosten.

CSVD is gerelateerd aan de veelvoorkomende risicofactoren voor hart- en vaatziekten, waaronder hoge leeftijd, roken, hoge bloeddruk en diabetes mellitus (suikerziekte). Het is te verwachten dat de gezondheidsproblemen die geassocieerd zijn met cSVD steeds frequenter zullen voorkomen binnen de huidige, ouder wordende, bevolking.

\section{Valorisatie van dit proefschrift}

Hoewel er verschillende theorieën bestaan, is het exacte ontstaansmechanisme van cSVD onbekend. Meer duidelijkheid over het ontstaan van de ziekte is noodzakelijk om een passende behandeling te kunnen bieden. Op dit moment is er (te) weinig wetenschappelijk bewijs beschikbaar als het gaat om welke specifieke behandeling voor patiënten met cSVD zinvol is. Na een lacunair herseninfarct, waarvan 
aangenomen wordt dat het door CSVD is veroorzaakt, wordt behandeling gestart die gebaseerd is op de kennis over het behandelen van een herseninfarct in het algemeen. Hierbij wordt mogelijk te weinig rekening gehouden met de onderliggende oorzaak van het herseninfarct. De huidige behandeling na een lacunair herseninfarct is gericht op secundaire preventie, oftewel het verlagen van het herhalingsrisico, door het behandelen van beïnvloedbare risicofactoren. Ten aanzien van behandeling voor cSVD lijkt het zinvol om de groep patiënten die geen herseninfarct hebben doorgemaakt, maar wel uitingen van cSVD op MRI laten zien, te screenen voor risicofactoren zoals hoge bloeddruk en diabetes en ze daarvoor te behandelen. Meer inzicht in het ontstaan van cSVD zal kunnen leiden tot een meer gerichte behandeling en op termijn winst opleveren voor de gezondheid en het welzijn van de individuele patiënt resulterend in een gunstig effect op onze maatschappij.

Dit proefschrift draagt bij aan het onderzoek naar het ontstaan en de toename van cSVD. We hebben ons daarbij voornamelijk gericht op markers in het bloed die inzicht kunnen geven in processen in het lichaam, en dan met name de bloedvaten, die cSVD kunnen veroorzaken.

De belangrijkste meerwaarde van dit proefschrift ten opzichte van eerdere studies naar dit onderwerp is het feit dat we hebben gekeken naar de toename van cSVD op MRI over een periode van 2 jaar. Eerdere studies onderzochten voornamelijk de relatie tussen de markers in het bloed en MRI-uitingen op een enkel punt in de tijd (cross-sectioneel onderzoek). Onderzoek dat kijkt naar toename van de MRI-uitingen in de tijd (longitudinaal onderzoek), maakt een (gevonden) associatie sterker. Oftewel: het vaststellen van de aanwezigheid van de ziekte onder bepaalde omstandigheden geeft waardevolle informatie, echter de factoren die ervoor zorgen dat de ziekte ontstaat en toeneemt in de tijd zijn belangrijker en zullen met longitudinaal onderzoek betrouwbaarder kunnen worden vastgesteld. Deze resultaten kunnen worden ingezet om nieuwe theorieën en behandelingen te toetsen in de toekomst. Hierbij kan bijvoorbeeld gedacht worden aan een therapie die het endotheel beschermt.

\section{Vitamine B12 en andere bloedmarkers}

In dit proefschrift wordt aangetoond dat lagere bloedwaardes van vitamine B12 meer witte stofveranderingen geven in de hersenen passend bij cSVD. Helaas hebben eerdere studies nog niet kunnen aantonen dat het verhogen van de vitamine B12 waarde in het bloed minder progressie geeft van cSVD. Deze studies hadden mogelijk een te korte follow-up duur of zijn uitgevoerd in de verkeerde 
patiënten(sub)groepen. Daarom is het zinvol om dit verder te onderzoeken. Zeker gezien het feit dat vitamine B12 een goedkope en niet belastende behandeling is. Verder ondersteunt dit proefschrift de rol van tPA (een enzym dat een rol speelt in oplossen van stolsels in de bloedvaten) in het ontstaan en toename van cSVD en werpt dit tPA, of de processen waarin tPA betrokken is, opnieuw op als mogelijke aangrijpingspunten voor therapie.

De bevindingen ten aanzien van de andere onderzochte markers zijn teleurstellend in de zin dat het niet leidt tot meer inzicht in het ontstaan van cSVD en dus ook niet direct leidt tot aangrijpingspunten voor een behandeling. Verder soortgelijk onderzoek naar deze bloedmarkers is niet zinvol. Dit proefschrift benadrukt het belang van het exploreren van andere methoden om endotheelfunctie te onderzoeken. Hierbij moet gedacht worden aan onderzoek in grotere patiëntengroepen, maar ook onderzoek met nieuwe beeldvormende technieken.

\section{Total cSVD Schaal}

Door onze onderzoeksgroep werd recent een nieuwe schaal geïntroduceerd die de uitingen van cSVD op MRI bundelt, een total cSVD schaal. In het onderzoeksveld van de cSVD was het lange tijd normaal om naar één specifieke verandering in de hersenen te kijken en dan een uitspraak te doen over een eventuele associatie tussen deze verandering en de gevolgen voor de patiënt. Een voorbeeld hiervan is de associatie tussen loopproblemen en witte stof veranderingen in de hersenen. Het is echter meer waarschijnlijk dat de klachten die een patiënt of zijn omgeving ervaart een resultaat zijn van de optelsom aan veranderingen in de hersenen. Het uniform vastleggen van deze veranderingen in een schaal die breed wordt gedragen, is van meerwaarde binnen het onderzoeksveld. De total cSVD schaal is hiervan een goed voorbeeld. In dit proefschrift wordt de bruikbaarheid van de schaal voor onderzoeksdoeleinden verder onderstreept. Er zijn aanwijzingen dat de schaal kan worden gebruikt om de meest kwetsbare patiënten binnen de groep met cSVD op te sporen.

\section{Small vessel disease als multi-orgaan ziekte}

Dit proefschrift draagt ten slotte bij aan het inzicht dat small vessel disease in de hersenen tegelijk op gaat met small vessel disease in andere organen. Bij het vaststellen van het risicoprofiel en ook de behandeling van cSVD is het belangrijk om meerdere orgaansystemen te betrekken. Naast de hersenen, kan small vessel disease onder andere voorkomen in de nieren, het hart en het netvlies. Het zien van small vessel disease als een multi-orgaan ziekte vraagt om bewustwording. Dit geldt niet 
alleen voor de neurologen die cSVD vaststellen, maar zeker ook voor internisten (vasculair internisten, nefrologen), geriaters, cardiologen en huisartsen die betrokken zijn bij behandeling van nierfalen, hoge bloeddruk en diabetes. Op dit moment is er aandacht voor orgaanschade door diabetes mellitus in de ogen en nieren. Echter de lange termijn effecten voor de hersenen komen veel minder vaak ter sprake. De bewustwording van de gevolgen die bijvoorbeeld diabetes en een hoge bloeddruk kunnen hebben op de hersenen is zeer relevant voor de patiënt zelf. Een gezonde(re) leefstijl, waaronder stoppen met roken en maatregelen nemen om bloeddruk en bloedsuiker te reguleren, geeft minder risico op hart- en vaatziekten. Het is van belang dat de patiënt beseft dat stemmings-, geheugen en bewegingsbeperkingen ook onderdeel kunnen uitmaken van deze hart- en vaatziekte. Dit zijn belangrijke thema's voor de ouder wordende bevolking en kunnen mogelijk de individuele patiënt motiveren om adviezen ten aanzien van preventie en behandeling strikter op te volgen.

\section{Conclusie}

De gevolgen van cSVD in onze vergrijzende bevolking zijn niet gering en zullen in de tijd enkel toenemen. Dit gaat gepaard met negatieve effecten op de kwaliteit van leven van patiënten en betrokkenen en met oplopende maatschappelijke kosten. Gezien deze economische en maatschappelijke impact is verder onderzoek naar het ontstaan en gerichte preventie en behandeling noodzakelijk. De resultaten in dit proefschrift zijn van algemeen belang, omdat deze bijdragen aan de toename van inzicht in de progressie van cSVD en aan een verdere bewustwording van de omvang van deze aandoening. 


Dankwoord 

Professor dr. van Oostenbrugge, beste Robert. In 2007 solliciteerde ik als student bij jou voor een wetenschapsstage. In het gesprek werd ik overvallen door de grote hoeveelheid informatie die op mij af kwam. Binnen no-time stond ik buiten, enthousiast, maar met een stage-onderwerp wat ik zelf nog niet volledig begreep. Dat eerste gesprek is kenmerkend voor jouw unieke en efficiënte manier van werken en communiceren. Al snel leerde ik dat korte vragen (en niet meer dan één per email!) het best werkt. Door de jaren heen was je er altijd voor vragen en advies, maar na een korte aanwijzing liet je me meestal zelf verder zwemmen. Dit was vaak een uitdaging, maar ook erg leuk en enorm leerzaam. Jouw enthousiasme voor onderzoek, de neurologie en ook de opleiding was en is inspirerend. Heel veel dank voor je begeleiding in de afgelopen 10 jaar!

Dr. Staals, beste Julie. Jij bent voor dit proefschrift van onschatbare waarde geweest. Jouw scherpe blik als wetenschapper en je zorgvuldigheid waren een belangrijke steun in mijn onderzoek. Je was altijd beschikbaar voor overleg en heel vlot en secuur in het reviseren van mijn manuscripten. Als ik weer eens verstrikt raakte in de database, was jij de reddende engel.

Ook in de kliniek heb ik je leren kennen als iemand met een kritische en heldere blik. Voor mij ben je een voorbeeld van hoe een neuroloog en supervisor moet zijn. Bedankt voor al je hulp, je geduld en voor de fijne samenwerking!

Beste Iris en Rob. Jullie harde werk, samen met Julie, aan de laci-database heeft er voor gezorgd dat mijn onderzoek een solide basis had. Bedankt daarvoor en voor jullie hulp bij het interpreteren van de eerder verzamelde data.

Alle andere vasculaire collega's in het MUMC, in willekeurige volgorde: Caroline, Debbie, Eleana, Floris, Marjolein, Martine, Pim en Renske. Dank voor de fijne samenwerking en kennisuitwisseling, maar zeker ook voor de gezelligheid op de onderzoekskamer en tijdens de congressen. Ik hoop dat er nog vele ESOCs (met of zonder Tiger Tiger ;-) ) gaan volgen.

Beste Henk. Na samenwerking in het Dordtse treffen we elkaar in het Maastrichtse. Ik wil je niet alleen danken voor het plaatsnemen in mijn beoordelingscommissie, maar ook voor de inspirerende samenwerking in het Albert Schweitzer Ziekenhuis. Jij hebt voor mij bevestigd dat het bedrijven van de neurologie op een hoog (wetenschappelijk) niveau niet voorbehouden is aan de academie. Samen met de andere collega's in Albert Schweitzer Ziekenhuis, die ik daar ook hartelijk voor wil 
bedanken, heb jij er voor gezorgd dat de start van mijn carrière als neuroloog zeer waardevol was.

Alle oud collega's van de neurologie van het MUMC: bedankt voor een fijne en leerzame opleidingstijd. Laura, Jessie en Janneke, jullie wil ik graag in het bijzonder bedanken. Met ons jaarclubje hebben we tijdens de opleiding veel lol gehad. Het is zo fijn om de leuke en minder leuke dingen rondom werk - en de rest van het leven met elkaar te kunnen delen, ook nu nog. Op naar Dublin 2.0!

Lieve Doenja en Barbe. Wat ben ik dankbaar dat ik jullie in mijn leven heb. Wat geweldig dat jullie vandaag naast mij staan. Ik hoop dat onze levens op dezelfde manier verstrengeld blijven en dat we al het moois dat het leven te bieden heeft, samen mogen blijven beleven. Lieve Inge, onze vriendschap is mij zoveel waard! Al 30 jaar delen we lief en leed, maar wat is het fijn om nu weer echt dicht bij elkaar te zijn. Wie had kunnen voorspellen dat we nog eens samen in het mooie Rosmalen zouden wonen.

Lieve vrienden uit Maastricht en Breda. Het leven is zoveel meer dan alleen maar hard werken. Bedankt voor alle ontspanning tijdens mijn opleiding, het promoveren en het verdere werkende leven. Dat er nog vele weekendjes, skitrips, concerten, shopdates, carnavalsvieringen, borrelavonden en festivals mogen volgen.

Lieve Marian, Gert, Lieke, Maaike, Leandro en Alma. Het is heel fijn en een voorrecht om onderdeel van jullie familie te zijn. Marian, bedankt voor de mooie foto voor de cover.

Lieve Ben, Marloes, Aniek, Babette, Hilde, Thomas, Isa, Julien en Arjan. Het is heel bijzonder om als familie zo dicht bij elkaar te staan en ik hoop dat dat altijd zo blijft.

Lieve Yvonne, Eric, Maarten, Henno en Bowie. Bedankt voor alle liefde, ondersteuning en gezelligheid in de grote en kleine dingen in het leven.

Lieve Dries. Dank je wel voor al je onvoorwaardelijke steun. Jij herinnert mij er altijd aan wat er belangrijk is in het leven. Je geeft ruimte aan mijn ambities, maar kan mij ook op een prettige manier terugfluiten als ik mezelf voorbijloop. Dat we nu met $z^{\prime} n$ viertjes zijn, heeft mijn geluk nog completer gemaakt. Wat is het genieten om mijn leven met jou, Flo en Wout te mogen delen! 




\section{Curriculum vitae}



Ellen van Overbeek werd op 8 oktober 1984 geboren in Breda, Nederland. Zij groeide op in Breda en behaalde in 2002 haar gymnasium diploma cum laude op het Onze Lieve Vrouwelyceum. Aansluitend startte zij haar geneeskunde opleiding aan de Universiteit van Maastricht. Zij onderbrak haar opleiding kortdurend voor vrijwilligerswerk in het Tamale Teaching Hospital in Ghana. Na het hervatten van de opleiding liep zij haar laatste jaar stage op de afdeling neurologie in het Maastricht Universitair Medisch Centrum. Daar maakte zij een begin met wetenschappelijk onderzoek binnen de vasculaire neurologie. Na het behalen van haar artsexamen in december 2008, werkte zij in het Orbis Medisch Centrum (huidige Zuyderlandziekenhuis) te Sittard-Geleen. Vanaf september 2009 was zij werkzaam in het Maastricht Universitair Medisch Centrum op de afdeling neurologie waar zij in februari 2010 startte met de opleiding tot neuroloog. Onder begeleiding van professor dr. Robert van Oostenbrugge en dr. Julie Staals werd het onderzoek binnen de vasculaire neurologie voortgezet en dit leidde tot een promotietraject. In februari 2016 rondde zij haar opleiding tot neuroloog af. Van 1 augustus 2016 tot en met juni 2018 was zij werkzaam als neuroloog in het Albert Schweitzer Ziekenhuis te Dordrecht.

Ellen van Overbeek was born on October 8th in Breda, the Netherlands. She grew up in Breda and finished secondary school at the Onze Lieve Vrouwelyceum in 2002. Subsequently, she started medical school at Maastricht University. She worked as a volunteer in the Tamale Teaching Hospital in Ghana during a break from her studies. Afterwards she completed her last year of medical school at the Neurology department of the Maastricht University Medical Center where she started her research in the field of the vascular neurology. After obtaining her medical degree in December 2008, she worked at the Orbis Medical Center in Sittard-Geleen (nowadays Zuyderland Hospital). In September 2009 she started working at the Neurology department of the Maastricht University Medical Center, where she began her residency in February 2010. Under the guidance of prof. dr. Robert van Oostenbrugge and dr. Julie Staals she continued her efforts in the research field of the vascular neurology leading to a PhD thesis. In February 2016 she finished her residency. From August 2016 until June 2018 she worked as a neurologist at the Albert Schweitzer Hospital in Dordrecht. 

List of Publications 

van Overbeek EC, Staals J, van Oostenbrugge RJ. Decreased kidney function is associated with progression of cerebral microbleeds in lacunar stroke patients. International Journal of Stroke. 2016;11(6):695-700

van Overbeek EC, Staals J, Knottnerus ILH, ten Cate H, van Oostenbrugge RJ. Plasma tPA-activity and progression of cerebral white matter hyperintensities in lacunar stroke patients. PLoS One. 2016;11(3):e0150740. doi: 10.1371/journal.pone.0150740

van Overbeek EC, Staals J, van Oostenbrugge RJ. Vitamin B12 and Progression of White matter lesions. A 2-Year Follow-Up Study in First-Ever Lacunar Stroke Patients. PLoS One. 2013;8(10): e78100. doi:10.1371/journal.pone.0078100

van Overbeek EC, van Oostenbrugge RJ. Reply to the Letter by Sharma et al: Hyperdense middle cerebral artery sign and stroke outcomes after intravenous thrombolysis. Cerebrovascular Diseases.2011;31:209

van Overbeek EC, Janknegt R, ter Berg HMW, Top J, Sportel E, Heddema ER. Failure of vancomycin treatment for meningitis caused by vancomycin-susceptible Enterococcus faecium. Scandinavian Journal of Infectious Diseases. 2010; 42: 794796

van Overbeek EC, Knottnerus ILH, van Oostenbrugge RJ. Disappearing hyperdense middle cerebral artery sign is associated with striatocapsular infarcts on follow-up CT in ischemic stroke patients treated with intravenous thrombolysis. Cerebrovascular Diseases. 2010;30:285-289 
